\title{
Use of matching methods in observational studies with critical patients and renal outcomes. Scoping review
}

\section{Utilización de los métodos de emparejamiento en estudios observacionales con pacientes críticos y desenlaces renales. Revision exploratoria}

\author{
Henry Oliveros Rodríguez ${ }^{\mathrm{a}, \mathrm{b}}$ (D), Giancarlo Buitragoc, Paola Castellanos Saavedra ${ }^{\mathrm{d}}$
}

a PhD Program in Clinical Epidemiology, Department of Clinical Epidemiology and Biostatistics, Pontificia Universidad Javeriana. Bogotá, Colombia.

b Medical School, Universidad de la Sabana. Chía, Colombia.

${ }^{c}$ Clinical Epidemiology and Biostatistics Department, Pontificia Universidad Javeriana. Bogotá, Colombia.

${ }^{\mathrm{d}}$ Medical School, Pontificia Universidad Javeriana. Bogotá, Colombia.

Correspondence: Cra. 7 No. 40-62, PhD Program in Clinical Epidemiology, Department of Clinical Epidemiology and Biostatistics, Pontificia Universidad Javeriana, Bogotá, Colombia. E-mail: h.oliverosr@javeriana.edu.co

\section{What do we know about this problem?}

In observational studies, matching methods are increasingly being used to control for confounding variables derived from non-random assignment of individuals to exposure groups. Multivariate regression or matching algorithms are the methods most frequently used to address confounding risk.

\section{What does this new study add?}

The use of these methods, such as the propensity score, is not always adequate, as is also the case with the reporting of study findings. A scoping review was conducted in order to assess the use and reporting of these methods, describing the aspects that need to be taken into account in the report.

How to cite this article:

Oliveros Rodríguez H, Buitrago G, Castellanos Saavedra P. Use of matching methods in observational studies with critical patients and renal outcomes. Scoping review. Colombian Journal of Anesthesiology. 2021;49:e944.

\section{Abstract}

Introduction

Although the use of matching techniques in observational studies has been increasing, it is not always adequate. Clinical trials are not always feasible in critically ill patients with renal outcomes, and observational studies are an important alternative.

\section{Objective}

Through a scoping review, determine the available evidence on the use of matching methods in studies involving critically ill patients and renal outcome assessments.

\section{Methods}

Medline, Embase, and Cochrane databases were used to identify articles published between 1992 and week 10 of 2020. Studies had to assess different exposures in critically ill patients with renal outcomes using propensity score matching.

\section{Results}

Most publications are cohort studies 94 (94.9\%), with five (5.1\%) reporting cross-sectional studies. The main pharmacological intervention was the use of antibiotics in seven studies (7.1\%) and the main risk factor studied was renal injury prior to ICU admission in 10 studies (10.1\%). The use of standardized means to assess balance of baseline characteristics was found in only 28 studies (28.2\%). Most studies 95 (96\%) used logistic regression to calculate the propensity score.

\section{Conclusion}

Major inconsistencies were observed regarding the use of methods and reporting of findings. Considerations related to the use of propensity score matching methods and reporting of findings are summarized.

\section{Keywords}

Critical illness; critical care; renal replacement therapy; acute kidney injury; propensity score. 


\section{Resumen}

Introducción

El uso de técnicas de emparejamiento en estudios observacionales ha ido en aumentoy no siempre se usa adecuadamente. Los experimentos clínicos no siempre son factibles en los pacientes críticos con desenlaces renales, por lo que los estudios observacionales son una alternativa importante.

\section{Objetivo}

Mediante una revisión de alcance, determinar la evidencia disponible sobre la utilización de los métodos de emparejamiento en los estudios que incluyen pacientes críticamente enfermos y que evalúan desenlaces renales.

\section{Métodos}

Se utilizaron las bases de datos de Medline, Embase, y Cochrane para identificar artículos publicados entre 1992 y 2020 hasta la semana 10, que estudiaran diferentes exposiciones en el paciente crítico con desenlaces renales y utilizaran métodos de emparejamiento por propensión.

\section{Resultados}

La mayoría de las publicaciones (94) son estudios de Cohorte $(94,9 \%)$, cinco estudios (5,1 \%) correspondieron a cross-secctional. La principal intervención farmacológica fue el uso de antibióticos en siete estudios (7,1\%) y el principal factor de riesgo estudiado fue la lesión renal previa al ingreso a $\mathrm{UCl}$ en diez estudios (10,1\%). El balance entre las características de base evaluado mediante medias estandarizadas se encontró solo en 28 estudios $(28,2 \%$ ). La mayoría de los estudios 95 (96\%) utilizaron regresión logística para calcular el índice de propensión.

\section{Conclusiones}

Se observaron grandes inconsistencias en la utilización de los métodos y en el informe de los hallazgos. Se hace un resumen de los aspectos por considerar en la utilización de los métodos y reporte de los hallazgos con el emparejamiento por índice de propensión.

Palabras clave

Enfermedad crítica; cuidados intensivos; terapia de reemplazo renal; lesión renal aguda; puntaje de propensión.

\section{INTRODUCTION}

A clinical trial is the quintessential design to determine, in most cases, causal associations between exposures and the outcomes that it seeks to establish. Random subject assignment, coupled with adequate sample size, allows for homogenous distribution of baseline characteristics among the individuals in the comparison groups. However, controlled clinical trials are not always feasible due to ethical reasons, costs, or other and, therefore, observational studies are an important option in clinical research, despite the higher probability of obtaining biased estimations (1). Hence the need to use methods designed to control for confounding variables.

Causal inference techniques have been developed over the past few years, propensity score matching (PSM) being one of the most frequently used to control confounding variables. The goal of matching using the propensity index is to achieve a balance of baseline characteristics in the comparison groups (2-6).

Success in achieving adequate balance of baseline variables depends on the correct specification of the propensity score (PS) model. This requires including all potential confounding variables, i.e., those that could modify both the probability of being exposed or receiving the treatment, as well as the occurrence of the outcome $\underline{(7-9)}$.

The boom of scientific papers that describe the use of these methods requires editors, peer reviewers and researchers in the area of critical medicine to be knowledgeable of how studies that include those methods should be reported. Publications using PSM have been reviewed in other clinical settings. In the urological literature, Nayan found deficient reporting (10) and, more recently, Yao (11) conducted a review of the application of PS methods in treated cancer patients assessing inconsistencies. However, no studies exploring the use of matching methods in critically ill patients with renal outcomes have been found to date.

In this work, an exploratory systematic review was conducted based on the available evidence in critical medicine of the studies that assessed the effects of different interventions and risk factors in renal outcomes, using matching techniques. The aim is to describe the methods employed and give recommendations regarding their adequate use.

\section{METHODOLOGY}

The protocol followed the PRISMA guidelines for Scoping Reviews.

\section{Eligibility criteria}

The studies included in the review had to assess different exposures in critically ill 
patients and to describe renal outcomes. PSM techniques should have been included in the analysis.

The Medline, Embase and Cochrane databases were queried for the period between week 1 of 1990 and week 10 of 2020 , using the following search strategy:

\section{((((renaldysfunction) OR (renaloutcomes)) OR (acute renal failure)) AND ((((critical care patients) OR (intensive care unit)) OR (critical illness)) OR (critical ill))) AND ((( (propensity score matched analysis) OR (propensity-matched)) OR (propensity score matching)) OR (propensity score)) Filters: Adult: 19+ years, Humans.}

\section{Study selection and classification}

All observational cohort and cross-sectional studies were included. Based on titles and abstracts, two reviewers ( $\mathrm{HO}$ and $\mathrm{CB}$ ) working independently selected the analytical studies that met the criteria of critically ill patients, use of propensity score matching (PSM) and assessment of renal outcomes. In cases of disagreement, a third reviewer (PC) reviewed the full text in order to settle the discrepancy.

\section{Study characteristics}

The year of publication, journal, country of origin, treatments or exposures, and the criteria to evaluate the methodological quality of the matching methods described by authors like Austin, Nayan and Yao were taken into account $\underline{(6,10,11)}$ :

1. Publication year, author and country

2. Exposures or treatments assessed

3. Study type: cohort, cross-sectional

4. Method used to estimate the propensity score (logistic, probit, Poisson, regression trees, neuronal networks)

5. Description of the covariables included in the propensity score model

6. Rationale for the use of covariables

7. Matching algorithm description (nearest neighbor, Caliper, Greedy Matching)

8. Description of subject coincidence method

9. Assessment of covariable balance between exposure groups (standardized differences of $p$ value)

10. Description of statistical methods designed to assess exposure effect on outcomes. Need to incorporate standard error adjustments due to matching-originated dependence.

\section{Summary of the results}

The full text of each of the studies was pairedreviewed by the authors ( $\mathrm{HO}$ and $\mathrm{CB}$ ) in order to assess the items required be reported in observational studies that use PSM, in accordance with Austin's recommendation. The information contained in the studies was entered into an Excel database according to the list of study characteristics, determining whether the relevant criterion was met or not, or whether it was not reported (Complementary content 1 , Table 1).

\section{RESULTS}

The search strategy identified 123 studies (4,5,12-96). Of these, 99 were selected based on title and abstract reviews in accordance with the inclusion criteria (Figure 1).

The first study was published in 2002 and, as shown in Figure 2 and Complementary content 2 , the number of published studies has grown since then.

The largest number of publications (35) corresponded to American journals (35.3\%) and the journals with the largest number of publications were Critical Care with 13 studies (13.2\%), Critical Care Medicine, 11 studies (11.2\%) and Intensive Care Medicine, 7 studies (7.14\%) (Complementary content 3 and 4).
TABLE 1. Items that need to be taken into account in observational studies that use PSM methods.

\begin{tabular}{|c|c|}
\hline Characteristic & $n(\%)$ \\
\hline \multicolumn{2}{|l|}{ Study type } \\
\hline Cohort & $94(94.9)$ \\
\hline Cross-sectional & $5(5.1)$ \\
\hline \multicolumn{2}{|l|}{ PS calculation method } \\
\hline Logistic regression & 95(96.0) \\
\hline Not reported & $4(4.0)^{*}$ \\
\hline \multicolumn{2}{|l|}{ Matching method } \\
\hline Agreementmatching & $64(65.7)$ \\
\hline Stratification & 13(13.1) \\
\hline Covariable in one model & $12(12.1)$ \\
\hline IPW (weighting) & $3(3.0)$ \\
\hline Stratification + covariable & $1(1.0)$ \\
\hline IPW + stratification & $1(1.0)$ \\
\hline Not reported & $5(5.1) *$ \\
\hline \multicolumn{2}{|l|}{ Closeness determination } \\
\hline Nearest neighbor & $14(14.1)$ \\
\hline Caliper & $12(12.1)$ \\
\hline Greedy Matching & $12(12.1)$ \\
\hline Nearest neighbor + caliper & $10(10.1)$ \\
\hline Not reported & $51(51.5)^{*}$ \\
\hline \multicolumn{2}{|l|}{ Balance assessment } \\
\hline$p$ value & $54(54.5)$ \\
\hline Standardized means & $21(21.2)$ \\
\hline C statistic & $9(9.1)$ \\
\hline ROC curve & $7(7.1)$ \\
\hline Standardized means $+p$ value & $4(4.0)$ \\
\hline Standardized means $+C$ statistic & $2(2.0)$ \\
\hline Standardized means + ROC value & $1(1.0)$ \\
\hline Not reported & $1(1.0)^{*}$ \\
\hline \multicolumn{2}{|l|}{ Methods in the analysis } \\
\hline Student's t test & 19(19.2) \\
\hline Fisher's exact test-Mann-Whitney U test & $17(17.2)$ \\
\hline Fisher exact test-chi-square test & $17(17.2)$ \\
\hline chi-square test Wilcoxon rank & $14(4.1)$ \\
\hline Kaplan Meier-Log rank & $7(7.1)$ \\
\hline McNemar & $3(3.0)$ \\
\hline Mann-Whitney rank & $3(3.0)$ \\
\hline Cochran test-Fisher exact test. & $2(2.0)$ \\
\hline Cochran test-Fisher exact test. & $2(2.0)$ \\
\hline Not reported & $17(17.2)^{*}$ \\
\hline \multicolumn{2}{|l|}{ Covariable description } \\
\hline Yes & 97(97.9) \\
\hline No/Not reported & $2(2.0)$ \\
\hline
\end{tabular}

*Number of articles with no reporting of the assessed criterion. IPV: inverse probability weighting. SOURCE: Authors. 
FIGURE 1. Flow diagram of the selection of studies assessing critically ill patients with renal injury using matching methods.

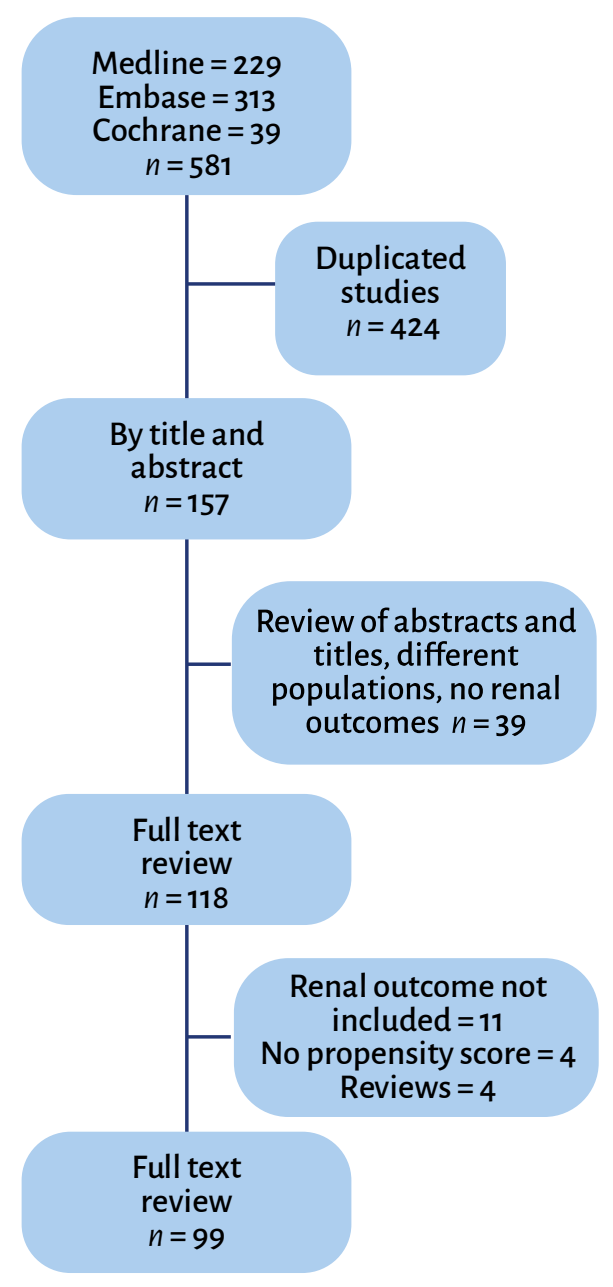

SOURCE: Authors.

In terms of exposures or treatments assessed in the selected publications, pharmacological interventions were the most frequent, in 33 studies (33.3\%), followed by assessment of surgical and other invasive procedures in 20 studies (20.4\%); risk factors were third, assessed in 19 studies (19.4\%); 16 studies with dialysis therapy were fourth (16.3\%); and, finally, 11 studies assessed administrative processes and biomarkers (11.2\%) (Complementary content 5).

For PS estimations, 95 studies (95.9\%) used logistic regression, and the use of covariables in PS calculations was reported
FIGURE 2. Number of publications per year with adjusted propensity score for every 1000 publications with and without PS

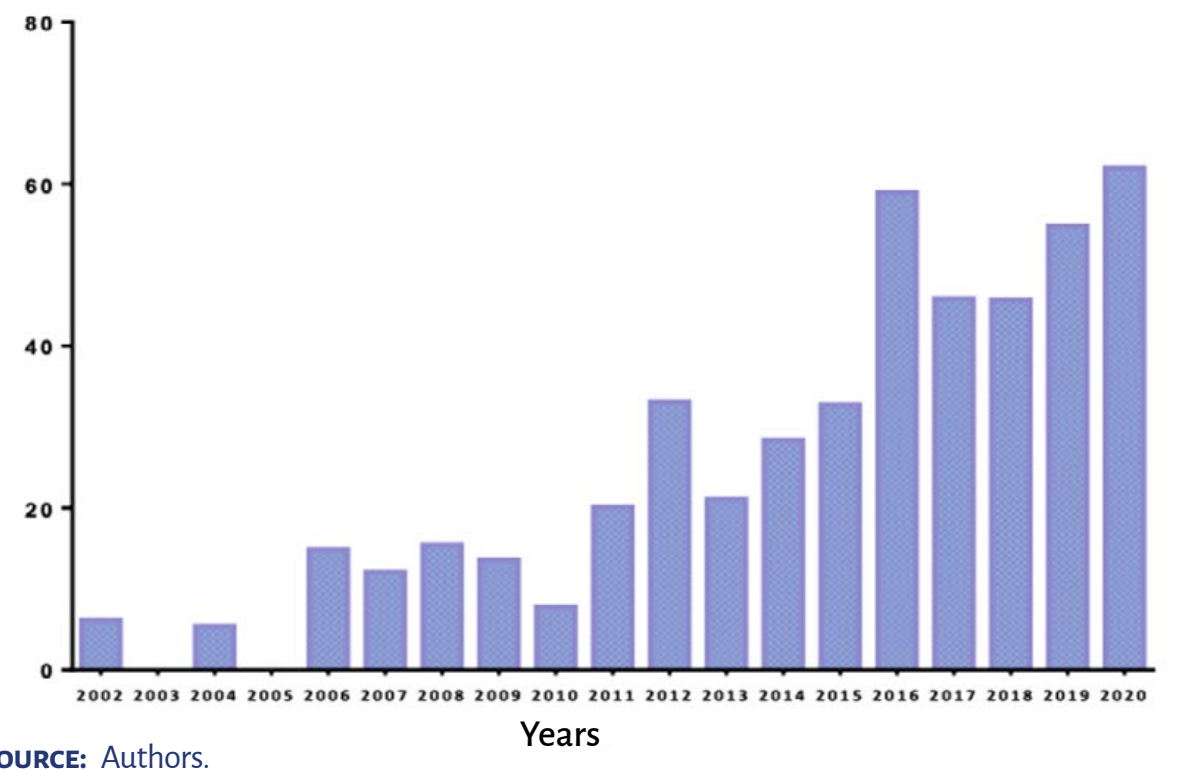

and justified in the majority of studies. Only two studies (2.0\%) did not describe the rationale for the use of covariables.

\section{Matching methodology reporting}

In terms of the type of PSM, the most frequentwasmatchingin62studies (64.3\%), followed by the stratification method in 13 studies (13.2\%). The propensity index was used as covariable in the multivariate analysis in 12 studies (12.2\%); and 5\% of the studies did not mention the matching algorithm. Regarding the selection of the proximity method in control assignments, it was found that the nearest neighbor method was used in 14 studies (14.2\%), followed by caliper, Greedy Matching and nearest neighbor + caliper, with 12 (12.2\%), $12(12.2 \%)$ and $9(9.2 \%)$, respectively. The majority of the studies, 51 (52.0\%), did not report a particular method. When assessing baseline characteristic balancing through the calculation of standardized mean differences, it was reported only in 27 studies $(27.6 \%)$. In terms of tests used for analyzing the effect of the exposure on outcome, parametric tests such as Student's $\mathrm{t}$ test for independent samples were used in 18 studies (18.4\%). Only 10 of the studies reviewed (10\%) reported how standard error calculation was approached.

\section{Evolution of matching methods}

Key to achieving balance of baseline characteristics is the PS method used. Figure 3 shows that matching was the most widely used, followed by stratification and the use of propensity index as a covariable in a multivariate analysis model; change of algorithms over time can also be observed, with initial predominance of the propensity index as a covariable, with incorporation of inverse probability weighting (IPW) having occurred only recently.

\section{DISCUSSION}

This scoping review identified 98 studies published in the past 18 years that used the PSM methodology. It was found that 51 studies (52\%) did not report the closeness algorithm used for matching, 
FIGURE 3. Evolution of the use of matching algorithms.

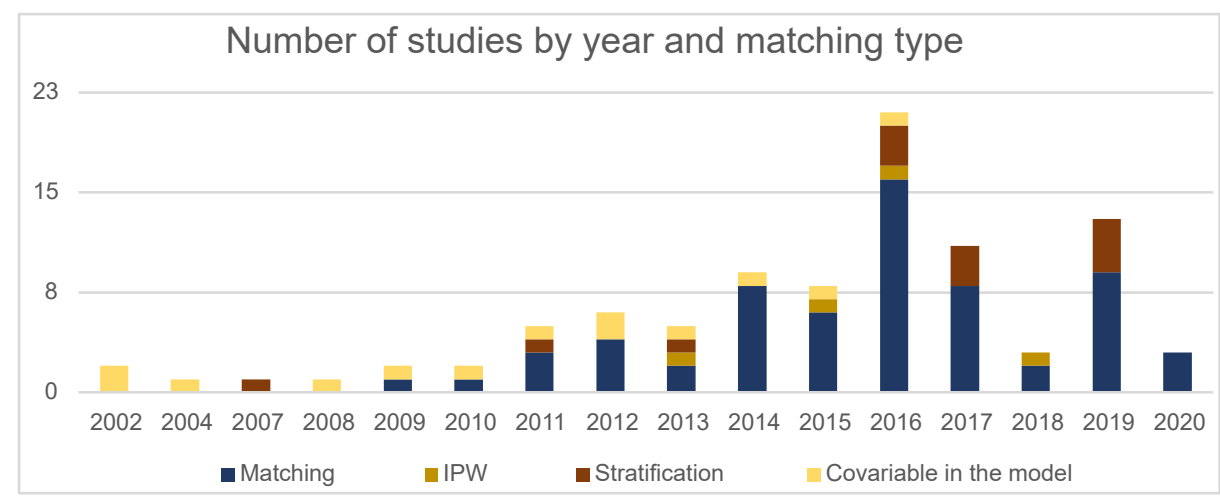

IPW: inverse probability weighting. souRCE: Authors.

and the balance of baseline characteristics was inadequately assessed in 54 studies $(55 \%)$ and consequently, adequate control of confounding variables could not be ascertained in half of the studies. On the other hand, matching was the predominant method, reported in 63 studies (64.3\%), while more robust methods such as IPW were used only in 3 studies (3.1\%). However, it was found that all studies published in the last three years reported the balance of baseline characteristics in the form of standardized differences; they were all cohort studies with adequate mention of the matching methods, which is evident in the 19 studies published between 2018 and 2020; and only 5 studies did not specify the closeness algorithm.

These findings are consistent with those described by Nayan and Austin $\underline{(10,97)}$, who assessed studies in urology and cardiovascular surgery. In these areas of medicine, significant inconsistencies are also found in the reports of the procedures used with the PSM methodology. These inconsistencies do not only compromise the estimated validity but could also introduce estimation bias, additional to inconsistencies in variance calculation and residual confounding due to omission of non-observed variables.

In terms of the balance of baseline characteristics, the consensus is that it should be done through comparison of differences in standardized means both in the exposed as well as the non-exposed groups and it is expected that these differences should not be higher than $10 \%$. Balance assessment by $\mathrm{p}$ value only is not appropriate, given sample size influence on these values (Complementary content 6 ).

\section{Why is it important to report the matching method employed?}

The choice of the matching method can determine the presence of greater or smaller bias, greater or smaller variance.

In matching (98-100) it is unlikely that two subjects in a population will have equal score so, in practice, matching is usually done on the basis of propensity score "closeness" which means that a treated subject with an estimated $\operatorname{Pr}[T=1 \mid X]$ probability of being treated of 0.67492 , can be matched with a not treated subject with an estimated $\operatorname{Pr}[T=1 \mid X]$ probability of 0.67510 . Now then, there are several ways to define closeness, one of them being nearest neighbor distance or the use of a caliper based on 0.2 standard deviations from the logarithmic transformation of the propensity score $(99,101)$. In matching, the definition of closeness implies balance between bias and accuracy: if the closeness criteria are too permissive, individuals with relatively different values will be matched among themselves, giving rise to a variable score distribution between the treated and the not treated population, and creating estimation risk (101,102); but if closeness criteria are too stringent, matching will exclude many subjects, giving rise to wider $95 \%$ confidence intervals and lower accuracy (103).

Additionally, the consequence of probability assumptions different from zero and lower than $1 \underline{(1)}$ in the PS, will determine that matching will only be done for scores greater than 0 and lower than 1 that coincide in treated and not treated subjects, restricting the population to the common support region (99). The consequence of limiting to the common support region will be a smaller population size and, therefore, lower accuracy (104) (Figure 4).

Third, sample restriction may result in a limited causal effect, i.e., a causal estimator being far from the initial study population.

Fourth, when the sample is restricted to the common support region, it could maintain the subjects that benefit the most from the intervention, excluding those who benefit the least, with the obvious result of biased estimates.

As for the matching by stratification method described by Rosebaum and Rubin (1), five strata are created and individuals exhibiting similar but not identical values are matched; they demonstrated up to $90 \%$ elimination of bias derived from observed confounding variables. Stratification also has limitations, given that differences in distributions between treated and not treated subjects are found in each of the strata, compromising subject interchangeability with the stratum $(2,105)$. Finally, another method consists of using the propensity score as a continuous covariable together with other covariables in the multivariate analysis (106). With this approach, an indicator variable that shows treatment status and the estimated propensity score is included (6). Hernán and Robins (107) highlight that when the propensity score is included in the regression it is important to include an interaction term between the score and the set of covariables; the new limitation 
FICURE 4. Common support region in relation to the PS in treated and not treated subject distributions.

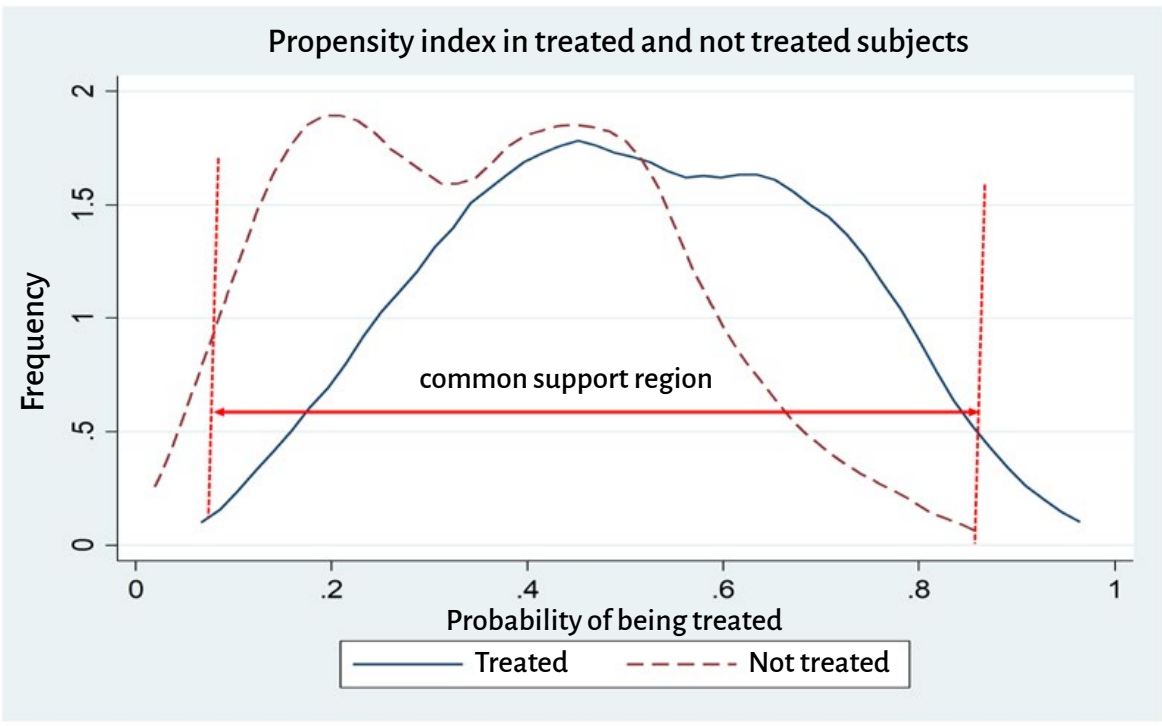

SOURCE: Authors.

with the regression is that the parameters cannot be interpreted causality.

In view of the above considerations regarding the variations that may occur with the use of matching methods in terms of standard error calculation and the choice of statistical tests to assess exposure in relation to outcome, there is a need to adhere to the criteria reported in the literature, summarized in Table 2 $(6,10,97,108)$, so that they are considered in the analysis and reporting of the results of studies using PSM.

Not less important than the assessment of the above criteria in matching methods is the criterion used for selecting the variables when building the model for propensity index calculation. This work found that, although 97 studies (97.9\%) reported the variables used in PS calculation, none of the studies included a thorough discussion of the relationship of each of the included variables with both the exposure as well as the outcome, considering that exposurerelated variables included in the model will not contribute to the estimation but will actually increase the estimator standard error. Something similar can also happen with exposure-associated variables with just a weak association with the outcome, while variables associated only with the outcomes which are included in the model, would diminish the estimator standard error (109). Special attention must be paid to variables found in the causal pathway as intermediate variables because they not only do not contribute but, when included, would cancel out the sought effect which, in this case, is estimating the probability of being treated or exposed. Current observational studies aimed at establishing causality include directed acyclic graphs (DAGs) which are a valuable tool to clarify relationships of observed confounding variables and intermediate variables within the causal pathway.

\section{CONCLUSIONS}

Studies of critically ill patients that assess renal function outcomes and apply PS vary significantly in terms of reporting of the methods used for the analysis and treatment of exposure, outcome and confounding variables. Results must be interpreted in the light of the differences in the results derived from the use of matching algorithms, assessment of balance between the groups in terms in baseline characteristics, and the use of analytical methods for the exposure variable; this will result in the limitations discussed above, consisting mainly of the balance between bias and accuracy. Moreover, clinical judgement will have to be used as a starting point to determine the plausibility of the relationship between the exposures and outcomes under study, taking into account the great limitation imposed by the variables that will notbeobserved.

The methodological criteria proposed in the literature which establish the correct use of methods when it comes to analyzing and reporting the results of studies that use PSM were applied in this review.

\section{ETHICAL RESPONSIBILITIES}

\section{Human and animal protection}

The authors declare that no human or animal experiments were carried out as part of this research.

\section{Data confidentiality}

The authors declare that the protocols of their center pertaining to patient data were followed.

\section{Right to privacy and informed consent}

The authors declare that no patient data appear in this article.

The authors obtained the informed consent of the patients and/or subjects referred to in this article. This document is kept by the corresponding author.

\section{ACKNOWLEDGEMENTS}

\section{Authors contributions}

$\mathrm{HO}, \mathrm{GB}$ and PAC participated in question formulation and design conception; review of the articles; data analysis; writing of 
TABLE 2. Description of methods used in the studies that apply propensity scores in the literature that assesses renal outcomes in critically ill patients.

\begin{tabular}{|c|c|c|c|}
\hline Section & Description & Alternatives & Interpretation \\
\hline Title & $\begin{array}{l}\text { Identifies type } \\
\text { of study and } \\
\text { methodology to be } \\
\text { used }\end{array}$ & Cohort, cross-secctional & $\begin{array}{l}\text { One of the advantages of the propensity score is that it allows to } \\
\text { separate the design from the analysis; cohort designs make PS } \\
\text { estimation easier according to the identification of variables found } \\
\text { temporarily before the exposure, whereas in cross-sectional and case- } \\
\text { control designs establishing this temporality is not possible (1). }\end{array}$ \\
\hline Abstract & $\begin{array}{l}\text { Provides information } \\
\text { on study objective, } \\
\text { methods, results and } \\
\text { conclusions }\end{array}$ & $\begin{array}{l}\text { Design: } \\
\text { 1. Cohort, cross-sectional } \\
\text { 2. Participants } \\
\text { 3. Sample size } \\
\text { 4. Exposure and } \\
\text { outcomes 5. Estimates } \\
\text { and their accuracy }\end{array}$ & $\begin{array}{l}\text { Failing to provide information in the summary will prevent the } \\
\text { study from being adequately selected in preliminary searches. }\end{array}$ \\
\hline Introduction & $\begin{array}{l}\text { Introduction to the } \\
\text { context, data source } \\
\text { datos }\end{array}$ & $\begin{array}{l}\text { Highlights the importance } \\
\text { of the study, states study } \\
\text { objective }\end{array}$ & $\begin{array}{l}\text { Provides information on the topic, states the background for the study, } \\
\text { highlights the value and usefulness of the work; provides only the } \\
\text { necessary information. }\end{array}$ \\
\hline \multirow[t]{5}{*}{ Methods } & $\begin{array}{l}\text { Describes the } \\
\text { method for } \\
\text { propensity score } \\
\text { estimation }\end{array}$ & $\begin{array}{l}\text { Models: logistic, probit, } \\
\text { regression tress, neuronal } \\
\text { networks }\end{array}$ & $\begin{array}{l}\text { Describing the method is important for the reproducibility of the } \\
\text { of the results; machine learning methods can be more difficult } \\
\text { to interpret and do not offer a clear advantage over conventional } \\
\text { statistical methods } \underline{(2)} .\end{array}$ \\
\hline & $\begin{array}{l}\text { Describes how the } \\
\text { information was } \\
\text { collected }\end{array}$ & $\begin{array}{l}\text { Administrative databases, } \\
\text { electronic medical records }\end{array}$ & $\begin{array}{l}\text { Database validation, description of algorithms for diagnosis } \\
\text { determinations, approach to missing data. }\end{array}$ \\
\hline & $\begin{array}{l}\text { Describes the } \\
\text { covariables included } \\
\text { in the model and } \\
\text { inclusion rationale }\end{array}$ & $\begin{array}{l}\text { Exposure-associated } \\
\text { confounding variables }\end{array}$ & $\begin{array}{l}\text { Compliance of the conditional independence assumption. } \\
\text { Selection bias is assumed to be due only to observable } \\
\text { characteristics, requiring the inclusion of all the characteristics that } \\
\text { cause selection bias }(7,102,107) \text {. }\end{array}$ \\
\hline & $\begin{array}{l}\text { Describes matching } \\
\text { algorithm }\end{array}$ & $\begin{array}{l}\text { Matching, weighting, } \\
\text { stratification and use } \\
\text { of propensity score as } \\
\quad \text { covariable }\end{array}$ & $\begin{array}{l}\text { The choice of the matching algorithm is not based on principles and, } \\
\text { therefore, it is mainly arbitrary. Most matching algorithms depend on } \\
\text { the order of data observation. } \\
\text { Non-matched observations are discarded, resulting in loss of accuracy } \\
\text { and power. } \\
\text { When propensity score is included in a regression, the fact that it } \\
\text { can interact with treatment is often forgotten, hence the need to } \\
\text { adequately specify the regression model and assess that interaction } \\
\qquad \underline{(6,101) .}\end{array}$ \\
\hline & $\begin{array}{l}\text { Describes closeness } \\
\text { methods in exposed } \\
\text { and non-exposed } \\
\text { subjects according to } \\
\text { propensity score }\end{array}$ & $\begin{array}{l}\text { Nearest neighbor, Kernel, } \\
\text { caliper, Greedy Matching }\end{array}$ & $\begin{array}{l}\text { Closeness criteria condition a balance between bias and accuracy; } \\
\text { therefore, very stringent closeness criteria result in the exclusion of } \\
\text { many subjects, increasing variance, while very loose criteria match } \\
\text { individuals with somewhat different characteristics, increasing bias } \\
\qquad \underline{(99,101)} .\end{array}$ \\
\hline
\end{tabular}




\begin{tabular}{|c|c|c|c|}
\hline Section & Description & Alternatives & Interpretation \\
\hline \multirow[t]{2}{*}{ Methods } & $\begin{array}{l}\text { Matching quality: } \\
\text { describes methods } \\
\text { used to assess balance } \\
\text { between groups in } \\
\text { terms of baseline } \\
\text { characteristics }\end{array}$ & $\begin{array}{l}\text { Use of standardized mean } \\
\text { differences, } p \text { value, graphic } \\
\text { assessment }\end{array}$ & $\begin{array}{l}\text { The } p \text { value is independent from sample size; small differences } \\
\text { are found as significant in large samples, standardized differences } \\
\text { must be preferred for balance assessment }(7) \text {. }\end{array}$ \\
\hline & $\begin{array}{l}\text { Mentions the type of } \\
\text { statistical analysis }\end{array}$ & $\begin{array}{l}\text { Uses tests such as } \\
\text { McNemar, conditional } \\
\text { logistic regression log Rank } \\
\text { adjusted, Cox proportional } \\
\text { risk models, matching- } \\
\text { stratified }\end{array}$ & $\begin{array}{l}\text { Measurement dependencies must be taken into account; failure } \\
\text { to do so will result in standard error inconsistencies when tests for } \\
\text { independent samples are applied } \underline{(103) .}\end{array}$ \\
\hline \multirow[t]{2}{*}{ Results } & $\begin{array}{l}\text { Describes participant } \\
\text { population according } \\
\text { to the percentage of } \\
\text { matched individuals }\end{array}$ & $\begin{array}{c}\text { Common support region, } \\
\text { trimming }\end{array}$ & $\begin{array}{l}\text { Limitation to this common support region requires considering } \\
\text { that results cannot be interpolated to the study population; } \\
\text { any effect of the limitation and trimming on the result must be } \\
\text { verified; few verification techniques have been described. }\end{array}$ \\
\hline & $\begin{array}{l}\text { Describes standard } \\
\text { error calculation used } \\
\text { to obtain confidence } \\
\text { intervals }\end{array}$ & $\begin{array}{l}\text { Use of: } \\
\text { 1. Bootstrapping } \\
\text { 2. Robust errors } \\
\text { 3. Jacknife } \\
\text { 4. Analytically }\end{array}$ & $\begin{array}{l}\text { The variance due to propensity score estimation as well as } \\
\text { the variance due to the matching method (with or without } \\
\text { replacement) must be incorporated. }\end{array}$ \\
\hline \multirow[t]{3}{*}{ Discussion } & $\begin{array}{l}\text { Discusses the } \\
\text { limitations of the } \\
\text { study }\end{array}$ & Population proportion & $\begin{array}{l}\text { The more the population is restricted, the farther from the study } \\
\text { population and other subsequent populations will the causal } \\
\text { estimator be. }\end{array}$ \\
\hline & & Residual confounding & $\begin{array}{l}\text { Residual confounding must be expected when confounding } \\
\text { variables are not being observed. } \\
\text { Confounding variables that may affect the result must be } \\
\text { recognized and named; a sensitivity analysis may be included in } \\
\text { the best scenario. }\end{array}$ \\
\hline & & Accuracy & Standard error calculation limitations must be taken into account. \\
\hline
\end{tabular}

SOURCE: Authors.

the manuscript; critical review; and final approval of the manuscript.

\section{Assistance with the study}

None declared.

\section{Financial support and sponsorship}

None declared.

\section{Conflict of interest}

The authors have no conflict of interest to disclose.

\section{Presentaciones}

None declared.

\section{Appreciation}

None declared.

\section{REFERENCES}

1. Rosenbaum PR, Rubin DB. Reducing bias in observational studies using subclassification on the Propensity Score. ] Am Statist Assoc. 1984;79:516-24. doi: http://doi. org/10.2307/2288398.

2. Glass TA, Goodman SN, Hernan MA, Samet JM. Causal inference in public health. Annu Rev Public Health. 2013;34:61-75. doi: http://doi.org/10.1146/annurev-publhealth-031811-124606. 
3. Hernan MA. A definition of causal effect for epidemiological research. J Epidemiol Community Health. 2004;58(4):265-71.

4. Liborio AB, Leite TT, Neves FM, Teles F, Bezerra CT. AKI complications in critically ill patients: association with mortality rates and RRT. CJASN. 2015;10(1):21-8. doi: http://doi. org/10.2215/cjn.04750514.

5. Dou L, Lan H, Reynolds DJ, Gunderson TM, Kashyap R, Gajic O, et al. Association between obstructive sleep apnea and acute kidney injury in critically III Patients: A propensity-matched study. Nephron. 2017;135(2):137-46. doi: http://doi.org/10.1159/000453367.

6. Austin PC. An introduction to propensity score methods for reducing the effects of confounding in observational studies. Multivariate Behavioral Research. 2011;46:399-424. doi: http://doi.org/10.1080/00273171.2011.568786.

7. Johnson SR, Tomlinson GA, Hawker CA, Granton JT, Feldman BM. Propensity Score methods for bias reduction in observational studies of treatment effect. Rheum Dis Clin North Am. 2018;44(2):203-13. doi: http://doi. org/10.1016/j.rdc.2018.01.002.

8. Garrido MM, Kelley AS, Paris ], Roza K, Meier DE, Morrison RS, et al. Methods for constructing and assessing propensity scores. Health Serv Res. 2014;49(5):1701-20. doi: http://doi. org/10.1111/1475-6773.12182.

9. Raghunathan K, Layton JB, Ohnuma T, Shaw AD. Observational research using Propensity Scores. Adv Chronic Kidney Dis. 2016;23(6):367-72. doi: http://doi.org/10.1053/j.ackd.2016.11.010.

10. Nayan M, Hamilton R], Juurlink DN, Finelli A, Kulkarni CS, Austin PC. Critical appraisal of the application of propensity score methods in the urology literature. BJU international. 2017;120(6):87380. doi: http://doi.org/10.1111/bju.13930.

11.Yao XI, Wang X, Speicher P], Hwang ES, Cheng P, Harpole DH, et al. Reporting and Guidelines in Propensity Score Analysis: A systematic review of cancer and cancer surgical studies. ] Natl Cancer Inst. 2017;109(8):djw323. doi: http://doi.org/10.1093/jnci/djw323.

12. Mehta RL, McDonald B, Gabbai F, Pahl M, Farkas A, Pascual MT, et al. Nephrology consultation in acute renal failure: does timing matter? Am ] Med. 2002;113(6):456-61.
13. Mehta RL, Pascual MT, Soroko S, Chertow GM. Diuretics, mortality, and nonrecovery of renal function in acute renal failure. JAMA. 2002;288(20):2547-53.

14. Uchino S, Doig CS, Bellomo R, Morimatsu $H$, Morgera S, Schetz M, et al. Diuretics and mortality in acute renal failure. Crit Care Med. 2004;32(8):1669-77.

15. Cho KC, Himmelfarb J, Paganini E, Ikizler TA, Soroko SH, Mehta RL, et al. Survival by dialysis modality in critically ill patients with acute kidney injury. ] Am Society Nephrol. 2006;17(11):3132-8. doi: http://doi.org/10.1681/ asn.2006030268.

16. Liu KD, Himmelfarb ], Paganini E, Ikizler TA, Soroko SH, Mehta RL, et al. Timing of initiation of dialysis in critically ill patients with acute kidney injury. Clin ] Am Soc Nephrol. 2006;1(5):915-9. doi: http://doi.org/10.2215/ cjn.01430406.

17. Uchino S, Bellomo R, Kellum JA, Morimatsu $\mathrm{H}$, Morgera S, Schetz MR, et al. Patient and kidney survival by dialysis modality in critically ill patients with acute kidney injury. Int ] Artificial Organs. 2007;30(4):281-92.

18. Schortgen F, Girou E, Deye N, Brochard L. The risk associated with hyperoncotic colloids in patients with shock. Int Care Med. 2008;34(12):2157-68. doi: http://doi. org/10.1007/s00134-008-1225-2.

19. Bagshaw SM, Lapinsky S, Dial S, Arabi Y, Dodek P, Wood C, et al. Acute kidney injury in septic shock: clinical outcomes and impact of duration of hypotension prior to initiation of antimicrobial therapy. Int Care Med. 2009;35(5):871-81. doi: http://doi.org/10.1007/ s00134-008-1367-2.

20. Benedetto U, Luciani R, Goracci M, Capuano F, Refice S, Angeloni E, et al. Miniaturized cardiopulmonary bypass and acute kidney injury in coronary artery bypass graft surgery. Ann Thor Surg. 2009;88(2):529-35. doi: http://doi. org/10.1016/j.athoracsur.2009.03.072.

21. Billings FT, Pretorius M, Siew ED, Yu C, Brown N]. Early postoperative statin therapy is associated with a lower incidence of acute kidney injury after cardiac surgery. ] Cardiothor Vasc Anesth. 2010;24(6):913-20. doi: http://doi.org/10.1053/j.jvca.2010.03.024.

22. Chamchad D, Horrow JC, Nachamchik L, Sutter FP, Samuels LE, Trace CL, et al. The impact of immediate extubation in the operating room after cardiac surgery on intensive care and hospital lengths of stay. ] Cardiothor Vasc Anesth. 2010;24(5):780-4. doi: http://doi.org/10.1053/j.jvca.2010.04.002.

23. Engoren M. Does erythrocyte blood transfusion prevent acute kidney injury? Propensity-matched case control analysis. Anesthesiology. 2010;113(5):1126-33. doi: http://doi. org/10.1097/ALN. ob013e181f7of56.

24. Chou YH, Huang TM, Wu VC, Wang CY, Shiao $\mathrm{CC}$, Lai CF, et al. Impact of timing of renal replacement therapy initiation on outcome of septic acute kidney injury. Crit Care (London, England). 2011;15(3):R134. doi: http://doi. org/10.1186/cc10252.

25. Le Manach Y, Ibanez Esteves C, Bertrand M, Goarin JP, Fleron $\mathrm{MH}$, Coriat $\mathrm{P}$, et al. Impact of preoperative statin therapy on adverse postoperative outcomes in patients undergoing vascular surgery. Anesthesiology. 2011;114(1):98-104. doi: http://doi.org/10.1097/ ALN.obo13e31820254a6.

26. Lee EH, Chin JH, Choi DK, Hwang BY, Choo S], Song JG, et al. Postoperative hypoalbuminemia is associated with outcome in patients undergoing off-pump coronary artery bypass graft surgery. ] Cardiothor Vasc Anesth. 2011;25(3):462-8. doi: http://doi.org/10.1053/j. jvca.2010.09.008.

27. Shahin ], DeVarennes B, Tse CW, Amarica DA, Dial S. The relationship between inotrope exposure, six-hour postoperative physiological variables, hospital mortality and renal dysfunction in patients undergoing cardiac surgery. Crit Care (London, England). 2011;15(4):R162. doi: http://doi.org/10.1186/ CC10302.

28. Attaran S, Saleh HZ, Shaw M, Ward A, Pullan $M$, Fabri BM. Does the outcome improve after radiofrequency ablation for atrial fibrillation in patients undergoing cardiac surgery? A propensity-matched comparison. Eur ] Cardio-thoracic Surg. 2012;41(4):806-10; discussion 10-1. doi: http://doi.org/10.1093/ejcts/ezr107.

29. Azuma N, Uchida H, Kokubo T, Koya A, Akasaka N, Sasajima T. Factors influencing wound healing of critical ischaemic foot after bypass surgery: is the angiosome important in selecting bypass target artery? Eur ] Vas Endovasc Surg. 2012;43(3):322-8. doi: http://doi.org/10.1016/j.ejvs.2011.12.001. 
30. Clec'h C, Darmon M, Lautrette A, Chemouni F, Azoulay E, Schwebel C, et al. Efficacy of renal replacement therapy in critically ill patients: a propensity analysis. Crit Care (London, England). 2012;16(6):R236. doi: http:// doi.org/10.1186/cc11905.

31. Lee EH, Baek SH, Chin JH, Choi DK, Son H], Kim W], et al. Preoperative hypoalbuminemia is a major risk factor for acute kidney injury following off-pump coronary artery bypass surgery. Int Care Med. 2012;38(9):1478-86. doi: http://doi.org/10.1007/s00134-012-2599-8.

32. Vaara ST, Reinikainen M, Kaukonen KM, Pettila V. Association of ICU size and annual case volume of renal replacement therapy patients with mortality. Acta Anaesthesiol Scand. 2012;56(9):1175-82. doi: http://doi.org/10.1111/ j.1399-6576.2012.02747.x.

33. Wu VC, Lai CF, Shiao CC, Lin YF, Wu PC, Chao CT, et al. Effect of diuretic use on 30day postdialysis mortality in critically ill patients receiving acute dialysis. PloS One. 2012;7(3):e30836. doi: http://doi.org/10.1371/ journal.pone.0030836.

34. Apel M, Maia VP, Zeidan M, Schinkoethe C, Wolf G, Reinhart K, et al. End-stage renal disease and outcome in a surgical intensive care unit. Crit Care (London, England). 2013;17(6):R298. doi: http://doi.org/10.1186/cc13167.

35. Bayer O, Schwarzkopf D, Doenst T, Cook D, Kabisch B, Schelenz C, et al. Perioperative fluid therapy with tetrastarch and gelatin in cardiac surgery--a prospective sequential analysis. Crit Care Med. 2013;41(11):2532-42. doi: http:// doi.org/10.1097/CCM.obo13e3182978fb6.

36. Ehrmann S, Badin ], Savath L, Pajot O, Garot D, Pham T, et al. Acute kidney injury in the criticaIly ill: is iodinated contrast medium really harmful? Crit Care Med. 2013;41(4):1017-26. doi: http://doi.org/10.1097/CCM.ob013e318275871a.

37. Leite TT, Macedo E, Pereira SM, Bandeira SR, Pontes $\mathrm{PH}$, Garcia AS, et al. Timing of renal replacement therapy initiation by AKIN classification system. Crit Care (London, England). 2013;17(2):R62. doi: http://doi.org/10.1186/ CC12593.

38. Costa e Silva VT, Liano F, Muriel A, Diez R, de Castro I, Yu L. Nephrology referral and outcomes in critically ill acute kidney injury patients. PloS One. 2013;8(8):e70482. doi: http:// doi.org/10.1371/journal.pone.0070482.
39. Brewer R, Theurer PF, Cogan CM, Bell CF, Prager RL, Paone G. Morbidity but not mortality is decreased after off-pump coronary artery bypass surgery. Ann Thor Surg. 2014;97(3):831-6. doi: http://doi.org/10.1016/j.athoracsur.2013.08.062.

40. Elmistekawy E, McDonald B, Hudson C, Ruel M, Mesana T, Chan V, et al. Clinical impact of mild acute kidney injury after cardiac surgery. Ann Thor Surg. 2014;98(3):815-22. doi: http:// doi.org/10.1016/j.athoracsur.2014.05.008.

41. Iwagami M, Yasunaga H, Doi K, Horiguchi H, Fushimi K, Matsubara T, et al. Postoperative polymyxin $\mathrm{B}$ hemoperfusion and mortality in patients with abdominal septic shock: a propensity-matched analysis. Crit Care Med. 2014;42(5):1187-93. doi: http://doi. org/10.1097/ccm.0000000000000150.

42. Raghunathan K, Shaw A, Nathanson B, Sturmer T, Brookhart A, Stefan MS, et al. Association between the choice of IV crystalloid and in-hospital mortality among critically ill adults with sepsis. Crit Care Med. 2014;42(7):1585-91. doi: http://doi. org/10.1097/ccm.0000000000000305.

43. Linder A, Fjell C, Levin A, Walley KR, Russell JA, Boyd JH. Small acute increases in serum creatinine are associated with decreased long-term survival in the critically ill. Am ] Resp Crit Care Med. 2014;189(9):1075-81. doi: http://doi.org/10.1164/rccm.201311-2097OC.

44. Oh H], Lee M], Kim CH, Kim DY, Lee HS, Park JT, et al. The benefit of specialized team approaches in patients with acute kidney injury undergoing continuous renal replacement therapy: propensity score matched analysis. Crit Care (London, England). 2014;18(4):454. doi: http://doi.org/10.1186/ s13054-014-0454-8.

45. Picard W, Bazin F, Clouzeau B, Bui HN, Soulat M, Guilhon E, et al. Propensity-based study of aminoglycoside nephrotoxicity in patients with severe sepsis or septic shock. Antimicrobial Agents Chemother. 2014;58(12):7468-74. doi: http://doi.org/10.1128/aac.03750-14.

46. Vaara ST, Pettila V, Kaukonen KM, Bendel S, Korhonen AM, Bellomo R, et al. The attributable mortality of acute kidney injury: a sequentially matched analysis. Crit Care Med. 2014;42(4):878-85. doi: http://doi.org/10.1097/ ccm.0000000000000045.

47. Wald R, Shariff SZ, Adhikari NK, Bagshaw SM, Burns KE, Friedrich JO, et al. The asso- ciation between renal replacement therapy modality and long-term outcomes among critically ill adults with acute kidney injury: a retrospective cohort study. Crit Care Med. 2014;42(4):868-77. doi: http://doi.org/10.1097/ ccm.0000000000000042.

48. Ding W, Ji Q, Wei Q, Shi Y, Ma R, Wang C. Prophylactic application of an intra-aortic baIloon pump in high-risk patients undergoing off-pump coronary artery bypass grafting. Cardiology. 2015;131(2):109-15. doi: http://doi. org/10.1159/000377720.

49. Horkan CM, Purtle SW, Mendu ML, Moromizato T, Gibbons FK, Christopher KB. The association of acute kidney injury in the critically ill and postdischarge outcomes: a cohort study. Crit Care Med. 2015;43(2):354-64. doi: http:// doi.org/10.1097/ccm.0000000000000706.

50. Leite TT, Macedo E, Martins Ida S, Neves FM, Liborio AB. Renal outcomes in critically III patients receiving propofol or midazolam. Clin ] Am Society Nephrol. 2015;10(11):1937-45. doi: http://doi.org/10.2215/cjn.02330315.

51. Sang BH, Bang JY, Song JG, Hwang CS. Hypoalbuminemia within two postoperative days is an independent risk factor for acute kidney injury following living donor liver transplantation: A Propensity Score analysis of 998 consecutive patients. Crit Care Med. 2015;43(12):2552-61. doi: http://doi. org/10.1097/ccm.0000000000001279.

52. Shaw AD, Schermer CR, Lobo DN, Munson $\mathrm{SH}$, Khangulov V, Hayashida DK, et al. Impact of intravenous fluid composition on outcomes in patients with systemic inflammatory response syndrome. Crit Care (London, England). 2015;19:334. doi: http://doi.org/10.1186/s13054015-1045-Z.

53. Shen TC, Wang IK, Wei CC, Lin CL, Tsai CT, Hsia TC, et al. The risk of septicemia in end-stage renal disease with and without renal transplantation: A propensity-matched cohort study. Medicine. 2015;94(34):e1437. doi: http:// doi.org/10.1097/md.0000000000001437.

54. Allen C], Ruiz XD, Meizoso JP, Ray J], Livingstone AS, Schulman $\mathrm{Cl}$, et al. Is hydroxyethyl starch safe in penetrating trauma patients? Military Med. 2016;181(5 Suppl):152-5. doi: http://doi.org/10.7205/milmed-d-15-00132.

55. Bonnet V, Boisselier C, Saplacan V, Belin A, Gerard JL, Fellahi JL, et al. The role of age and comorbidities in postoperative outcome of $\mathrm{mi}$ - 
tral valve repair: A propensity-matched study Medicine. 2016;95(25):e3938. doi: http://doi org/10.1097/md.0000000000003938.

56. Carmona P, Paredes F, Mateo E, Mena-Duran AV, Hornero F, Martinez-Leon ]. Is off-pump technique a safer procedure for coronary revascularization? A propensity score analysis of 20 years of experience. Interact Cardiovasc Thor Surg. 2016;22(5):612-8. doi: http://doi. org/10.1093/icvts/ivwo05.

57. Thongprayoon C, Cheungpasitporn W, Harrison AM, Kittanamongkolchai $W$, Ungprasert P, Srivali N, et al. The comparison of the commonly used surrogates for baseline renal function in acute kidney injury diagnosis and staging. BMC Nephrol. 2016;17:6. doi: http:// doi.org/10.1186/s12882-016-0220-z.

58. Cipolle MD, Ingraham Lopresto BC, Pirrung JM, Meyer EM, Manta C, Nightingale AS, et al. Embedding a trauma hospitalist in the trauma service reduces mortality and 30-day trauma-related readmissions. ] Trauma Acute Care Surg. 2016;81(1):178-83. doi: http://doi. org/10.1097/ta.0000000000001062.

59. Clark E, Kumar A, Langote A, Lapinsky S, Dodek P, Kramer A, et al. Septic shock in chronic dialysis patients: clinical characteristics, antimicrobial therapy and mortality. Intens Care Med. 2016;42(2):222-32. doi: http://doi. org/10.1007/s00134-015-4147-9.

60. Hammond DA, Smith MN, Painter JT, Meena NK, Lusardi K. Comparative incidence of acute kidney injury in critically III patients receiving vancomycin with concomitant piperacillin-tazobactam or cefepime: A retrospective cohort study. Pharmacotherapy. 2016;36(5):463-71. doi: http://doi.org/10.1002/phar.1738.

61. Latour-Pérez ], Gómez-Tello V, de-Miguel-Balsa E, Llamas-Álvarez A, Carrillo-López A, Sánchez-Roman]A, etal. Routine invasive strategy in acute coronary syndrome patients with renal dysfunction. Results of the ARIAM-SEMICYUC registry. Med Int. 2016;40(5):280-8. doi: http://doi.org/10.1016/j.medin.2015.09.008.

62. Joung KW, Kong YG, Yoon SH, Kim Y], Hwang $\mathrm{JH}$, Hong $\mathrm{B}$, et al. Comparison of postoperative acute kidney injury between ileal conduit and neobladder urinary diversions after radical cystectomy: A propensity score matching analysis. Medicine. 2016;95(36):e4838. doi: http://doi.org/10.1097/ md.0000000000004838.
63. Jun IG, Lee B, Kim SO, Shin W], Bang JY, Song JG, et al. Comparison of acute kidney injury between $\mathrm{ABO}$-compatible and $\mathrm{ABO}$-incompatible living donor liver transplantation: $A$ propensity matching analysis. Liver Transplant. 2016;22(12):1656-65. doi: http://doi. org/10.1002/lt.24634.

64. Karamanos E, Dulchavsky S, Beale E, Inaba $\mathrm{K}$, Demetriades $\mathrm{D}$. Diabetes mellitus in patients presenting with adhesive small bowel obstruction: Delaying surgical intervention results in worse outcomes. World ] Surg. 2016;40(4):863-9. doi: http://doi.org/10.1007/ s00268-015-3338-4.

65. Lai WH, Rau CS, Wu SC, Chen YC, Kuo PJ, Hsu SY, et al. Post-traumatic acute kidney injury: a cross-sectional study of trauma patients. Scand J Trauma, Res Emerg Med. 2016;24(1):136. doi: http://doi.org/10.1186/s13049-016-0330-4.

66. Lin CY, Tsai FC, Chen YC, Lee HA, Chen SW, Liu KS, et al. Correlation of preoperative renal insufficiency with mortality and morbidity after aortic valve replacement: A Propensity Score matching analysis. Medicine. 2016;95(9):e2576. doi: http://doi.org/10.1097/ md.0000000000002576.

67. Mazzeffi M, Galvagno S, Gammie JS, Tanaka $\mathrm{K}$. Impact of aspirin use on morbidity and mortality in massively transfused cardiac surgery patients: a propensity score matched cohort study. J Anesthesia. 2016;30(5):817-25. doi: http://doi.org/10.1007/s00540-016-2213-2.

68. Penuelas O, Muriel A, Frutos-Vivar F, Fan E, Raymondos K, Rios F, et al. Prediction and outcome of intensive care unit-acquired paresis. ] Intens Care Med. 2018;33(1):16-28. doi: http:// doi.org/10.1177/0885066616643529.

69. Park JY, An JN, Jhee JH, Kim DK, Oh H], Kim $\mathrm{S}$, et al. Early initiation of continuous renal replacement therapy improves survival of elderly patients with acute kidney injury: a multicenter prospective cohort study. Crit Care (London, England). 2016;20(1):260. doi: http:// doi.org/10.1186/s13054-016-1437-8.

70. Ruan SY, Wu HY, Lin HH, Wu HD, Yu C], Lai MS. Inhaled nitric oxide and the risk of renal dysfunction in patients with acute respiratory distress syndrome: a propensity-matched cohort study. Crit Care (London, England). 2016;20(1):389. doi: http://doi.org/10.1186/ s13054-016-1566-0.
71. Thongprayoon C, Cheungpasitporn W, Srivali N, Harrison AM, Gunderson TM, Kittanamongkolchai $W$, et al. AKI after transcatheter or surgical aortic valve replacement. ] Am Society Nephrol. 2016;27(6):1854-60. doi: http:// doi.org/10.1681/asn.2015050577.

72. Chan M], Lee CC, Chen SW, Tsai FC, Lin P], Fan PC, et al. Effect of different surgical type of coronary artery bypass grafting on kidney injury: A propensity score analysis. Medicine. 2017;96(45):e8395. doi: http://doi.org/10.1097/ md.0000000000008395.

73. Dos Santos TOC, Oliveira MAS, Monte JCM, Batista MC, Pereira Junior VG, Dos Santos BFC, et al. Outcomes from a cohort of patients with acute kidney injury subjected to continuous venovenous hemodiafiltration: The role of negative fluid balance. Plos One. 2017;12(4):e0175897. doi: http://doi. org/10.1371/journal.pone.0175897.

74. Shum HP, Chan KC, Tam CW, Yan WW, Chan TM. Impact of renal replacement therapy on survival in patients with KDICO Stage 3 acute kidney injury: A propensity score matched analysis. Nephrology. 2018;23:1081-9. doi: http://doi.org/10.1111/nep.13164.

75. McDonald JS, McDonald RJ, Williamson EE, Kallmes DF, Kashani K. Post-contrast acute kidney injury in intensive care unit patients: a propensity score-adjusted study. Intens Care Med. 2017;43(6):774-84. doi: http://doi. org/10.1007/s00134-017-4699-y.

76. Kashani K, Thongprayoon C, Cheungpasitporn W, lacovella GM, Akhoundi A, Albright RC, Jr. Association between mortality and replacement solution bicarbonate concentration in continuous renal replacement therapy: A propensity-matched cohort study. PloS One. 2017;12(9):e0185064. doi: https://doi. org/10.1371/journal.pone.0185064

77. Kovacheva VP, Aglio LS, Boland TA, Mendu ML, Gibbons FK, Christopher KB. Acute kidney injury after craniotomy is associated with increased mortality: A cohort study. Neurosurgery. 2016;79(3):389-96. doi: http://doi. org/10.1227/neu.0000000000001153.

78. Legouis D, Galichon P, Bataille A, Chevret $S$, Provenchere $S$, Boutten $A$, et al. Rapid occurrence of chronic kidney disease in patients experiencing reversible acute kidney injury after cardiac surgery. Anesthesiology. 2017;126(1):39-46. doi: http://doi.org/10.1097/ aln.0000000000001400. 
79. Marik PE, Khangoora V, Rivera R, Hooper $\mathrm{MH}$, Catravas ]. Hydrocortisone, vitamin c, and thiamine for the treatment of severe sepsis and septic shock: A retrospective before-after study. Chest. 2017;151(6):1229-38. doi: http:// doi.org/10.1016/j.chest.2016.11.036.

80. Yu SC, Kuo JR, Shiue YL, Yu ZX, Ho CH, Wu $\mathrm{CC}$, et al. One-year mortality of patients with chronic kidney disease after spinal cord injury: A 14-year population-based study. World Neurosurg. 2017;105:462-9. doi: http://doi.org/10.1016/j.wneu.2017.06.009.

81. Huang ST, Ke TY, Chuang YW, Lin CL, $\mathrm{Kao} \mathrm{CH}$. Renal complications and subsequent mortality in acute critically ill patients without pre-existing renal disease. CMA]. 2018;190(36):E1070-E80. doi: http://doi. org/10.1503/cmaj.171382.

82. Wang AY, Trongtrakul K, Bellomo R, Li Q, Cass $A$, Gallagher $M$, et al. HMG-CoA reductase inhibitors (statins) and acute kidney injury: $A$ secondary analysis of renal study outcomes. Nephrology (Carlton). 2019;24(9):912-8. doi: http://doi.org/10.1111/nep.13597.

83. Praca APA, Nassar AP, Jr., Caruso P. Outcomes of cancer patients discharged from ICU after a decision to forgo life-sustaining therapies. Crit Care Med. 2019;47(6):e454-e60. doi: http:// doi.org/10.1097/CCM.0000000000003729.

84. McCoy IE, Montez-Rath ME, Chertow GM, Chang TI. Estimated effects of early diuretic use in critical illness. Crit Care Explor. 2019;1(7):e0021. doi: http://doi.org/10.1097/ CCE. 0000000000000021.

85. Zeeshan M, Hamidi M, Feinstein A], Gries L, Jehan F, Sakran J, et al. Four-factor prothrombin complex concentrate is associated with improved survival in trauma-related hemorrhage: A nationwide propensity-matched analysis. J Trauma Acute Care Surg. 2019;87(2):274-81. doi: http://doi.org/10.1097/ TA.0000000000002262.

86. Gaudard P, Saour M, Morquin D, David H, Eliet J, Villiet $M$, et al. Acute kidney injury during daptomycin versus vancomycin treatment in cardiovascular critically ill patients: a propensity score matched analysis. BMC Infect Dis. 2019;19(1):438. doi: http://doi. org/10.1186/s12879-019-4077-1.

87. Pitta RD, Gasparetto ], De Moraes TP, Telles JP, Tuon FF. Antimicrobial therapy with aminoglycoside or meropenem in the intensive care unit for hospital associated infections and risk factors for acute kidney injury. Eur ] Clin Microbiol Infect Dis. 2020;39(4):723-8. doi: http://doi.org/10.1007/s10096-019-03779-6.

88. Schubert SA, Hawkins RB, Mehaffey JH, Fonner CE, Rich JB, Speir AM, et al. Preoperative beta-blocker use correlates with worse outcomes in patients undergoing aortic valve replacement. ] Thorac Cardiovasc Surg. 2019;158(6):1589-97-e3. doi: http://doi.org/10.1016/j.jtcvs.2018.12.108.

89. Jiang W, Shen B, Wang Y, Xu J, Luo Z, Ding X, et al. Potentially modifiable predictors for renal replacement therapy in patients with cardiac surgery associated-acute kidney injury: A Propensity Score-matched case-control study. Braz J Cardiovasc Surg. 2019;34(1):33-40. doi: http://doi.org/10.21470/1678-9741-2018-0206.

90. Shen Y, Zhang W, Shen Y. Early diuretic use and mortality in critically ill patients with vasopressor support: a propensity score-matching analysis. Crit Care (London, England). 2019;23(1):9. doi: http://doi.org/10.1186/s13054019-2309-9.

91. Miyamoto $Y$, Iwagami M, Aso S, Yasunaga $\mathrm{H}$, Matsui $\mathrm{H}$, Fushimi K, et al. Association between intravenous contrast media exposure and non-recovery from dialysis-requiring septic acute kidney injury: a nationwide observational study. Intens Care Med. 2019;45(11):1570-9. doi: http://doi.org/10.1007/ s00134-019-05755-2.

92. Chou YH, Huang TM, Wu VC, Chen WS, Wang $\mathrm{CH}$, Chou NK, et al. Associations between preoperative continuation of renin-angiotensin system inhibitor and cardiac surgery-associated acute kidney injury: a propensity score-matching analysis. ] Nephrol. 2019;32(6):957-66. doi: http://doi.org/10.1007/ s40620-019-00657-4.

93. Goto Y, Koyama K, Katayama S, Tonai K, Shima J, Koinuma T, et al. Influence of contrast media on renal function and outcomes in patients with sepsis-associated acute kidney injury: a propensity-matched cohort study. Crit Care (London, England). 2019;23(1):249. doi: http://doi.org/10.1186/s13054-019-2517-3.

94. Williams LS, Walker GR, Loewenherz JW, Gidel LT. Association of contrast and acute kidney injury in the critically III: A Propensity-Matched Study. Chest. 2020;157(4):866-76. doi: http://doi.org/10.1016/j.chest.2019.10.005.
95. Abudayyeh A, Song ], Abdelrahim M, Dahbour I, Page VD, Zhou S, et al. Renal replacement therapy in patients with stage IV Cancer admitted to the intensive care unit with acute kidney injury at a comprehensive cancer center was not associated with survival. Am ] Hosp Palliat Care. 2020;37(9):707-15. doi: http://doi.org/10.1177/1049909120902115.

96. Zhao G], Xu C, Ying JC, Lu WB, Hong GL, Li $M F$, et al. Association between furosemide administration and outcomes in critically ill patients with acute kidney injury. Crit Care (London, England). 2020;24(1):75. doi: http:// doi.org/10.1186/s13054-020-2798-6.

97. Austin PC. Propensity-score matching in the cardiovascular surgery literature from 2004 to 2006: a systematic review and suggestions for improvement. ] Thor Cardiovasc Surg. 2007;134(5):1128-35. doi: http://doi.org/10.1016/j.jtcvs.2007.07.021.

98. Rosenbaum PR RD. The central role of the propensity score in observational studies for causal effects. Biometrika. 1983;70(1):4.

99. Rosenbaum PR RD. Constructing a control group using multivariate matched sampling methods that incorporate the propensity score. Am Stat. 1985;39(1):3.

100. Ospina-Tascón GA, Hernández G, Álvarez I, Calderón-Tapia LE, Manzano-Núnez R, Sánchez-Ortiz Al, et al. Effects of very early start of norepinephrine in patients with septic shock: a propensity score-based analysis. Crit Care (London, England). 2020;24(1):52. doi: http:// doi.org/10.1186/s13054-020-2756-3.

101. Austin PC. Optimal caliper widths for propensity-score matching when estimating differences in means and differences in proportions in observational studies. Pharm Stat. 2011;10(2):15061. doi: http://doi.org/10.1002/pst.433.

102. Steiner PM, Cook TD, Shadish WR, Clark $\mathrm{MH}$. The importance of covariate selection in controlling for selection bias in observational studies. Psychol Methods. 2010;15(3):250-67. doi: http://doi.org/10.1037/a0018719.

103. Hullsiek KH, Louis TA. Propensity score modeling strategies for the causal analysis of observational data. Biostatistics. 2002;3(2):179-93. doi: http://doi.org/10.1093/ biostatistics/3.2.179. 
104. Petersen ML, Porter KE, Gruber S, Wang Y, van der Laan M]. Diagnosing and responding to violations in the positivity assumption. Stat Methods Med Res. 2012;21(1):31-54. doi: http://doi.org/10.1177/0962280210386207.

105. VanderWeele T], Hernan MA. Causal Inference Under Multiple Versions of Treatment. ] Causal Inference. 2013;1(1):1-20. doi: http:// doi.org/10.1515/jci-2012-0002.

106. Rubin DB. On principles for modeling pro- pensity scores in medical research. Pharmacoepidemiol Drug Saf. 2004;13(12):855-7. doi: http://doi.org/10.1002/pds.968.

107. VanderWeele T], Hernan MA, Tchetgen Tchetgen E], Robins JM. Re: Causality and causal inference in epidemiology: the need for a pluralistic approach. Int ] Epidemiol. 2016;45(6):2199-200. doi: http://doi. org/10.1093/ije/dyw162.

108. Ali MS, Groenwold RH, Belitser SV, Pest- man WR, Hoes AW, Roes KC, et al. Reporting of covariate selection and balance assessment in propensity score analysis is suboptimal: a systematic review. J Clin Epidemiol. 2015;68(2):112-21. doi: http://doi.org/10.1016/j. jclinepi.2014.08.011.

109. Brookhart MA, Schneeweiss S, Rothman K], Glynn R], Avorn ], Sturmer T. Variable selection for propensity score models. Am J Epidemiol. 2006;163(12):1149-56. doi: http://doi. org/10.1093/aje/kwj149. 


\section{COMPLEMENTAR CONTENT}

COMPLEMENTAR CONTENT 1. Study characteristics assessed.

\begin{tabular}{|c|c|c|c|c|c|c|c|c|c|c|c|}
\hline Year & Author & Journal & Country & $\begin{array}{l}\text { Study } \\
\text { type }\end{array}$ & Exposure & Variables & $\begin{array}{l}\text { Matching } \\
\text { algorithm }\end{array}$ & Closeness & $\begin{array}{c}\text { Balance } \\
\text { assessment }\end{array}$ & $\begin{array}{l}\text { Analytical } \\
\text { method } \\
\text { used }\end{array}$ & Outcomes \\
\hline 2002 & Ravindra L. & $\begin{array}{l}\text { The Ameri- } \\
\text { can Journal } \\
\text { of Medicine }\end{array}$ & $\begin{array}{l}\text { United } \\
\text { States }\end{array}$ & Cohort & $\begin{array}{l}\text { Timing of nephrology } \\
\text { consult in acute renal } \\
\text { failure (early vs. late). }\end{array}$ & $\begin{array}{l}\text { Age, sex, urinary output, } \\
\text { liver failure, hematological } \\
\text { insufficiency, heart rate, and } \\
\text { serum creatinine and BUN }\end{array}$ & $\begin{array}{c}\text { Covariable in } \\
\text { one model }\end{array}$ & $\begin{array}{l}\text { Not } \\
\text { reported }\end{array}$ & ROC values & $\begin{array}{l}\text { Logistic } \\
\text { regression }\end{array}$ & Mortality \\
\hline 2002 & Mehta RL & JAMA & $\begin{array}{l}\text { United } \\
\text { States }\end{array}$ & Cohort & $\begin{array}{l}\text { Association of diure- } \\
\text { tics with adverse or } \\
\text { favorable outcomes } \\
\text { in critically ill patients } \\
\text { with acute renal } \\
\text { failure }\end{array}$ & $\begin{array}{l}\text { Age, nephrotoxic etiology } \\
\text { of acute renal failure, BUN, } \\
\text { acute respiratory failure and } \\
\text { congestive heart failure. }\end{array}$ & $\begin{array}{c}\text { Covariable in } \\
\text { one model }\end{array}$ & $\begin{array}{l}\text { Not } \\
\text { reported }\end{array}$ & ROC values & $\begin{array}{l}\text { Logistic } \\
\text { regression }\end{array}$ & Mortality \\
\hline 2004 & Uchino, S. & $\begin{array}{c}\text { Crit Care } \\
\text { Med }\end{array}$ & $\begin{array}{c}\text { Austra- } \\
\text { lia }\end{array}$ & Cohort & $\begin{array}{l}\text { Determination of the } \\
\text { impact of diuretics on } \\
\text { mortality rate in criti- } \\
\text { cally ill patients with } \\
\text { acute renal failure }\end{array}$ & $\begin{array}{l}\text { Patient age, simplified } \\
\text { acute physiology score II, } \\
\text { creatinine on ICU admissions, } \\
\text { need for renal replacement } \\
\text { therapy, time between ICU } \\
\text { admission and inclusion in } \\
\text { the study, central venous } \\
\text { pressure, Clasgow coma } \\
\text { score, vasopressor use, urine } \\
\text { volume during } 6 \text { hours prior } \\
\text { to inclusion, platelet count, } \\
\text { creatinine, arterial pH, septic } \\
\text { etiology, low cardiac output } \\
\text { etiology and other etiologies }\end{array}$ & $\begin{array}{c}\text { Covariable in } \\
\text { one model }\end{array}$ & $\begin{array}{l}\text { Not } \\
\text { reported }\end{array}$ & C statistic & $\begin{array}{l}\text { Logistic } \\
\text { regression }\end{array}$ & Mortality \\
\hline 2006 & Cho, K. C. & $\begin{array}{l}\text { J Am Soc } \\
\text { Nephrol }\end{array}$ & $\begin{array}{l}\text { United } \\
\text { States }\end{array}$ & Cohort & $\begin{array}{l}\text { Survival by dialysis } \\
\text { modality (continuous vs. } \\
\text { intermittent) in critically } \\
\text { ill patients with acute } \\
\text { renal injury }\end{array}$ & $\begin{array}{l}\text { Age, liver failure, sepsis, } \\
\text { thrombocytopenia, blood urea } \\
\text { nitrogen and serum creatinine }\end{array}$ & Not reported & $\begin{array}{l}\text { Not } \\
\text { reported }\end{array}$ & ROC values & $\begin{array}{l}\text { Logistic } \\
\text { regression } \\
\text { and Cox } \\
\text { regression }\end{array}$ & Survival \\
\hline 2006 & Liu, K. D. & $\begin{array}{c}\text { Clin ] Am Soc } \\
\text { Nephrol }\end{array}$ & $\begin{array}{l}\text { United } \\
\text { States }\end{array}$ & Cohort & $\begin{array}{l}\text { Association between } \\
\text { dialysis initiation } \\
\text { (early vs. late) and } \\
\text { mortality. }\end{array}$ & $\begin{array}{l}\text { Age, liver failure, sepsis, } \\
\text { thrombocytopenia, and serum } \\
\text { creatinine and stratification } \\
\text { by site and modality of initial } \\
\text { dialysis }\end{array}$ & Not reported & $\begin{array}{l}\text { Not } \\
\text { reported }\end{array}$ & ROC values & $\begin{array}{l}\text { Logistic } \\
\text { regression } \\
\text { and Cox } \\
\text { regression }\end{array}$ & Mortality \\
\hline 2007 & S. Uchino & $\begin{array}{l}\text { The } \\
\text { International } \\
\text { Journal of } \\
\text { Artificial } \\
\text { Organs }\end{array}$ & $\begin{array}{l}\text { United } \\
\text { States }\end{array}$ & Cohort & $\begin{array}{l}\text { Renal replacement } \\
\text { therapy (continuous } \\
\text { vs. intermittent) to } \\
\text { assess impact on } \\
\text { survival and renal } \\
\text { recovery }\end{array}$ & $\begin{array}{l}\text { ATrterial pH, furosemide dose, } \\
\text { creatinine, gastrointestinal } \\
\text { medical admission, } \\
\text { immunomodulation, use of } \\
\text { pulmonary artery catheter, } \\
\text { hepatorenal syndrome, } \\
\text { mechanical ventilation, mean } \\
\text { arterial pressure and Clasgow } \\
\text { coma score }\end{array}$ & Stratification & $\begin{array}{l}\text { Not } \\
\text { reported }\end{array}$ & PValue & $\begin{array}{l}\text { Logistic } \\
\text { regression }\end{array}$ & Survival \\
\hline 2008 & $\begin{array}{l}\text { Schort- } \\
\text { gen, } F \text {. }\end{array}$ & $\begin{array}{l}\text { Intensive } \\
\text { Care Med }\end{array}$ & France & Cohort & $\begin{array}{l}\text { The risk of renal } \\
\text { adverse events in } \\
\text { patients with shock } \\
\text { resuscitated with } \\
\text { hypo-oncotic colloids, } \\
\text { artificial hyperoncotic } \\
\text { colloids, hyperoncotic } \\
\text { albumin or crystalloids }\end{array}$ & $\begin{array}{l}\text { Demographic characteristics, } \\
\text { admission category (i.e., } \\
\text { planned or unplanned } \\
\text { medical, surgical, with the } \\
\text { type of surgery), potentially } \\
\text { life-threatening underlying } \\
\text { disease, immunodeficiency, } \\
\text { risk factors for acute renal } \\
\text { failure and use of nephrotoxic } \\
\text { drugs. Simplified acute } \\
\text { physiology score (SAPS II) } \\
\text { and the number of organ } \\
\text { dysfunction }\end{array}$ & $\begin{array}{c}\text { Covariable in } \\
\text { one model }\end{array}$ & $\begin{array}{l}\text { Not } \\
\text { reported }\end{array}$ & P Value & $\begin{array}{l}\text { Logistic } \\
\text { regression }\end{array}$ & $\begin{array}{l}\text { Renal } \\
\text { failure }\end{array}$ \\
\hline
\end{tabular}




\begin{tabular}{|c|c|c|c|c|c|c|c|c|c|c|c|}
\hline Year & Author & Journal & Country & $\begin{array}{l}\text { Study } \\
\text { type }\end{array}$ & Exposure & Variables & $\begin{array}{l}\text { Matching } \\
\text { algorithm }\end{array}$ & Closeness & $\begin{array}{c}\text { Balance } \\
\text { assessment }\end{array}$ & $\begin{array}{l}\text { Analytical } \\
\text { method } \\
\text { used }\end{array}$ & Outcomes \\
\hline 2009 & $\begin{array}{l}\text { Bagshaw, } \\
\text { S.M. }\end{array}$ & $\begin{array}{l}\text { Intensive } \\
\text { Care Med }\end{array}$ & Canada & Cohort & $\begin{array}{l}\text { In patients with septic } \\
\text { shock, describe the } \\
\text { association between } \\
\text { time of onset of } \\
\text { hypotension and } \\
\text { effective antimicrobial } \\
\text { therapy and onset and } \\
\text { severity of early acute } \\
\text { renal failure }\end{array}$ & $\begin{array}{c}\text { Age, sex, comorbidity, } \\
\text { source of infection, surgical } \\
\text { status, need for mechanical } \\
\text { ventilation, need for } \\
\text { vasopressors, APACHE II score, } \\
\text { hospital setting and study year }\end{array}$ & $\begin{array}{c}\text { Covariable in } \\
\text { one model }\end{array}$ & $\begin{array}{l}\text { Not } \\
\text { reported }\end{array}$ & ROC values & $\begin{array}{l}\text { Logistic } \\
\text { regression } \\
\text { and Cox } \\
\text { regression }\end{array}$ & $\begin{array}{l}\text { Renal } \\
\text { failure }\end{array}$ \\
\hline 2009 & $\begin{array}{l}\text { Benedet- } \\
\text { to, } U \text {. }\end{array}$ & $\begin{array}{l}\text { The Annals } \\
\text { of thoracic } \\
\text { surgery }\end{array}$ & Italy & Cohort & $\begin{array}{l}\text { Association between } \\
\text { on-pump coronary } \\
\text { artery bypass grafting } \\
\text { (CABC) vs. mini } \\
\text { cardiopulmonary } \\
\text { bypass systems (mini- } \\
\text { CPB) and reduced } \\
\text { incidence of acute } \\
\text { renal failure }\end{array}$ & $\begin{array}{l}\text { Age, sex, body mass index } \\
\text { (BMI), preoperative CFR, } \\
\text { diabetes mellitus, chronic } \\
\text { obstructive pulmonary } \\
\text { disease requiring treatment, } \\
\text { hypertension, peripheral } \\
\text { vascular disease, NYHA class } \\
\text { III/IV, left ventricular ejection } \\
\text { fraction, prior percutaneous } \\
\text { coronary intervention, } \\
\text { myocardial infarction within } \\
\text { 30 days, emergency surgery, } \\
\text { preoperative medications } \\
\text { including blockers, angiotensin } \\
\text { converting enzyme inhibitors } \\
\text { or angiotensin receptor } \\
\text { blockers, aspirin and clopidogrel } \\
\text { within } 5 \text { days after surgery; } \\
\text { primary surgeon, number of } \\
\text { grafts per patient and CPB } \\
\text { time; postoperative variables } \\
\text { including red blood cell } \\
\text { transfusions and low cardiac } \\
\text { output incidence }\end{array}$ & $\begin{array}{l}\text { Coincidence } \\
\text { matching }\end{array}$ & $\begin{array}{l}\text { Coincidence } \\
\text { matching } \\
\text { Nearest } \\
\text { neighbor }\end{array}$ & Cstatistic & $\begin{array}{l}\text { Logistic } \\
\text { regression }\end{array}$ & $\begin{array}{l}\text { Renal } \\
\text { failure }\end{array}$ \\
\hline 2010 & Billings & $\begin{array}{l}\text { Journal of } \\
\text { Cardiotho- } \\
\text { racic and } \\
\text { Vascular } \\
\text { Anesthesia }\end{array}$ & $\begin{array}{l}\text { United } \\
\text { States }\end{array}$ & Cohort & $\begin{array}{l}\text { Pre- and postoperative } \\
\text { use of statins and } \\
\text { incidence of acute } \\
\text { renal failure in } \\
\text { patients taken to } \\
\text { cardiac surgery }\end{array}$ & $\begin{array}{l}\text { Preoperative treatment with } \\
\text { statins, baseline creatinine, } \\
\text { age, sex, history of diabetes, } \\
\text { history of hypertensive } \\
\text { disease, BMI, baseline left } \\
\text { ventricular ejection fraction, } \\
\text { preoperative diuretic, } \\
\text { preoperative use of ACEi, valve } \\
\text { surgery, use of CBP, time on } \\
\text { CBP, aortic cross-clamping } \\
\text { time, intraoperative inotropic } \\
\text { support, intraoperative } \\
\text { coronary catheterization, } \\
\text { postoperative surgical re- } \\
\text { exploration, postoperative } \\
\text { diuretic, and extubation time }\end{array}$ & $\begin{array}{l}\text { Stratification } \\
\text { y Covariable } \\
\text { in one model }\end{array}$ & $\begin{array}{l}\text { Not } \\
\text { reported }\end{array}$ & PValue & $\begin{array}{l}\text { Logistic } \\
\text { regression }\end{array}$ & $\begin{array}{l}\text { Renal } \\
\text { failure }\end{array}$ \\
\hline 2010 & $\begin{array}{c}\text { Chamchad, } \\
\text { D. }\end{array}$ & $\begin{array}{l}\text { J Cardio- } \\
\text { thorac Vasc } \\
\text { Anesth }\end{array}$ & $\begin{array}{l}\text { United } \\
\text { States }\end{array}$ & Cohort & $\begin{array}{l}\text { Immediate extubation } \\
\text { in the operating room } \\
\text { after cardiac surgery } \\
\text { associated with } \\
\text { intensive care and } \\
\text { hospital length }\end{array}$ & $\begin{array}{l}\text { Age, sex, BMI, ethnicity, } \\
\text { preoperative serum creatinine, } \\
\text { NYHA, reoperation, CABC, } \\
\text { valve procedure, DM, } \\
\text { hypertension, COPD, use of BB, } \\
\text { angina, reintubation, bleeding, } \\
\text { postoperative renal failure, } \\
\text { postoperative atrial fibrillation, } \\
\text { time on CPB, priority of the } \\
\text { surgery, off-pump operation, } \\
\text { surgical priority }\end{array}$ & $\begin{array}{l}\text { Coincidence } \\
\text { matching }\end{array}$ & $\begin{array}{l}\text { Creedy } \\
\text { matching }\end{array}$ & $\begin{array}{l}\text { Standardized } \\
\text { measurements }\end{array}$ & $\begin{array}{l}\text { Logistic } \\
\text { regression } \\
\text { and Cox } \\
\text { regression }\end{array}$ & Estancia \\
\hline 2010 & $\begin{array}{l}\text { Engoren, } \\
\text { M. }\end{array}$ & $\begin{array}{l}\text { Anesthesio- } \\
\text { logy }\end{array}$ & $\begin{array}{l}\text { United } \\
\text { States }\end{array}$ & Cohort & $\begin{array}{l}\text { Red blood cell } \\
\text { transfusion vs. no } \\
\text { transfusion in patients } \\
\text { with acute pulmonary } \\
\text { injury for the } \\
\text { development of acute } \\
\text { renal failure }\end{array}$ & Not described & Not reported & $\begin{array}{l}\text { Not } \\
\text { reported }\end{array}$ & Not reported & $\begin{array}{l}\text { Logistic } \\
\text { regression }\end{array}$ & $\begin{array}{l}\text { Renal } \\
\text { failure }\end{array}$ \\
\hline
\end{tabular}




\begin{tabular}{|c|c|c|c|c|c|c|c|c|c|c|c|}
\hline Year & Author & Journal & Country & $\begin{array}{l}\text { Study } \\
\text { type }\end{array}$ & Exposure & Variables & $\begin{array}{l}\text { Matching } \\
\text { algorithm }\end{array}$ & Closeness & $\begin{array}{c}\text { Balance } \\
\text { assessment }\end{array}$ & $\begin{array}{c}\text { Analytical } \\
\text { method } \\
\text { used }\end{array}$ & Outcomes \\
\hline 2011 & Chou, Y. H. & Crit Care & Taiwán & Cohort & $\begin{array}{l}\text { Impact of early or } \\
\text { late initiation of renal } \\
\text { replacement therapy } \\
\text { in patients with acute } \\
\text { renal failure of septic } \\
\text { origin }\end{array}$ & $\begin{array}{l}\text { Demographics, } \\
\text { comorbidities, septic AKI } \\
\text { development after surgery } \\
\text { (or not), and indications for } \\
\text { TSR. Biochemical data such } \\
\text { as complete red blood cell } \\
\text { count, blood urea nitrogen } \\
\text { (BUN), serum creatinine } \\
\text { (sCr), serum glutamate- } \\
\text { oxaloacetate transaminase } \\
\text { (COT), total serum bilirubin, } \\
\text { serum albumin and serum } \\
\text { potassium (sK+) were } \\
\text { documented on admission } \\
\text { to the ICU and initiation of } \\
\text { RRT. Clinical parameters } \\
\text { included heart rate, systolic } \\
\text { and diastolic blood pressure, } \\
\text { central venous pressure } \\
\text { (CVP), partial oxygen } \\
\text { pressure in arterial blood } \\
\text { gases and inspired oxygen } \\
\text { fraction. Severity scores } \\
\text { included Glasgow Coma } \\
\text { Scale (GCS), acute physiology } \\
\text { score and chronic health } \\
\text { evaluation II (APACHE II), } \\
\text { sequence organ failure } \\
\text { assessment (SOFA) and } \\
\text { simplified acute physiology } \\
\text { score III (SOFA III). The use of } \\
\text { mechanical ventilation was } \\
\text { documented and inotropic } \\
\text { equivalent dose was } \\
\text { calculated. }\end{array}$ & $\begin{array}{l}\text { Coincidence } \\
\text { matching }\end{array}$ & $\begin{array}{c}\text { Not } \\
\text { reported }\end{array}$ & PValue & $\begin{array}{l}\text { Logistic } \\
\text { regression } \\
\text { and Cox } \\
\text { regression }\end{array}$ & Mortality \\
\hline 2011 & Kawar, E. & Jaapa & $\begin{array}{l}\text { United } \\
\text { States }\end{array}$ & Cohort & $\begin{array}{l}\text { Comparison of clinical } \\
\text { outcomes between } \\
\text { pages admitted to } \\
\text { an intensive careunit } \\
\text { managed by residents vs. } \\
\text { medical assistant }\end{array}$ & $\begin{array}{l}\text { Age, sex, admission } \\
\text { diagnoses, patient origin } \\
\text { before admission to the } \\
\text { ICU and insurance status, } \\
\text { tachycardia (heart rate } \\
150 \text { beats per minute), } \\
\text { arrhythmia, hypotension, } \\
\text { stroke, coma, intracranial } \\
\text { mass, gastrointestinal } \\
\text { bleeding and need for } \\
\text { mechanical ventilation, } \\
\text { cardiopulmonary } \\
\text { resuscitation (CPR) within } 24 \\
\text { hours before admission, liver } \\
\text { cirrhosis, serum creatinine } \\
\text { or metastatic cancer, } \\
\text { readmission to the ICU. }\end{array}$ & $\begin{array}{l}\text { Coincidence } \\
\text { matching }\end{array}$ & $\begin{array}{c}\text { Not } \\
\text { reported }\end{array}$ & PValue & $\begin{array}{l}\text { Logistic } \\
\text { regression } \\
\text { and Cox } \\
\text { regression }\end{array}$ & $\begin{array}{l}\text { Length of } \\
\text { stay and } \\
\text { mortality }\end{array}$ \\
\hline
\end{tabular}




\begin{tabular}{|c|c|c|c|c|c|c|c|c|c|c|c|}
\hline Year & Author & Journal & Country & $\begin{array}{l}\text { Study } \\
\text { type }\end{array}$ & Exposure & Variables & $\begin{array}{l}\text { Matching } \\
\text { algorithm }\end{array}$ & Closeness & $\begin{array}{c}\text { Balance } \\
\text { assessment }\end{array}$ & $\begin{array}{l}\text { Analytical } \\
\text { method } \\
\text { used }\end{array}$ & Outcomes \\
\hline 2011 & $\begin{array}{c}\text { Le Manach, } \\
\text { Y. }\end{array}$ & Anesthesiology & France & Cohort & $\begin{array}{l}\text { Chronic statin } \\
\text { treatment compared } \\
\text { to no statin treatment } \\
\text { in terms of the main } \\
\text { postoperative adverse } \\
\text { events in patients } \\
\text { undergoing vascular } \\
\text { surgery }\end{array}$ & $\begin{array}{l}\text { Age, sex, admission diagnoses, } \\
\text { patient origin before } \\
\text { admission to the ICU and } \\
\text { insurance status, tachycardia } \\
\text { (heart rate } 150 \text { beats per } \\
\text { minute), arrhythmia, } \\
\text { hypotension, stroke, } \\
\text { coma, intracranial mass, } \\
\text { gastrointestinal bleeding } \\
\text { and need for mechanical } \\
\text { ventilation, cardiopulmonary } \\
\text { resuscitation (CPR) within } \\
24 \text { hours before admission, } \\
\text { liver cirrhosis, high serum } \\
\text { creatinine levels ( } \leq 2 \mathrm{mg} / \mathrm{dL} \text { ) } \\
\text { or metastatic cancer. Physician } \\
\text { and staff names and whether } \\
\text { the patients was being } \\
\text { readmitted to the ICU }\end{array}$ & $\begin{array}{l}\text { Covariable in } \\
\text { one model }\end{array}$ & $\begin{array}{l}\text { Not } \\
\text { reported }\end{array}$ & C statistic & $\begin{array}{l}\text { Logistic } \\
\text { regression }\end{array}$ & Mortality \\
\hline 2011 & Lee, E. H. & $\begin{array}{l}\text { J Cardio- } \\
\text { thorac Vasc } \\
\text { Anesth }\end{array}$ & Korea & Cohort & $\begin{array}{c}\text { Immediate } \\
\text { postoperative } \\
\text { hypoalbuminemia } \\
\text { value as a marker } \\
\text { of outcome after } \\
\text { off-pump coronary } \\
\text { artery bypass grafting } \\
\text { (OPCABC) }\end{array}$ & $\begin{array}{l}\text { Sex, age, body mass index } \\
\text { (BMI), diabetes mellitus, } \\
\text { hypertension, chronic } \\
\text { pulmonary disease, } \\
\text { renal failure, prior stroke, } \\
\text { preoperative ejection fraction, } \\
\text { preoperative hematocrit, } \\
\text { preoperative albumin, } \\
\text { European System for Cardiac } \\
\text { Operative Risk (EuroSCORE) and } \\
\text { EuroSCORE logistic additive }\end{array}$ & $\begin{array}{l}\text { Coincidence } \\
\text { matching }\end{array}$ & $\begin{array}{l}\text { Not } \\
\text { reported }\end{array}$ & PValue & $\begin{array}{l}\text { Logistic } \\
\text { regression }\end{array}$ & $\begin{array}{l}\text { Renal } \\
\text { failure }\end{array}$ \\
\hline 2011 & Shahin, J. & Crit Care & Canada & Cohort & $\begin{array}{l}\text { Relationship between } \\
\text { inotrope use and } \\
\text { hospital mortality and } \\
\text { renal dysfunction in } \\
\text { patients undergoing } \\
\text { cardiac surgery }\end{array}$ & $\begin{array}{l}\text { Parsonnet score and low } \\
\text { left ventricular ejection } \\
\text { fraction, age, sex, bypass time, } \\
\text { procedure type, CABC only } \\
\text { or other procedures and the } \\
\text { perioperative use of intra- } \\
\text { aortic balloon pump }\end{array}$ & Stratification & $\begin{array}{l}\text { Greedy } \\
\text { mat- } \\
\text { ching }\end{array}$ & PValue & $\begin{array}{l}\text { Logistic } \\
\text { regression }\end{array}$ & Mortality \\
\hline 2012 & Attaran & $\begin{array}{l}\text { European } \\
\text { Journal of } \\
\text { Cardio-Tho- } \\
\text { racic Surgery }\end{array}$ & UK & Cohort & $\begin{array}{c}\text { Radiofrequency } \\
\text { ablation for atrial } \\
\text { fibrillation in patients } \\
\text { undergoing cardiac } \\
\text { surgery in relation to } \\
\text { a better outcome and } \\
\text { postoperative survival } \\
\text { rate }\end{array}$ & $\begin{array}{c}\text { Age, BMI, female gender, } \\
\text { class IV angina, recent } \\
\text { acute MI, current smoker, } \\
\text { DM, hypercholesterolemia, } \\
\text { hypertension, respiratory } \\
\text { disease, cerebrovascular } \\
\text { disease, renal dysfunction, } \\
\text { three-vessel disease, priority } \\
\text { surgery, rheumatic valve } \\
\text { disease, euroSCORE, LVEF } \\
<30 \%\end{array}$ & $\begin{array}{l}\text { Coincidence } \\
\text { matching }\end{array}$ & $\begin{array}{l}\text { Not } \\
\text { reported }\end{array}$ & PValue & $\begin{array}{l}\text { Logistic } \\
\text { regression }\end{array}$ & Mortality \\
\hline 2012 & Azuma, N. & $\begin{array}{l}\text { Eur J Vasc } \\
\text { Endovasc } \\
\text { Surg }\end{array}$ & Japan & Cohort & $\begin{array}{c}\text { Determination of } \\
\text { factors that affect } \\
\text { ischemic wound } \\
\text { healing and the role of } \\
\text { angiosome in bypass } \\
\text { surgery }\end{array}$ & $\begin{array}{l}\text { Diabetes, end-stage renal } \\
\text { disease, heel ulcer, Rutherford } \\
\text { classification, serum albumin } \\
\text { and CRP }\end{array}$ & $\begin{array}{l}\text { Coincidence } \\
\text { matching }\end{array}$ & $\begin{array}{l}\text { Not } \\
\text { reported }\end{array}$ & PValue & $\begin{array}{l}\text { Logistic } \\
\text { regression }\end{array}$ & Survival \\
\hline 2012 & Clec'h, C. & Crit Care & France & Cohort & $\begin{array}{l}\text { Association of renal } \\
\text { replacement therapy } \\
\text { with in-hospital } \\
\text { mortality in ICU } \\
\text { patients with acute } \\
\text { renal failure }\end{array}$ & $\begin{array}{l}\text { Increase in creatinine } \\
\text { reflected by the RIFLE score, } \\
\text { oliguria reflecte in 24-hour } \\
\text { urine output and SAPS II score, } \\
\text { blood urea nitrogen, serum } \\
\text { creatinine and potassium } \\
\text { (before RRT initiation), fluid } \\
\text { accumulation (reflected by the } \\
\text { difference in patient weight } \\
\text { when reaching maximum } \\
\text { RIFLE class as compared to } \\
\text { weight on admission to the } \\
\text { ICU) and SAPS II score }\end{array}$ & $\begin{array}{l}\text { Coincidence } \\
\text { matching }\end{array}$ & $\begin{array}{l}\text { Not } \\
\text { reported }\end{array}$ & PValue & $\begin{array}{l}\text { Logistic } \\
\text { regression }\end{array}$ & Mortality \\
\hline
\end{tabular}




\begin{tabular}{|c|c|c|c|c|c|c|c|c|c|c|c|}
\hline Year & Author & Journal & Country & $\begin{array}{l}\text { Study } \\
\text { type }\end{array}$ & Exposure & Variables & $\begin{array}{l}\text { Matching } \\
\text { algorithm }\end{array}$ & Closeness & $\begin{array}{c}\text { Balance } \\
\text { assessment }\end{array}$ & $\begin{array}{c}\text { Analytical } \\
\text { method } \\
\text { used }\end{array}$ & Outcomes \\
\hline 2012 & Lee, E. H. & $\begin{array}{l}\text { Intensive } \\
\text { Care Med }\end{array}$ & Korea & Cohort & $\begin{array}{l}\text { Association between } \\
\text { preoperative low } \\
\text { levels of serum } \\
\text { albumin and acute } \\
\text { renal injury after off- } \\
\text { pump coronary artery } \\
\text { bypass }\end{array}$ & $\begin{array}{c}\text { Age, body mass index, } \\
\text { baseline renal function, left } \\
\text { ventricular ejection fraction, li- } \\
\text { ver disease, diabetes mellitus, } \\
\text { occlusive peripheral vascular } \\
\text { disease and chronic obstructi- } \\
\text { ve pulmonary disease }\end{array}$ & $\begin{array}{l}\text { Coincidence } \\
\text { matching }\end{array}$ & $\begin{array}{l}\text { Greedy } \\
\text { matching }\end{array}$ & Cstatistic & $\begin{array}{l}\text { Logistic } \\
\text { regression }\end{array}$ & $\begin{array}{l}\text { Renal } \\
\text { failure }\end{array}$ \\
\hline 2012 & Vaara, S. T. & $\begin{array}{l}\text { Acta Anaes- } \\
\text { thesiol Scand }\end{array}$ & Finland & Cohort & $\begin{array}{l}\text { Volume of annual cases } \\
\text { in an intensive care } \\
\text { unit of patients treated } \\
\text { with renal replacement } \\
\text { therapy due to acute } \\
\text { renal injury and its } \\
\text { association with in- } \\
\text { hospital mortality }\end{array}$ & $\begin{array}{l}\text { Cender, age, BMI, elective } \\
\text { surgery, intra-aortic balloon, } \\
\text { cardiopulmonary resuscitation, } \\
\text { comorbidities, systemic organ } \\
\text { failure, among others }\end{array}$ & $\begin{array}{l}\text { Covariable in } \\
\text { one model }\end{array}$ & $\begin{array}{c}\text { Not } \\
\text { reported }\end{array}$ & PValue & $\begin{array}{l}\text { Logistic } \\
\text { regression }\end{array}$ & Mortality \\
\hline 2012 & Wu, V. C. & PLoS One & Taiwan & Cohort & $\begin{array}{l}\text { Impact of diuretic use } \\
\text { and dose on mortality } \\
\text { in critically ill patients } \\
\text { with acute renal injury } \\
30 \text { days after dialysis }\end{array}$ & $\begin{array}{l}\text { Cender, age, BMI, elective } \\
\text { surgery, intra-aortic } \\
\text { balloon, cardiopulmonary } \\
\text { resuscitation, comorbidities, } \\
\text { systemic organ failure, among } \\
\text { others }\end{array}$ & $\begin{array}{l}\text { Covariable in } \\
\text { one model }\end{array}$ & $\begin{array}{c}\text { Not } \\
\text { reported }\end{array}$ & PValue & $\begin{array}{l}\text { Logistic } \\
\text { regression } \\
\text { and Cox } \\
\text { regression }\end{array}$ & Mortality \\
\hline 2013 & Apel, M. & Crit Care & $\begin{array}{l}\text { Cer- } \\
\text { many }\end{array}$ & Cohort & $\begin{array}{l}\text { End-stage renal disease } \\
\text { is independently } \\
\text { associated with a } \\
\text { higher risk of death } \\
\text { following major } \\
\text { surgical procedures }\end{array}$ & $\begin{array}{l}\text { Age, sex, comorbidities, SAPS } \\
\text { II, surgery type and SOFA } \\
\text { subitems on admission to } \\
\text { the ICU }\end{array}$ & $\begin{array}{l}\text { Coincidence } \\
\text { matching }\end{array}$ & $\begin{array}{c}\text { Creedy } \\
\text { matching }\end{array}$ & PValue & $\begin{array}{l}\text { Logistic } \\
\text { regression }\end{array}$ & Mortality \\
\hline 2013 & Bayer, $\mathrm{O}$. & $\begin{array}{l}\text { Critical Care } \\
\text { Medicine }\end{array}$ & $\begin{array}{l}\text { Cer- } \\
\text { many }\end{array}$ & Cohort & $\begin{array}{l}\text { Comparison of } \\
\text { perioperative fluid } \\
\text { management in } \\
\text { cardiac surgery } \\
\text { patients using colloids } \\
\text { vs. crystalloids with } \\
\text { dialysis, cardiovascular } \\
\text { stabilization, fluid } \\
\text { balance and mortality }\end{array}$ & $\begin{array}{l}\text { Age, hypertension, DM, } \\
\text { cirrhosis, NYHA IV, acute MI, } \\
\text { pulmonary hypertension, } \\
\text { bypass time, serum creatinine, } \\
\text { use of noradrenaline or } \\
\text { adrenaline, NSAIDs, diuretics, } \\
\text { ACEi, aminoglycosides, } \\
\text { glycopeptides, antifungals, } \\
\text { iodinated contrast media, } \\
\text { septic shock, SAPSII score }\end{array}$ & Stratification & $\begin{array}{c}\text { Not } \\
\text { reported }\end{array}$ & PValue & $\begin{array}{l}\text { Logistic } \\
\text { regression }\end{array}$ & Mortality \\
\hline 2013 & Ehrmann & $\begin{array}{l}\text { Critical Care } \\
\text { Medicine }\end{array}$ & France & Cohort & $\begin{array}{l}\text { Use vs. non use of } \\
\text { iodinated contrast } \\
\text { medium as related } \\
\text { to an increase in the } \\
\text { incidence of acute } \\
\text { renal injury in ICU } \\
\text { patients. }\end{array}$ & $\begin{array}{l}\text { Age, hypertension, creatinine } \\
\text { levels, chronic renal failure, } \\
\text { diabetes, respiratory failure, } \\
\text { coma, trauma, fluid use } 12 \\
\text { h before inclusion, use of } \\
\text { mechanical ventilation, shock, } \\
\text { lactate, Sequential Organ } \\
\text { Failure Assessment (SOFA) and } \\
\text { sepsis. }\end{array}$ & $\begin{array}{l}\text { Coincidence } \\
\text { matching }\end{array}$ & $\begin{array}{c}\text { Not } \\
\text { reported }\end{array}$ & PValue & $\begin{array}{l}\text { Logistic } \\
\text { regression }\end{array}$ & $\begin{array}{l}\text { Renal } \\
\text { failure }\end{array}$ \\
\hline 2013 & Leite, T. T. & Crit Care & Brazil & Cohort & $\begin{array}{l}\text { Determination of the } \\
\text { association between } \\
\text { early vs. late initiation } \\
\text { of dyalisis after AKIN } \\
\text { stage } 3 \text { classification } \\
\text { and in-hospital } \\
\text { mortality in critically } \\
\text { ill patients }\end{array}$ & $\begin{array}{l}\text { Demographic, clinical and } \\
\text { laboratory data on ICU } \\
\text { admission and on the day of } \\
\text { renal replacement therapy } \\
\text { initiation }\end{array}$ & $\begin{array}{c}\text { IPW } \\
\text { (weighting) }\end{array}$ & $\begin{array}{c}\text { Not } \\
\text { reported }\end{array}$ & $\begin{array}{l}\text { Standardized } \\
\text { measure- } \\
\text { ments+ } \\
\text { significance }\end{array}$ & $\begin{array}{l}\text { Logistic } \\
\text { regression }\end{array}$ & Mortality \\
\hline 2013 & $\begin{array}{l}\text { Verônica } \\
\text { Torres } \\
\text { Costa e } \\
\text { Silva }\end{array}$ & PLOS ONE & Brazil & Cohort & $\begin{array}{l}\text { Time of early vs. late } \\
\text { nephrology consult } \\
\text { and association with } \\
\text { prognosis in patients } \\
\text { with acute renal } \\
\text { failure in the ICU }\end{array}$ & $\begin{array}{l}\text { Late consult: Diuresis, serum } \\
\text { creatinine levels, surgical AKI } \\
\text { and mechanical ventilation } \\
\text { Nephrology consult: SAPS } \\
\text { 3, CSA score, diuresis, serum } \\
\text { creatinine levels, potassium } \\
\text { and bicarbonate levels }\end{array}$ & $\begin{array}{l}\text { Covariable in } \\
\text { one model }\end{array}$ & $\begin{array}{c}\text { Not } \\
\text { reported }\end{array}$ & ROC values & $\begin{array}{l}\text { Logistic } \\
\text { regression }\end{array}$ & $\begin{array}{c}\text { Mortality } \\
\text { and Renal } \\
\text { failure }\end{array}$ \\
\hline
\end{tabular}




\begin{tabular}{|c|c|c|c|c|c|c|c|c|c|c|c|}
\hline Year & Author & Journal & Country & $\begin{array}{l}\text { Study } \\
\text { type }\end{array}$ & Exposure & Variables & $\begin{array}{l}\text { Matching } \\
\text { algorithm }\end{array}$ & Closeness & $\begin{array}{c}\text { Balance } \\
\text { assessment }\end{array}$ & $\begin{array}{c}\text { Analytical } \\
\text { method } \\
\text { used }\end{array}$ & Outcomes \\
\hline 2014 & Brewer, R. & $\begin{array}{l}\text { Ann Thorac } \\
\text { Surg }\end{array}$ & $\begin{array}{l}\text { United } \\
\text { States }\end{array}$ & Cohort & $\begin{array}{l}\text { Comparison between } \\
\text { on-pump and } \\
\text { off-pump coronary } \\
\text { revascularization } \\
\text { surgery }\end{array}$ & $\begin{array}{l}\text { Age, gender, race, mortality } \\
\text { risk, body surface area, smoker, } \\
\text { preoperative creatinine, } \\
\text { hypertension, DM, dyslipidemia, } \\
\text { dialysis, chronic pulmonary } \\
\text { diseases, peripheral vascular } \\
\text { disease, cerebrovascular disease, } \\
\text { prior stroke, prior acute MI, heart } \\
\text { failure, type of surgery, number } \\
\text { of compromised vessels, VEF } \\
<40 \% \text {, left trunk stenosis }>50 \% \text {, } \\
\text { preoperative intra-aortic balloon }\end{array}$ & $\begin{array}{l}\text { Coincidence } \\
\text { matching }\end{array}$ & $\begin{array}{c}\text { Not } \\
\text { reported }\end{array}$ & PValue & $\begin{array}{l}\text { Logistic } \\
\text { regression }\end{array}$ & Mortality \\
\hline 2014 & $\begin{array}{l}\text { Elmiste- } \\
\text { kawy, E }\end{array}$ & $\begin{array}{l}\text { Ann Thorac } \\
\text { Surg }\end{array}$ & Canada & Cohort & $\begin{array}{l}\text { Incidence and } \\
\text { associated risk factors } \\
\text { in mild renal failure } \\
\text { and determination } \\
\text { of clinical impact } \\
\text { following } \\
\text { cardiovascular surgery }\end{array}$ & $\begin{array}{l}\text { Acute myocardial infarction, } \\
\text { age, angina class, atrial } \\
\text { fibrillation, cardiopulmonary } \\
\text { bypass, CARE score, central } \\
\text { nervous system complications, } \\
\text { left ventricular functional } \\
\text { class, coronary artery } \\
\text { disease, endocarditis, sex, } \\
\text { hypertension, intraoperative } \\
\text { blood transfusion, hospital } \\
\text { length of stay, length of ICU stay, } \\
\text { time on ventilation, surgical } \\
\text { priority, peripheral vascular } \\
\text { disease, preoperative creatinine, } \\
\text { preoperative hemoglobin, } \\
\text { preoperative intra-aortic } \\
\text { balloon pump, pulmonary } \\
\text { edema, repeat cardiac surgery, } \\
\text { shock, smoking }\end{array}$ & $\begin{array}{l}\text { Coincidence } \\
\text { matching }\end{array}$ & $\begin{array}{l}\text { Nearest } \\
\text { neighbor }\end{array}$ & PValue & $\begin{array}{l}\text { Logistic } \\
\text { regression }\end{array}$ & Mortality \\
\hline 2014 & $\begin{array}{l}\text { Iwagami, } \\
\text { M. }\end{array}$ & $\begin{array}{l}\text { Crit Care } \\
\text { Med }\end{array}$ & Japan & Cohort & $\begin{array}{l}\text { Effect of postoperative } \\
\text { polymyxin B } \\
\text { hemoperfusion on } \\
\text { mortality in patients } \\
\text { with abdominal septic } \\
\text { shock }\end{array}$ & $\begin{array}{l}\text { Age, sex, surgery-related } \\
\text { findings; use of noradrenaline, } \\
\text { dopamine and dobutamine; } \\
\text { previously defined organ } \\
\text { dysfunctions (6), hospital } \\
\text { volumes and hospital type } \\
\text { (teaching or non-teaching } \\
\text { hospital) }\end{array}$ & $\begin{array}{l}\text { Coincidence } \\
\text { matching }\end{array}$ & $\begin{array}{l}\text { Nearest } \\
\text { neighbor }\end{array}$ & Cstatistic & $\begin{array}{l}\text { Logistic } \\
\text { regression }\end{array}$ & Mortality \\
\hline 2014 & $\begin{array}{l}\text { Raghuna- } \\
\text { than }\end{array}$ & $\begin{array}{l}\text { Critical Care } \\
\text { Medicine }\end{array}$ & $\begin{array}{l}\text { United } \\
\text { States }\end{array}$ & Cohort & $\begin{array}{l}\text { Association between } \\
\text { the use of crystalloids } \\
\text { and in-hospital } \\
\text { mortality in critically } \\
\text { ill adult patients with } \\
\text { sepsis }\end{array}$ & Not described & $\begin{array}{l}\text { Coincidence } \\
\text { matching }\end{array}$ & $\begin{array}{l}\text { Greedy } \\
\text { mat- } \\
\text { ching }\end{array}$ & PValue & $\begin{array}{l}\text { Logistic } \\
\text { regression }\end{array}$ & Mortality \\
\hline 2014 & Linder, A. & $\begin{array}{l}\text { Am] Respir } \\
\text { Crit Care } \\
\text { Med }\end{array}$ & Canada & Cohort & $\begin{array}{l}\text { At least one episode of } \\
\text { mild acute renal failure } \\
\text { (stage1) vs. absence of } \\
\text { renal failure associated } \\
\text { with long-term survival } \\
\text { after recovery from } \\
\text { critical disease }\end{array}$ & $\begin{array}{l}\text { Sex, age, diabetes, MAP (lower } \\
\text { baseline), noradrenaline } \\
\text { treatment, lactate level on day } \\
\text { 1, chronic heart failure, COPD, } \\
\text { chronic liver failure, chronic } \\
\text { steroid treatment, malignancy } \\
\text { and HIV }\end{array}$ & $\begin{array}{l}\text { Coincidence } \\
\text { matching }\end{array}$ & Caliper & PValue & Regresión & Survival \\
\hline 2014 & Oh, H. J. & Crit Care & Korea & Cohort & $\begin{array}{l}\text { Benefit of a team } \\
\text { that specializes in } \\
\text { acute renal injury } \\
\text { patients undergoing } \\
\text { continuous renal } \\
\text { replacement therapy }\end{array}$ & $\begin{array}{l}\text { Age, gender, mean arterial } \\
\text { pressure, APACHE II, organ } \\
\text { failure, age-adjusted Charlson } \\
\text { comorbidity index, RIFLE } \\
\text { scale, contributing factors, } \\
\text { use of anticoagulation, use } \\
\text { of diuretics, laboratory tests } \\
\text { (hemoglobin, leukocytes, } \\
\text { creatinine, bicarbonate, BUN, } \\
\text { total cholesterol, albumin, CRP, } \\
\text { arterial pH and total bilirubin) }\end{array}$ & $\begin{array}{l}\text { Coincidence } \\
\text { matching }\end{array}$ & $\begin{array}{l}\text { Creedy } \\
\text { matching }\end{array}$ & PValue & $\begin{array}{l}\text { Logistic } \\
\text { regression } \\
\text { and Cox } \\
\text { regression }\end{array}$ & Survival \\
\hline
\end{tabular}




\begin{tabular}{|c|c|c|c|c|c|c|c|c|c|c|c|}
\hline Year & Author & Journal & Country & $\begin{array}{l}\text { Study } \\
\text { type }\end{array}$ & Exposure & Variables & $\begin{array}{l}\text { Matching } \\
\text { algorithm }\end{array}$ & Closeness & $\begin{array}{l}\text { Balance } \\
\text { assessment }\end{array}$ & $\begin{array}{l}\text { Analytical } \\
\text { method } \\
\text { used }\end{array}$ & Outcomes \\
\hline 2014 & Picard, W & $\begin{array}{l}\text { Antimicrob } \\
\text { Agents } \\
\text { Chemother }\end{array}$ & France & Cohort & $\begin{array}{l}\text { Determine the } \\
\text { nephrotoxicity risk } \\
\text { associated with } \\
\text { aminoglycoside } \\
\text { treatment }\end{array}$ & $\begin{array}{l}\text { Age, gender, nosocomial sepsis, } \\
\text { sepsis origin, sepsis severity, } \\
\text { organ failure, rhabdomyolysis, } \\
\text { renal graft of single functional } \\
\text { kidney, DM, cirrhosis, } \\
\text { pre-existing renal failure, } \\
\text { nephrotoxic treatments, ACE } \\
\text { inhibitors/ARBs, use of diuretics, } \\
\text { high osmolarity contrast } \\
\text { medium, use of hydoxyethyl } \\
\text { starches, NSAIDs, antibiotics }\end{array}$ & $\begin{array}{l}\text { Covariable in } \\
\text { one model }\end{array}$ & $\begin{array}{l}\text { Not } \\
\text { reported }\end{array}$ & PValue & $\begin{array}{l}\text { Cox } \\
\text { regression }\end{array}$ & $\begin{array}{l}\text { Renal } \\
\text { failure }\end{array}$ \\
\hline 2014 & Vaara, S. T. & $\begin{array}{l}\text { Crit Care } \\
\text { Med }\end{array}$ & Finland & Cohort & $\begin{array}{l}\text { Excess mortality } \\
\text { attributable to acute } \\
\text { renal injury }\end{array}$ & $\begin{array}{l}\text { Excess mortality attributable } \\
\text { to acute renal injury }\end{array}$ & $\begin{array}{l}\text { Coincidence } \\
\text { matching }\end{array}$ & $\begin{array}{l}\text { Not } \\
\text { reported }\end{array}$ & $\begin{array}{l}\text { Standardized } \\
\text { measure- } \\
\text { ments+ } \\
\text { significance }\end{array}$ & $\begin{array}{l}\text { Logistic } \\
\text { regression }\end{array}$ & Mortality \\
\hline 2014 & Wald, R. & $\begin{array}{l}\text { Crit Care } \\
\text { Med }\end{array}$ & Canada & Cohort & $\begin{array}{l}\text { Intermittent vs. } \\
\text { continuous dialysis } \\
\text { associated with the } \\
\text { risk of chronic dialysis }\end{array}$ & $\begin{array}{l}\text { Age, sex, hospitalization year, } \\
\text { number of admissions and } \\
\text { emergency room visits, number } \\
\text { of visits to family physician, } \\
\text { nephrologist, internist, } \\
\text { cardiologist, geriatrician } \\
\text { and psychiatrist; coronary } \\
\text { artery, carotid or peripheral } \\
\text { artery revascularization, } \\
\text { heart valve surgery, coronary } \\
\text { angiography, cardiac stress } \\
\text { test, echocardiography, 12-lead } \\
\text { individual electrocardiography } \\
\text { or outpatient 24-hour } \\
\text { electrocardiography, pacemaker } \\
\text { insertion or carotid Doppler } \\
\text { ultrasound within the 5years } \\
\text { prior to hospitalization and } \\
\text { ARI diagnosis, major infection, } \\
\text { alcoholism, chronic renal } \\
\text { disease, liver dysfunction, } \\
\text { heart failure, myocardial } \\
\text { infarction, diabetes mellitus, } \\
\text { cancer, cerebrovascular disease, } \\
\text { myocardial infarction or angina } \\
\text { and peripheral artery disease } \\
\text { within } 5 \text { years prior to the date } \\
\text { of hospital admission, Charlson } \\
\text { comorbidity index, sepsis, non- } \\
\text { ruptured aortic aneurysm repair, } \\
\text { heart surgery, mechanical } \\
\text { ventilation and initiation of } \\
\text { dialysis in a teaching hospital }\end{array}$ & $\begin{array}{l}\text { Coincidence } \\
\text { matching }\end{array}$ & $\begin{array}{l}\text { Nearest } \\
\text { neighbor }\end{array}$ & $\begin{array}{l}\text { Standardi- } \\
\text { zed measu- } \\
\text { rements }\end{array}$ & $\begin{array}{l}\text { Logistic } \\
\text { regression } \\
\text { and Cox } \\
\text { regression }\end{array}$ & $\begin{array}{l}\text { Renal } \\
\text { failure }\end{array}$ \\
\hline 2015 & Chiang, Y. & $\begin{array}{l}\text { J Cardio- } \\
\text { thorac Vasc } \\
\text { Anesth }\end{array}$ & $\begin{array}{l}\text { United } \\
\text { States }\end{array}$ & Cohort & $\begin{array}{l}\text { Effect of pulmonary } \\
\text { artery catheterization } \\
\text { on clinical outcomes } \\
\text { after cardiac surgery in } \\
\text { high risk patients }\end{array}$ & $\begin{array}{l}\text { Demographic characteristics, } \\
\text { preoperative characteristics } \\
\text { (hypertension, } \\
\text { hypercholesterolemia, } \\
\text { diabetes mellitus, obesity, } \\
\text { prior stroke, coronary heart } \\
\text { disease, endocarditis, chronic } \\
\text { obstructive pulmonary } \\
\text { disease, pulmonary } \\
\text { hypertension, peripheral } \\
\text { vascular disease, chronic renal } \\
\text { failure, dialysis, liver disease, } \\
\text { substance abuse, previous } \\
\text { CABC, prior valve surgery), } \\
\text { elective surgery, type of } \\
\text { cardiac surgery, CABC, single } \\
\text { valve CABC surgery, double or } \\
\text { triple CABC surgery }\end{array}$ & $\begin{array}{l}\text { Coincidence } \\
\text { matching }\end{array}$ & $\begin{array}{l}\text { Not } \\
\text { reported }\end{array}$ & PValue & $\begin{array}{l}\text { Logistic } \\
\text { regression }\end{array}$ & Mortality \\
\hline
\end{tabular}




\begin{tabular}{|c|c|c|c|c|c|c|c|c|c|c|c|}
\hline Year & Author & Journal & Country & $\begin{array}{l}\text { Study } \\
\text { type }\end{array}$ & Exposure & Variables & $\begin{array}{l}\text { Matching } \\
\text { algorithm }\end{array}$ & Closeness & $\begin{array}{c}\text { Balance } \\
\text { assessment }\end{array}$ & $\begin{array}{c}\text { Analytical } \\
\text { method } \\
\text { used }\end{array}$ & Outcomes \\
\hline 2015 & Ding, W. & Cardiology & China & Cohort & $\begin{array}{l}\text { Intra-aortic balloon } \\
\text { pump in relation to } \\
\text { early clinical outcome } \\
\text { in high risk patients } \\
\text { taken to elective } \\
\text { off-pump coronary } \\
\text { artery bypass grafting } \\
\text { (OPCABC) }\end{array}$ & $\begin{array}{l}\text { Age, sex, body mass index, } \\
\text { smoker, DM, hypertension, } \\
\text { dyslipidemia, renal } \\
\text { dysfunction, prior stroke, prior } \\
\text { acute MI, prior cardiac surgery, } \\
\text { number of compromised } \\
\text { coronary arteries, SYNTAX, } \\
\text { BNO, euroSOCRE, LVEF, distal } \\
\text { anastomosis }\end{array}$ & $\begin{array}{l}\text { Coincidence } \\
\text { matching }\end{array}$ & $\begin{array}{c}\text { Not } \\
\text { reported }\end{array}$ & PValue & $\begin{array}{l}\text { Logistic } \\
\text { regression }\end{array}$ & Mortality \\
\hline 2015 & $\begin{array}{l}\text { Horkan, } \\
\text { C. M. }\end{array}$ & $\begin{array}{l}\text { Crit Care } \\
\text { Med }\end{array}$ & $\begin{array}{l}\text { United } \\
\text { States }\end{array}$ & Cohort & $\begin{array}{l}\text { Acute renal injury } \\
\text { in patients who } \\
\text { survived critical care } \\
\text { and association } \\
\text { of post-discharge } \\
\text { outcomes (readmission } \\
\text { beyond } 30 \text { days after } \\
\text { discharge, post- } \\
\text { discharge mortality } \\
\text { and progression to end- } \\
\text { stage renal disease) }\end{array}$ & $\begin{array}{l}\text { Age, sex, race, Deyo-Charlson } \\
\text { index, type of patient and } \\
\text { risk classification, injury, } \\
\text { failure, loss of renal function } \\
\text { or end-stage renal disease }\end{array}$ & $\begin{array}{l}\text { Covariable in } \\
\text { one model }\end{array}$ & Caliper & PValue & $\begin{array}{l}\text { Logistic } \\
\text { regression } \\
\text { and Cox } \\
\text { regression }\end{array}$ & $\begin{array}{c}\text { Mortality } \\
\text { and Renal } \\
\text { failure }\end{array}$ \\
\hline 2015 & Leite, T. T. & $\begin{array}{l}\text { Clin J Am Soc } \\
\text { Nephrol }\end{array}$ & Brazil & Cohort & $\begin{array}{l}\text { Renal outcomes in } \\
\text { critically ill patients } \\
\text { receiving propofol or } \\
\text { midazolam }\end{array}$ & $\begin{array}{l}\text { Sex, age, non-renal admission, } \\
\text { simplified acute physiology } \\
\text { score I and sequential organ } \\
\text { failure evaluation, main } \\
\text { comorbidities, type of ICU } \\
\text { admission (medical, surgical } \\
\text { or coronary), sepsis diagnosis, } \\
\text { admission, Clasgow Coma } \\
\text { Scale score, renal function } \\
\text { on admission to the ICU } \\
\text { (first serum creatinine } \\
\text { measurement available), need } \\
\text { for vasoactive drugs during the } \\
\text { first } 48 \text { hours in the ICU and } \\
\text { mean arterial pressure median } \\
\text { in the first } 48 \text { hours in the ICU }\end{array}$ & $\begin{array}{l}\text { Coincidence } \\
\text { matching }\end{array}$ & $\begin{array}{l}\text { Nearest } \\
\text { neighbor }\end{array}$ & $\begin{array}{l}\text { Standardized } \\
\text { measurements } \\
+ \text { significance }\end{array}$ & $\begin{array}{l}\text { Logistic } \\
\text { regression }\end{array}$ & $\begin{array}{l}\text { Renal } \\
\text { failure }\end{array}$ \\
\hline 2015 & $\begin{array}{l}\text { Alexandre } \\
\text { Liborio }\end{array}$ & $\begin{array}{l}\text { Nephrology } \\
\text { Dialysis } \\
\text { Transplanta- } \\
\text { tion }\end{array}$ & $\begin{array}{l}\text { United } \\
\text { States }\end{array}$ & Cohort & $\begin{array}{l}\text { Propofol vs. } \\
\text { midazolam. }\end{array}$ & $\begin{array}{l}\text { Sex, age, non-renal admission, } \\
\text { simplified acute physiology } \\
\text { score I and sequential organ } \\
\text { failure evaluation, main } \\
\text { comorbidities, type of ICU } \\
\text { admission (medical, surgical } \\
\text { or coronary), sepsis diagnosis, } \\
\text { admission, Clasgow Coma } \\
\text { Scale score, renal function on } \\
\text { admission to the ICU (first } \\
\text { serum creatinine measurement } \\
\text { available), need for vasoactive } \\
\text { drugs during the first } 48 \text { hours } \\
\text { in the ICU and mean arterial } \\
\text { pressure median in the first } 48 \\
\text { hours in the ICU }\end{array}$ & $\begin{array}{l}\text { Coincidence } \\
\text { matching }\end{array}$ & $\begin{array}{l}\text { Nearest } \\
\text { neighbor } \\
+ \text { caliper }\end{array}$ & $\begin{array}{l}\text { Standardized } \\
\text { measurements }\end{array}$ & $\begin{array}{l}\text { Logistic } \\
\text { regression }\end{array}$ & $\begin{array}{l}\text { Renal } \\
\text { failure }\end{array}$ \\
\hline 2015 & $\begin{array}{l}\text { Liborio, } \\
\text { A. B. }\end{array}$ & $\begin{array}{c}\text { Clin J Am Soc } \\
\text { Nephrol }\end{array}$ & Brazil & Cohort & $\begin{array}{l}\text { Complications of renal } \\
\text { failure in critically ill } \\
\text { patients associated } \\
\text { with mortality and } \\
\text { dialysis rates }\end{array}$ & $\begin{array}{l}\text { Age, SAPS-I/SOFA scores on } \\
\text { admission, maximum BUN, } \\
\text { cumulative fluid balance, } \\
\text { minimum bicarbonate, } \\
\text { maximum serum potassium } \\
\text { and main comorbidities, } \\
\text { including heart failure }\end{array}$ & $\begin{array}{l}\text { Coincidence } \\
\text { matching }\end{array}$ & $\begin{array}{l}\text { Nearest } \\
\text { neighbor }\end{array}$ & PValue & $\begin{array}{l}\text { Logistic } \\
\text { regression }\end{array}$ & $\begin{array}{c}\text { Mortality } \\
\text { and Renal } \\
\text { failure }\end{array}$ \\
\hline 2015 & Sang, B. H. & $\begin{array}{c}\text { Crit Care } \\
\text { Med }\end{array}$ & Korea & Cohort & $\begin{array}{c}\text { Influence of } \\
\text { postoperative } \\
\text { albumin level on the } \\
\text { prevalence of acute } \\
\text { renal injury after live } \\
\text { donor liver transplant }\end{array}$ & $\begin{array}{l}\text { Age, sex, BMI, diabetes, } \\
\text { hypertension, mean arterial } \\
\text { pressure, CHILD PUCH score, } \\
\text { model for end-stage liverdisease } \\
\text { score, hemoglobin, platelets, } \\
\text { albumin, sodium, total bilirubin, } \\
\text { creatinine, prothrombin timeand } \\
\text { intraoperative data }\end{array}$ & $\begin{array}{c}\text { IPW } \\
\text { (weighting) }\end{array}$ & $\begin{array}{c}\text { Not } \\
\text { reported }\end{array}$ & C statistic & $\begin{array}{l}\text { Logistic } \\
\text { regression } \\
\text { and Cox } \\
\text { regression }\end{array}$ & $\begin{array}{l}\text { Renal } \\
\text { failure }\end{array}$ \\
\hline
\end{tabular}




\begin{tabular}{|c|c|c|c|c|c|c|c|c|c|c|c|}
\hline Year & Author & Journal & Country & $\begin{array}{l}\text { Study } \\
\text { type }\end{array}$ & Exposure & Variables & $\begin{array}{l}\text { Matching } \\
\text { algorithm }\end{array}$ & Closeness & $\begin{array}{c}\text { Balance } \\
\text { assessment }\end{array}$ & $\begin{array}{l}\text { Analytical } \\
\text { method } \\
\text { used }\end{array}$ & Outcomes \\
\hline 2015 & Shaw, A. D. & Crit Care & $\begin{array}{l}\text { United } \\
\text { States }\end{array}$ & Cohort & $\begin{array}{l}\text { Type of intravenous } \\
\text { fluid administered } \\
\text { to patients with } \\
\text { systemic inflammatory } \\
\text { response syndrome } \\
\text { and association with } \\
\text { outcome }\end{array}$ & $\begin{array}{c}\text { Age, sex, race, admission } \\
\text { source, admission type, urban, } \\
\text { comorbidities }\end{array}$ & $\begin{array}{l}\text { Coincidence } \\
\text { matching }\end{array}$ & $\begin{array}{l}\text { Greedy } \\
\text { matching }\end{array}$ & PValue & $\begin{array}{l}\text { Logistic } \\
\text { regression }\end{array}$ & Mortality \\
\hline 2015 & Shen, T. C. & $\begin{array}{l}\text { Medicine } \\
\text { (Baltimore) }\end{array}$ & Japan & Cohort & $\begin{array}{l}\text { Risk of septicemia in } \\
\text { patients with end- } \\
\text { stage renal disease } \\
\text { with or without renal } \\
\text { transplant }\end{array}$ & $\begin{array}{l}\text { Age, sex, index date, } \\
\text { comorbidities (hepatitis } \\
\text { B, hepatitis C, Charlson } \\
\text { comorbidity index score) } \\
\text { and medications (steroids } \\
\text { and immunosuppressors } \\
\text { [cyclosporine, azathioprine, } \\
\text { mycophenolate mofetil and } \\
\text { tacrolimus]). }\end{array}$ & $\begin{array}{l}\text { Coincidence } \\
\text { matching }\end{array}$ & $\begin{array}{c}\text { Not } \\
\text { reported }\end{array}$ & PValue & $\begin{array}{l}\text { Logistic } \\
\text { regression } \\
\text { and Cox } \\
\text { regression }\end{array}$ & Mortality \\
\hline 2016 & Allen, C. J. & Mil Med & $\begin{array}{l}\text { United } \\
\text { States }\end{array}$ & Cohort & $\begin{array}{l}\text { Risk of acute renal } \\
\text { failure or death } \\
\text { in patients with } \\
\text { penetrating trauma } \\
\text { receiving a single } \\
\text { bolus of hydroxyethyl } \\
\text { starch during initial } \\
\text { fluid resuscitation }\end{array}$ & $\begin{array}{l}\text { Age and sex, injury } \\
\text { characteristics (injury severity } \\
\text { score, initial systolic blood } \\
\text { pressure, heart rate, Clasgow } \\
\text { scale), excess base, hematocrit, } \\
\text { need for blood transfusion, ICU } \\
\text { admission and surgery }\end{array}$ & $\begin{array}{l}\text { Coincidence } \\
\text { matching }\end{array}$ & $\begin{array}{l}\text { Nearest } \\
\text { neighbor }\end{array}$ & PValue & $\begin{array}{l}\text { Logistic } \\
\text { regression }\end{array}$ & $\begin{array}{l}\text { Mortality } \\
\text { and Renal } \\
\text { failure }\end{array}$ \\
\hline 2016 & Bonnet, V. & $\begin{array}{l}\text { Medicine } \\
\text { (Baltimore) }\end{array}$ & France & Cohort & $\begin{array}{l}\text { Comparison of } \\
\text { postoperative } \\
\text { complications of } \\
\text { mitral valve repair } \\
\text { taking into account } \\
\text { age under and } \\
\text { over } 80 \text { years and } \\
\text { comorbidities }\end{array}$ & $\begin{array}{l}\text { Age over and under } 80 \text { years, } \\
\text { sex, BMI, comorbidities, NYHA } \\
>=2, \text { LVEF }<45 \% \text {, pulmonary } \\
\text { hypertension, type of surgery, } \\
\text { surgical time }\end{array}$ & $\begin{array}{l}\text { Coincidence } \\
\text { matching }\end{array}$ & $\begin{array}{c}\text { Not } \\
\text { reported }\end{array}$ & Cstatistic & $\begin{array}{l}\text { Logistic } \\
\text { regression }\end{array}$ & Mortality \\
\hline 2016 & Carmona, $\mathrm{p}$ & $\begin{array}{l}\text { Interact } \\
\text { Cardiovasc } \\
\text { Thorac Surg }\end{array}$ & Spain & Cohort & $\begin{array}{c}\text { On or off- } \\
\text { pump coronary } \\
\text { revascularization } \\
\text { surgery comparing } \\
\text { intraoperative and } \\
\text { 30-day postoperative } \\
\text { outcomes }\end{array}$ & $\begin{array}{l}\text { Age, sex, EuroSCORE logistic, } \\
\text { smoking, obesity BMI }>30, \\
\text { hypertension under treatment, } \\
\text { dislipidemia under treatment, } \\
\text { diabetes mellitus under with } \\
\text { insulin treatment, past medical } \\
\text { history of stroke (stroke or } \\
\text { transient ischemic attack), } \\
\text { chronic pulmonary disease: } \\
\text { pulmonary disease under } \\
\text { treatment with bronchodilators } \\
\text { or steroids, clinical symptoms } \\
\text { of stable or unstable angina, } \\
\text { past history of percutaneeus } \\
\text { coronary intervention, history of } \\
\text { acute coronary syndrome within } \\
\text { the previous } 6 \text { months. Surgery, } \\
\text { intra-aortic balloon pump } \\
\text { implantation before surgery. } \\
\text { Chronic renal disease: defined } \\
\text { as preoperative creatinine } \\
\text { >2 mg/dLor need for renal } \\
\text { replacement therapy, peripheral } \\
\text { artery disease with intermittent } \\
\text { clinical symptoms. Lower } \\
\text { limb cladication, more than } \\
50 \% \text { carotid artery occlusion, } \\
\text { amputation of any limb due } \\
\text { to arterial disease, prior aortic } \\
\text { or lower limb artery surgery, } \\
\text { priority of the surgery: if the } \\
\text { case was intervened within the } \\
\text { first } 24 \text { hours after indication of } \\
\text { surgery or later }\end{array}$ & $\begin{array}{l}\text { Coincidence } \\
\text { matching }\end{array}$ & $\begin{array}{c}\text { Not } \\
\text { reported }\end{array}$ & ROC values & $\begin{array}{l}\text { Logistic } \\
\text { regression }\end{array}$ & Mortality \\
\hline 2016 & Chao, p. W. & $\begin{array}{l}\text { Crit Care } \\
\text { Med }\end{array}$ & Taiwan & Cohort & $\begin{array}{l}\text { Long-term results } \\
\text { in critically ill septic } \\
\text { patients who received } \\
\text { cardiopulmonary } \\
\text { resuscitation vs. those } \\
\text { who did not receive } \\
\text { resuscitation }\end{array}$ & $\begin{array}{l}\text { Age, year of onset, month } \\
\text { of onset, sex, urbanization } \\
\text { level, hospital level, Charlson } \\
\text { comorbidity idex score, } \\
\text { infection site, use of inotropic } \\
\text { agents, dialysis, ventilation, } \\
\text { days in the ICU, comorbidities, } \\
\text { concomitant medications }\end{array}$ & Stratification & $\begin{array}{l}\text { Nearest } \\
\text { neighbor }\end{array}$ & $\begin{array}{l}\text { Standardized } \\
\text { measurements }\end{array}$ & $\begin{array}{l}\text { Logistic } \\
\text { regression } \\
\text { and Cox } \\
\text { regression }\end{array}$ & Survival \\
\hline
\end{tabular}




\begin{tabular}{|c|c|c|c|c|c|c|c|c|c|c|c|}
\hline Year & Author & Journal & Country & $\begin{array}{l}\text { Study } \\
\text { type }\end{array}$ & Exposure & Variables & $\begin{array}{l}\text { Matching } \\
\text { algorithm }\end{array}$ & Closeness & $\begin{array}{c}\text { Balance } \\
\text { assessment }\end{array}$ & $\begin{array}{l}\text { Analytical } \\
\text { method } \\
\text { used }\end{array}$ & Outcomes \\
\hline 2016 & $\begin{array}{l}\text { Charat } \\
\text { Thongpra- } \\
\text { yoon }\end{array}$ & $\begin{array}{c}\text { BMC } \\
\text { Nephrology }\end{array}$ & $\begin{array}{l}\text { United } \\
\text { States }\end{array}$ & Cohort & $\begin{array}{l}\text { Effect of several } \\
\text { measurement methods } \\
\text { to determine baseline } \\
\text { creatinine levels on } \\
\text { the accuracy of acute } \\
\text { renal injury diagnosis in } \\
\text { critically ill patients }\end{array}$ & $\begin{array}{l}\text { Age, race, diabetes mellitus, } \\
\text { hypertension, coronary heart } \\
\text { disease, stroke, peripheral } \\
\text { vascular disease, congestive } \\
\text { heart failure and APACHE III } \\
\text { on admission to the ICU }\end{array}$ & Not reported & $\begin{array}{c}\text { Not } \\
\text { reported }\end{array}$ & Cstatistic & $\begin{array}{l}\text { Logistic } \\
\text { regression }\end{array}$ & $\begin{array}{l}\text { Renal } \\
\text { failure }\end{array}$ \\
\hline 2016 & $\begin{array}{l}\text { Cipolle, } \\
\text { M.D. }\end{array}$ & $\begin{array}{l}\text { J Trauma } \\
\text { Acute Care } \\
\text { Surg }\end{array}$ & $\begin{array}{l}\text { United } \\
\text { States }\end{array}$ & Cohort & $\begin{array}{l}\text { Differences in results } \\
\text { between trauma pa- } \\
\text { tients who received care } \\
\text { in the trauma hospital } \\
\text { program and patients } \\
\text { with similar medical } \\
\text { complexity trauma who } \\
\text { did notreceive care in the } \\
\text { trauma program }\end{array}$ & $\begin{array}{l}\text { Age, injury severity score } \\
\text { and pre-existing diabetes } \\
\text { mellitus conditions requiring } \\
\text { insulin therapy, hypertension, } \\
\text { congestive heart failure and } \\
\text { stroke }\end{array}$ & $\begin{array}{l}\text { Coincidence } \\
\text { matching }\end{array}$ & $\begin{array}{c}\text { Not } \\
\text { reported }\end{array}$ & PValue & $\begin{array}{l}\text { Logistic } \\
\text { regression }\end{array}$ & Mortality \\
\hline 2016 & Clark, E. & $\begin{array}{l}\text { Intensive } \\
\text { Care Med }\end{array}$ & Canada & Cohort & $\begin{array}{l}\text { Clinical characteristics } \\
\text { and in-hospital mor- } \\
\text { tality in patients with } \\
\text { end-stage chronic renal } \\
\text { failure o chronic dialysis } \\
\text { with septic shock as } \\
\text { compared to patients } \\
\text { with septic shock not on } \\
\text { chronic dialysis }\end{array}$ & $\begin{array}{l}\text { Age, sex, comorbidities } \\
\text { (cancer, immune compromise, } \\
\text { ICC, coronary artery disease, } \\
\text { elective or emergency surgery, } \\
\text { COPD, dibetes) and APACHE } \\
\text { II score }\end{array}$ & $\begin{array}{l}\text { Coincidence } \\
\text { matching }\end{array}$ & $\begin{array}{l}\text { Nearest } \\
\text { neighbor }\end{array}$ & $\begin{array}{l}\text { Standardized } \\
\text { measurements } \\
\text { and Cstatistic }\end{array}$ & $\begin{array}{l}\text { Logistic } \\
\text { regression } \\
\text { and Cox } \\
\text { regression }\end{array}$ & Mortality \\
\hline 2016 & $\begin{array}{l}\text { Hammond, } \\
\text { D. A. }\end{array}$ & $\begin{array}{l}\text { Pharmaco- } \\
\text { therapy }\end{array}$ & $\begin{array}{l}\text { United } \\
\text { States }\end{array}$ & Cohort & $\begin{array}{l}\text { Comparison of the } \\
\text { incidence of acute renal } \\
\text { failure development } \\
\text { in critically ill patients } \\
\text { who received } \\
\text { concomittant } \\
\text { vancomycin with } \\
\text { piperacillin-tazobactam } \\
\text { or cefepime }\end{array}$ & $\begin{array}{l}\text { Age, sex, BMI, initial creatinine, } \\
\text { creatinine at the time of antibiotic } \\
\text { initiation, SOFA, APACHEIV, sep- } \\
\text { ticshock, number of concomitant } \\
\text { antibiotics, initial vancomycin } \\
\text { levels, number of nephrotoxic } \\
\text { medications, length of stay, ad- } \\
\text { mission unit, infection-associated } \\
\text { length of stay, comorbidities }\end{array}$ & $\begin{array}{l}\text { IPW (weigh- } \\
\text { ting) }\end{array}$ & $\begin{array}{c}\text { Not } \\
\text { reported }\end{array}$ & PValue & $\begin{array}{l}\text { Logistic } \\
\text { regression }\end{array}$ & $\begin{array}{l}\text { Renal } \\
\text { failure }\end{array}$ \\
\hline 2016 & $\begin{array}{l}\text { Henriikka } \\
\text { Mildh }\end{array}$ & $\begin{array}{l}\text { Mildh et al. } \\
\text { Ann. Intensi- } \\
\text { ve Care }\end{array}$ & Finland & Cohort & $\begin{array}{l}\text { Three-year mortality in } \\
\text { survivors of } 30 \text { days of } \\
\text { critical care with acute } \\
\text { renal injury }\end{array}$ & $\begin{array}{l}\text { Age, comorbidities and ICU } \\
\text { admission and treatment } \\
\text { characteristics }\end{array}$ & $\begin{array}{l}\text { Coincidence } \\
\text { matching }\end{array}$ & Caliper & $\begin{array}{l}\text { Standardized } \\
\text { measurements }\end{array}$ & $\begin{array}{l}\text { Logistic } \\
\text { regression } \\
\text { and Cox } \\
\text { regression }\end{array}$ & Mortality \\
\hline 2016 & $\begin{array}{l}\text { J. Latour-Pé- } \\
\text { reza }\end{array}$ & $\begin{array}{l}\text { Med Inten- } \\
\text { siva }\end{array}$ & Spain & Cohort & $\begin{array}{l}\text { Assessment of the use } \\
\text { and effectiveness of } \\
\text { the routine invasive } \\
\text { strategy in patients } \\
\text { with non-ST elevation } \\
\text { acute coronary } \\
\text { syndrome with renal } \\
\text { dysfunction }\end{array}$ & $\begin{array}{l}\text { Age, sex, mode of access, } \\
\text { transport, delays and } \\
\text { access to the center, cardiac } \\
\text { catheterization availability, } \\
\text { coronary risk factors, prior } \\
\text { cardiovascular disease, prior } \\
\text { treatments (pharmacological } \\
\text { and coronary) and baseline } \\
\text { clinical status (blood pressure, } \\
\text { heart rate, initial EKC, initial } \\
\text { Killip, TIMI score, CRACE and } \\
\text { CRUSADE). }\end{array}$ & Stratification & $\begin{array}{c}\text { Not } \\
\text { reported }\end{array}$ & $\begin{array}{l}\text { Standardized } \\
\text { measurements }\end{array}$ & $\begin{array}{l}\text { Not } \\
\text { reported }\end{array}$ & Mortality \\
\hline 2016 & $\begin{array}{l}\text { Joung, } \\
\text { K.W. }\end{array}$ & $\begin{array}{l}\text { Medicine } \\
\text { (Baltimore) }\end{array}$ & Korea & Cohort & $\begin{array}{l}\text { Comparison of } \\
\text { postoperative acute } \\
\text { renal injury in ileal } \\
\text { conduit and urinary } \\
\text { shunting of the } \\
\text { neobladder following } \\
\text { radical cystectomy }\end{array}$ & $\begin{array}{l}\text { Sex, years, height, weight, } \\
\text { body mass index, history of } \\
\text { hypertension, diabetes mellitus, } \\
\text { coronary heart disease or } \\
\text { cerebrovascular disease, cancer } \\
\text { stage and grade, application of } \\
\text { neoadjuvant chemotherapy, } \\
\text { angiotensin converting enzyme } \\
\text { inhibitor, angiotensin receptor II } \\
\text { blocker or diuretic medications, } \\
\text { albumin, hematocrit, creatinine, } \\
\text { uric acid and placement of } \\
\text { ureteral stent }\end{array}$ & $\begin{array}{l}\text { Coincidence } \\
\text { matching }\end{array}$ & $\begin{array}{l}\text { Not } \\
\text { reported }\end{array}$ & PValue & $\begin{array}{l}\text { Logistic } \\
\text { regression }\end{array}$ & $\begin{array}{l}\text { Renal } \\
\text { failure }\end{array}$ \\
\hline
\end{tabular}




\begin{tabular}{|c|c|c|c|c|c|c|c|c|c|c|c|}
\hline Year & Author & Journal & Country & $\begin{array}{l}\text { Study } \\
\text { type }\end{array}$ & Exposure & Variables & $\begin{array}{l}\text { Matching } \\
\text { algorithm }\end{array}$ & Closeness & $\begin{array}{c}\text { Balance } \\
\text { assessment }\end{array}$ & $\begin{array}{l}\text { Analytical } \\
\text { method } \\
\text { used }\end{array}$ & Outcomes \\
\hline 2016 & $\underset{\substack{\text { Jun, I. C. } \\
*}}{ }$ & Liver Transpl & Korea & Cohort & $\begin{array}{l}\text { Incidence of acute } \\
\text { renal failure in } \\
\text { patients with live } \\
\text { donor liver transplant } \\
\text { with and without } A B O \\
\text { compatibility }\end{array}$ & $\begin{array}{l}\text { ABO compatibility, sex, age, } \\
\text { body weight, height, body mass } \\
\text { index (BMI), ABO type and } \\
\text { end-stage liver disease score } \\
\text { model (MELD); comorbidities } \\
\text { such as diabetes mellitus, } \\
\text { hypertension and coronary } \\
\text { artery diseease and preoperative } \\
\text { laboratory values such as } \\
\text { platelet count, prothrombin } \\
\text { time, normalized international } \\
\text { proportion and hemoglobin, } \\
\text { glucose, serum albumin, } \\
\text { serum sodium, total serum } \\
\text { bilirubin, sCr, serum sspartate } \\
\text { aminotransferase, serum } \\
\text { alanine aminotransferase, } \\
\text { and the highest intraoperative } \\
\text { IA titre. }\end{array}$ & Stratification & $\begin{array}{l}\text { Nearest } \\
\text { neighbor }\end{array}$ & $\begin{array}{l}\text { Standardized } \\
\text { measurements }\end{array}$ & $\begin{array}{l}\text { Logistic } \\
\text { regression } \\
\text { and Cox } \\
\text { regression }\end{array}$ & Survival \\
\hline 2016 & $\begin{array}{l}\text { Karama- } \\
\text { nos, E. }\end{array}$ & World ] Surg & $\begin{array}{l}\text { United } \\
\text { States }\end{array}$ & Cohort & $\begin{array}{l}\text { Impact of diabetes } \\
\text { mellitus on outcomes } \\
\text { of patients undergoing } \\
\text { emergency laparotomy } \\
\text { due to small bowel } \\
\text { adhesive obstruction }\end{array}$ & $\begin{array}{l}\text { Age, gender, BMI, } \\
\text { comorbidities, wound } \\
\text { classification, Charlson index, } \\
\text { inflammatory status at the } \\
\text { time of admission. }\end{array}$ & Not reported & $\begin{array}{c}\text { Not } \\
\text { reported }\end{array}$ & Cstatistic & $\begin{array}{l}\text { Logistic } \\
\text { regression }\end{array}$ & $\begin{array}{l}\text { Renal } \\
\text { failure }\end{array}$ \\
\hline 2016 & $\begin{array}{l}\text { Kerry C. } \\
\text { Cho }\end{array}$ & $\begin{array}{l}\text { Clinical } \\
\text { Science } \\
\text { Articles }\end{array}$ & $\begin{array}{l}\text { United } \\
\text { States }\end{array}$ & Cohort & & $\begin{array}{l}\text { Age, liver failure, sepsis, } \\
\text { thrombocytopenia, blood urea } \\
\text { nitrogen and serum creatinine }\end{array}$ & $\begin{array}{l}\text { Covariable in } \\
\text { one model }\end{array}$ & $\begin{array}{c}\text { Not } \\
\text { reported }\end{array}$ & P Value & $\begin{array}{l}\text { Logistic } \\
\text { regression } \\
\text { and Cox } \\
\text { regression }\end{array}$ & Survival \\
\hline 2016 & Lai, W. H. & $\begin{array}{c}\text { Scand J Trau- } \\
\text { ma Resusc } \\
\text { Emerg Med }\end{array}$ & Taiwan & $\begin{array}{l}\text { Cross- } \\
\text { sectional }\end{array}$ & $\begin{array}{l}\text { Incidence and clinical } \\
\text { presentation of post- } \\
\text { traumatic acute renal } \\
\text { failure in hospitalized } \\
\text { adult patients and its } \\
\text { association with shock }\end{array}$ & $\begin{array}{l}\text { Sex, years, comorbidity, } \\
\text { Clasgow scale, head/neck, } \\
\text { chest, abdomen or limb injury } \\
\text { according to severity on the } \\
\text { abbreviated injury scale for } \\
\text { each body region and injury } \\
\text { severity score (ISS). }\end{array}$ & $\begin{array}{l}\text { Coincidence } \\
\text { matching }\end{array}$ & $\begin{array}{c}\text { Not } \\
\text { reported }\end{array}$ & PValue & $\begin{array}{l}\text { Logistic } \\
\text { regression }\end{array}$ & $\begin{array}{c}\text { Mortality } \\
\text { and Renal } \\
\text { failure }\end{array}$ \\
\hline 2016 & Lin, C.Y. & $\begin{array}{l}\text { Medicine } \\
\text { (Baltimore) }\end{array}$ & Taiwán & Cohort & $\begin{array}{l}\text { Correlation of } \\
\text { preoperative renal } \\
\text { failure with mortality } \\
\text { and morbidity } \\
\text { after aortic valve } \\
\text { replacement vs. } \\
\text { patients without renal } \\
\text { failure. }\end{array}$ & $\begin{array}{l}\text { Preoperative demographics, } \\
\text { associated comorbidities, } \\
\text { surgical procedures and } \\
\text { hospital recovery were } \\
\text { compared between groups. } \\
\text { In-hospital mortality was } \\
\text { defined as death occurring } \\
\text { during hospitalization. } \\
\text { Emergency operations } \\
\text { included hemodynamically } \\
\text { unstable patients requiring a } \\
\text { high dose of inotropic agents, } \\
\text { endotracheal intubation or } \\
\text { mechanical circulatory support, } \\
\text { including intra-aortic balloon } \\
\text { pump (IABP) or extracorporeal } \\
\text { membrane oxygenation } \\
\text { (ECMO) before the surgery. }\end{array}$ & $\begin{array}{l}\text { Coincidence } \\
\text { matching }\end{array}$ & $\begin{array}{l}\text { Nearest } \\
\text { neighbor }\end{array}$ & PValue & $\begin{array}{l}\text { Logistic } \\
\text { regression }\end{array}$ & Mortality \\
\hline 2016 & $\begin{array}{l}\text { Mazzeffi, } \\
\text { M. }\end{array}$ & J Anesth & $\begin{array}{l}\text { United } \\
\text { States }\end{array}$ & Cohort & $\begin{array}{l}\text { Preoperative use of } \\
\text { aspirin associated } \\
\text { with cardiac surgery } \\
\text { patients with massive } \\
\text { transfusion. }\end{array}$ & $\begin{array}{l}\text { Type of surgery, urgency of the } \\
\text { surgery, year of the surgery, } \\
\text { cardiopulmonary bypass time, } \\
\text { use of antifibrinolytics, age, sex, } \\
\text { weight, height, preoperative } \\
\text { platelet count, preoperative } \\
\text { hematocrit, preoperative INR, } \\
\text { baseline hemodialysis, baseline } \\
\text { creatinine, chronic pulmonary } \\
\text { disease, hypertension, } \\
\text { diabetes, dislipidemia, } \\
\text { peripheral vascular disease, } \\
\text { cerebrovascular disease, } \\
\text { infectious endocarditis, prior } \\
\text { myocardial infarction, prior } \\
\text { cardiac intervention, congestive } \\
\text { heart failure within the 2 } \\
\text { weeks following surgery, use of } \\
\text { betablockers, use of statins and } \\
\text { use of warfarin }\end{array}$ & $\begin{array}{l}\text { Coincidence } \\
\text { matching }\end{array}$ & $\begin{array}{l}\text { Greedy } \\
\text { matching }\end{array}$ & PValue & $\begin{array}{l}\text { Logistic } \\
\text { regression }\end{array}$ & Mortality \\
\hline
\end{tabular}




\begin{tabular}{|c|c|c|c|c|c|c|c|c|c|c|c|}
\hline Year & Author & Journal & Country & $\begin{array}{l}\text { Study } \\
\text { type }\end{array}$ & Exposure & Variables & $\begin{array}{l}\text { Matching } \\
\text { algorithm }\end{array}$ & Closeness & $\begin{array}{c}\text { Balance } \\
\text { assessment }\end{array}$ & $\begin{array}{l}\text { Analytical } \\
\text { method } \\
\text { used }\end{array}$ & Outcomes \\
\hline 2016 & Moise, p. A. & $\begin{array}{l}\text { J Anesth } \\
\text { Clin Ther }\end{array}$ & $\begin{array}{l}\text { United } \\
\text { States }\end{array}$ & Cohort & $\begin{array}{l}\text { Comparing the results } \\
\text { of early treatment } \\
\text { with daptomycin } \\
\text { vs. vancomycin for } \\
\text { methicillin-resistant } \\
\text { Staphylococcus aureus } \\
\text { bacteremia }\end{array}$ & $\begin{array}{l}\text { Variables identified for mat- } \\
\text { ching were: age (<60 vs. }>60) \text {, } \\
\text { disease severity (ICU status) and } \\
\text { type of infection (intravascular, } \\
\text { extravascular or catheter). } \\
\text { Bacteremia clearing was used } \\
\text { to validate the hierarchy for the } \\
\text { type of infection. }\end{array}$ & $\begin{array}{l}\text { Coincidence } \\
\text { matching }\end{array}$ & $\begin{array}{c}\text { Not } \\
\text { reported }\end{array}$ & PValue & $\begin{array}{l}\text { Logistic } \\
\text { regression }\end{array}$ & Mortality \\
\hline 2016 & $\begin{array}{l}\text { Oscar } \\
\text { Peñuelas }\end{array}$ & $\begin{array}{l}\text { Journal of In- } \\
\text { tensive Care } \\
\text { Medicine }\end{array}$ & Spain & $\begin{array}{c}\text { Cross- } \\
\text { sectional }\end{array}$ & $\begin{array}{c}\text { Assessment of } \\
\text { predictors for ICU- } \\
\text { acquired paresis and } \\
\text { associated short-term } \\
\text { outcomes }\end{array}$ & $\begin{array}{l}\text { Age, SAPS II, chronic } \\
\text { obstructive pulmonary } \\
\text { disease, sepsis (leading to } \\
\text { mechanical ventilation or } \\
\text { as a complication during } \\
\text { mechanical ventilation), use } \\
\text { of neuromuscular blockade, } \\
\text { cardiovascular failure, renal } \\
\text { failure, hematological } \\
\text { insufficiency and days on } \\
\text { mechanical ventilation before } \\
\text { weaning }\end{array}$ & $\begin{array}{l}\text { Coincidence } \\
\text { matching }\end{array}$ & $\begin{array}{l}\text { Nearest } \\
\text { neighbor } \\
\text { y Caliper }\end{array}$ & $\begin{array}{l}\text { Standardized } \\
\text { measurements } \\
\text { y ROCvalues }\end{array}$ & $\begin{array}{l}\text { Logistic } \\
\text { regression }\end{array}$ & Mortality \\
\hline 2016 & Park, J. Y. & Crit Care & $\begin{array}{l}\text { South } \\
\text { Korea }\end{array}$ & Cohort & $\begin{array}{l}\text { Results of early vs. } \\
\text { late initiation of renal } \\
\text { replacement therapy }\end{array}$ & $\begin{array}{l}\text { Age, sex, } \mathrm{CCl} \text {, systolic arterial } \\
\text { pressure, prothrombin time } \\
\text { and total bilirubin level }\end{array}$ & $\begin{array}{l}\text { Coincidence } \\
\text { matching }\end{array}$ & $\begin{array}{l}\text { Nearest } \\
\text { neighbor } \\
\text { y Caliper }\end{array}$ & $\begin{array}{l}\text { Standardized } \\
\text { measurements } \\
\text { + significance }\end{array}$ & $\begin{array}{l}\text { Logistic } \\
\text { regression } \\
\text { and Cox } \\
\text { regression }\end{array}$ & Survival \\
\hline 2016 & Ruan, S. Y. & Crit Care & Taiwan & Cohort & $\begin{array}{l}\text { Risk of acute renal } \\
\text { failure associated with } \\
\text { inhaled nitric oxide } \\
\text { therapy in patients } \\
\text { with acute respiratory } \\
\text { distress syndrome }\end{array}$ & $\begin{array}{l}\text { Age, sex, year of entry to the } \\
\text { cohort, height, body weight, } \\
\text { ARDS etiology, simplified } \\
\text { acute physiology score II } \\
\text { (SAPS II) (15), lung injury } \\
\text { score (16), comorbidities, } \\
\text { ventilator settings, vital signs, } \\
\text { arterial blood gases, complete } \\
\text { blood count, creatinine and } \\
\text { bilirubin levels, urine output, } \\
\text { radiological pattern, and } \\
\text { use of vasopressors on the } \\
\text { first ARDS day. Creatinine } \\
\text { clearance was estimated using } \\
\text { the Cockcroft-Cault. }\end{array}$ & Stratification & Caliper & PValue & $\begin{array}{l}\text { Logistic } \\
\text { regression } \\
\text { and Cox } \\
\text { regression }\end{array}$ & $\begin{array}{l}\text { Renal } \\
\text { failure }\end{array}$ \\
\hline 2016 & $\begin{array}{l}\text { Thongpra- } \\
\text { yoon, C. }\end{array}$ & $\begin{array}{l}\text { J Am Soc } \\
\text { Nephrol }\end{array}$ & $\begin{array}{l}\text { United } \\
\text { States }\end{array}$ & Cohort & $\begin{array}{l}\text { Assessing the risk of } \\
\text { acute renal failure } \\
\text { in patients taken to } \\
\text { transcatheter aortic } \\
\text { valve replacement } \\
\text { (TAVR) vs. surgical } \\
\quad \text { aortic valve } \\
\text { replacement (SAVR) }\end{array}$ & $\begin{array}{l}\text { STS risk score, eCFR, sex, body } \\
\text { mass index, type of surgery } \\
\text { (elective vs. urgent/emergent), } \\
\text { presence of anemia, history of } \\
\text { diabetes mellitus, hypertension, } \\
\text { congestive heart failure, } \\
\text { peripheral vascular disease, } \\
\text { cerebrovascular disease, chronic } \\
\text { pulmonary disease, NYHA } \\
\text { (classes } 1 \text { and } 2 \text { vs. } 3 \text { and 4), } \\
\text { preoperative use of angiotensin } \\
\text { converting enzyme inhibitor or } \\
\text { angiotensin receptor blocker, } \\
\text { prior percutaneous cardiac } \\
\text { intervention, prior coronary } \\
\text { bypass grafting, prior aortic } \\
\text { valve surgery, cardiac rhythm } \\
\text { during surgery (normal vs other) } \\
\text { and aortic valve regurgitation } \\
\text { (none or trivial vs, mild, } \\
\text { moderate or severe) }\end{array}$ & $\begin{array}{l}\text { Coincidence } \\
\text { matching }\end{array}$ & Caliper & $\begin{array}{l}\text { Standardized } \\
\text { measurements }\end{array}$ & $\begin{array}{l}\text { Logistic } \\
\text { regression }\end{array}$ & $\begin{array}{l}\text { Renal } \\
\text { failure }\end{array}$ \\
\hline 2017 & Bentzer, p. & $\begin{array}{l}\text { Scand ] Trau- } \\
\text { ma Resusc } \\
\text { Emerg Med }\end{array}$ & Sweden & Cohort & $\begin{array}{l}\text { Effect of dextran-70 on } \\
\text { outcomes in patients } \\
\text { with severe sepsis }\end{array}$ & $\begin{array}{l}\text { Age, sex, chronic obstructive } \\
\text { pulmonary disease (COPD), } \\
\text { renal failure, diabetes, } \\
\text { outcome variables (except } \\
\text { mortality) and fluid } \\
\text { administration data. }\end{array}$ & $\begin{array}{l}\text { Coincidence } \\
\text { matching }\end{array}$ & $\begin{array}{l}\text { Greedy } \\
\text { mat- } \\
\text { ching }\end{array}$ & $\begin{array}{l}\text { Standardized } \\
\text { measurements }\end{array}$ & $\begin{array}{l}\text { Logistic } \\
\text { regression }\end{array}$ & $\begin{array}{l}\text { Mortality } \\
\text { and Renal } \\
\text { failure }\end{array}$ \\
\hline
\end{tabular}




\begin{tabular}{|c|c|c|c|c|c|c|c|c|c|c|c|}
\hline Year & Author & Journal & Country & $\begin{array}{l}\text { Study } \\
\text { type }\end{array}$ & Exposure & Variables & $\begin{array}{l}\text { Matching } \\
\text { algorithm }\end{array}$ & Closeness & $\begin{array}{c}\text { Balance } \\
\text { assessment }\end{array}$ & $\begin{array}{c}\text { Analytical } \\
\text { method } \\
\text { used }\end{array}$ & Outcomes \\
\hline 2017 & Chan, M. J. & $\begin{array}{l}\text { Medicine } \\
\text { (Baltimore) }\end{array}$ & Taiwán & $\begin{array}{c}\text { Cross- } \\
\text { sectional }\end{array}$ & $\begin{array}{l}\text { Effects of } 3 \text { different } \\
\text { surgical methods for } \\
\text { coronary revasculari- } \\
\text { zation in renal injury }\end{array}$ & $\begin{array}{l}\text { Age, sex, preoperative } \\
\text { creatinine level, cardiac } \\
\text { ejection fraction, emergent/ } \\
\text { urgent intervention, use of } \\
\text { intra-aortic balloon pump } \\
\text { (IABP), preoperative ventilator } \\
\text { use, diabetes mellitus, recent } \\
\text { myocardial infarction, shock } \\
\text { and chronic obstructive } \\
\text { pulmonary disease }\end{array}$ & $\begin{array}{l}\text { Coincidence } \\
\text { matching }\end{array}$ & $\begin{array}{c}\text { Not } \\
\text { reported }\end{array}$ & PValue & $\begin{array}{l}\text { Logistic } \\
\text { regression }\end{array}$ & $\begin{array}{l}\text { Renal } \\
\text { failure }\end{array}$ \\
\hline 2017 & $\begin{array}{c}\text { Dos } \\
\text { Santos, T. } \\
\text { O.C. }\end{array}$ & PLoS One & Brazil & $\begin{array}{c}\text { Cross- } \\
\text { sectional }\end{array}$ & $\begin{array}{c}\text { Mortality-related } \\
\text { factors in patients } \\
\text { admitted to the ICU } \\
\text { with acute renal } \\
\text { failure requiring } \\
\text { dialysis who } \\
\text { underwent continuous } \\
\text { veno-venous } \\
\text { hemodiafiltration } \\
\text { (CVVHDF) }\end{array}$ & $\begin{array}{l}\text { Age, comorbidities, severity of } \\
\text { the disease that caused AKI, } \\
\text { metabolic disorders, organ } \\
\text { dysfunction and weight gain } \\
\text { during the resuscitation phase. } \\
\text { Other factors that appear to } \\
\text { influence prognosis in these } \\
\text { patients are those related with } \\
\text { the therapy itself, including } \\
\text { type of dialysis modality, time } \\
\text { of initiation of the procedure, } \\
\text { administered dialysis dose, } \\
\text { metabolic control and volume } \\
\text { status obtained over the course } \\
\text { of treatment }\end{array}$ & $\begin{array}{l}\text { Coincidence } \\
\text { matching }\end{array}$ & $\begin{array}{c}\text { Not } \\
\text { reported }\end{array}$ & PValue & $\begin{array}{l}\text { Logistic } \\
\text { regression } \\
\text { and Cox } \\
\text { regression }\end{array}$ & Survival \\
\hline 2017 & Dou, L. & Nephron & $\begin{array}{l}\text { United } \\
\text { States }\end{array}$ & Cohort & $\begin{array}{l}\text { Obstructive sleep } \\
\text { apnea associated with } \\
\text { the risk of acute renal } \\
\text { failure in the intensive } \\
\text { care unit }\end{array}$ & $\begin{array}{l}\text { Age, BMI, history of CHF, CKD, } \\
\text { CPD, hypertension, diabetes, } \\
\text { high risk surgery, exposure } \\
\text { to nephrotoxins, mechanical } \\
\text { ventilation and APACHE III score }\end{array}$ & $\begin{array}{l}\text { Coincidence } \\
\text { matching }\end{array}$ & Caliper & $\begin{array}{l}\text { Standardized } \\
\text { measurements }\end{array}$ & $\begin{array}{l}\text { Logistic } \\
\text { regression }\end{array}$ & $\begin{array}{l}\text { Renal } \\
\text { failure }\end{array}$ \\
\hline 2017 & $\begin{array}{l}\text { Hoi-Ping } \\
\text { SHUM }\end{array}$ & Nephrology & China & $\begin{array}{c}\text { Cross- } \\
\text { sectional }\end{array}$ & $\begin{array}{l}\text { Impact of renal replace- } \\
\text { ment therapy on 90-day } \\
\text { mortality in critically ill } \\
\text { patients with KDICO } \\
\text { stage } 3 \text { renal failure }\end{array}$ & $\begin{array}{l}\text { Age, baseline CFR, worse } \\
\text { creatinine/potassium/ } \\
\text { bilirubin/platelet count level, } \\
\text { pH within the first } 24 \text { hours } \\
\text { of admission to the ICU and } \\
\text { APACHE IV score }\end{array}$ & $\begin{array}{l}\text { Coincidence } \\
\text { matching }\end{array}$ & $\begin{array}{l}\text { Nearest } \\
\text { neighbor } \\
\text { y Caliper }\end{array}$ & Cstatistic & $\begin{array}{l}\text { Logistic } \\
\text { regression } \\
\text { and Cox } \\
\text { regression }\end{array}$ & Mortality \\
\hline 2017 & $\begin{array}{l}\text { Jennifer S. } \\
\text { McDonald }\end{array}$ & $\begin{array}{l}\text { Intensive } \\
\text { Care Med }\end{array}$ & $\begin{array}{l}\text { United } \\
\text { States }\end{array}$ & Cohort & $\begin{array}{l}\text { Association between } \\
\text { intravenous iodinated } \\
\text { contrast material } \\
\text { administration and } \\
\text { later development } \\
\text { of post-contrast AKI, } \\
\text { emergent dialysis and } \\
\text { short-term mortality }\end{array}$ & $\begin{array}{l}\text { Age, serum creatinine before } \\
\mathrm{CT} \text { (sCr), changes in sCr prior } \\
\text { to exploration and SOFA } \\
\text { score, comorbidities, use of } \\
\text { nephrotoxic drugs, IV fluids } \\
\text { used, stability prior to CT }\end{array}$ & Stratification & $\begin{array}{c}\text { Not } \\
\text { reported }\end{array}$ & PValue & $\begin{array}{l}\text { Logistic } \\
\text { regression }\end{array}$ & $\begin{array}{c}\text { Mortality } \\
\text { and Renal } \\
\text { failure }\end{array}$ \\
\hline 2017 & $\begin{array}{c}\text { Kianoush } \\
\text { Kashan }\end{array}$ & PLOSONE & $\begin{array}{l}\text { United } \\
\text { States }\end{array}$ & Cohort & $\begin{array}{l}\text { Effect of bicarbonate } \\
\text { concentration in the } \\
\text { replacement solution } \\
\text { on patients in the ICU } \\
\text { that required CRRT } \\
\text { for AKI. }\end{array}$ & $\begin{array}{l}\mathrm{pH} \text {, bicarbonate, interaction } \\
\text { between } \mathrm{pH} \text { and bicarbonate, } \\
\text { presence of sepsis, use of } \\
\text { mechanical ventilation, } \\
\text { vasopressor administration, } \\
\text { intra-aortic balloon pump } \\
\text { (IABP) and Charlson } \\
\text { comorbidity index }\end{array}$ & $\begin{array}{l}\text { Coincidence } \\
\text { matching }\end{array}$ & Caliper & $\begin{array}{l}\text { Standardized } \\
\text { measurements }\end{array}$ & $\begin{array}{l}\text { Logistic } \\
\text { regression } \\
\text { and Cox } \\
\text { regression }\end{array}$ & Mortality \\
\hline 2017 & $\begin{array}{c}\text { Kovacheva, } \\
\text { V.p. }\end{array}$ & $\begin{array}{l}\text { Neurosur- } \\
\text { gery }\end{array}$ & $\begin{array}{l}\text { United } \\
\text { States }\end{array}$ & Cohort & $\begin{array}{c}\text { Determine ifAKI } \\
\text { in patients after } \\
\text { craniectomy is associated } \\
\text { with higher 30-day } \\
\text { mortality }\end{array}$ & $\begin{array}{l}\text { Age, sex, race (whitevs. } \\
\text { non-white), Deyo-Charlson } \\
\text { index, sepsis and chronic renal } \\
\text { disease covariables, severity of } \\
\text { the disease, intracranial bleeding, } \\
\text { subarachnoid hemorrhage, acute } \\
\text { respiratory failure and trauma }\end{array}$ & $\begin{array}{l}\text { Coincidence } \\
\text { matching }\end{array}$ & Caliper & PValue & $\begin{array}{l}\text { Logistic } \\
\text { regression } \\
\text { yCox }\end{array}$ & Mortality \\
\hline 2017 & $\begin{array}{l}\text { Latour- } \\
\text { Perez, ] }\end{array}$ & $\begin{array}{c}\text { Med } \\
\text { Intensiva }\end{array}$ & Spain & Cohort & $\begin{array}{l}\text { Assess the use an } \\
\text { effectiveness of the } \\
\text { routine invasive strate- } \\
\text { gy in patients with } \\
\text { non-ST elevation acute } \\
\text { coronary syndrome } \\
\text { with renal dysfunction }\end{array}$ & $\begin{array}{l}\text { Age, sex, clinics, mode of access, } \\
\text { transportation and delay in } \\
\text { accessing the center, availabi- } \\
\text { lity of cardiac catheterization, } \\
\text { coronary risk factors, prior } \\
\text { cardiovascular disease, previous } \\
\text { treatments (pharmacological } \\
\text { and coronary) and baseline } \\
\text { clinical status (blood pressure, } \\
\text { heart rate, initial EKC, initial } \\
\text { Killip, TIMI 24, CRACE and } \\
\text { CRUSADE scores }\end{array}$ & Stratification & $\begin{array}{c}\text { Not } \\
\text { reported }\end{array}$ & $\begin{array}{l}\text { Standardized } \\
\text { measurements } \\
+ \text { significance }\end{array}$ & $\begin{array}{l}\text { Logistic } \\
\text { regression }\end{array}$ & Mortality \\
\hline
\end{tabular}




\begin{tabular}{|c|c|c|c|c|c|c|c|c|c|c|c|}
\hline Year & Author & Journal & Country & $\begin{array}{l}\text { Study } \\
\text { type }\end{array}$ & Exposure & Variables & $\begin{array}{l}\text { Matching } \\
\text { algorithm }\end{array}$ & Closeness & $\begin{array}{c}\text { Balance } \\
\text { assessment }\end{array}$ & $\begin{array}{l}\text { Analytical } \\
\text { method } \\
\text { used }\end{array}$ & Outcomes \\
\hline 2017 & Legouis, D. & Anesthesiology & France & Cohort & $\begin{array}{l}\text { Impact of acute renal } \\
\text { injury in patients who } \\
\text { experience reversible } \\
\text { acute renal injury after } \\
\text { cardiac surgery }\end{array}$ & $\begin{array}{l}\text { Age, body mass index, } \\
\text { preoperative eCFR, clamping } \\
\text { and bypass time, European } \\
\text { logistic system for assessing } \\
\text { the cardiac surgery risk, left } \\
\text { ventricular ejection fraction } \\
\text { and type of surgery }\end{array}$ & $\begin{array}{l}\text { Coincidence } \\
\text { matching }\end{array}$ & $\begin{array}{l}\text { Nearest } \\
\text { neighbor } \\
\text { y Caliper }\end{array}$ & $\begin{array}{l}\text { Standardized } \\
\text { measurements }\end{array}$ & $\begin{array}{l}\text { Logistic } \\
\text { regression } \\
\text { and Cox } \\
\text { regression }\end{array}$ & $\begin{array}{l}\text { Renal } \\
\text { failure }\end{array}$ \\
\hline 2017 & Marik, p. E. & Chest & $\begin{array}{l}\text { United } \\
\text { States }\end{array}$ & Cohort & $\begin{array}{l}\text { Hydrocortisone, } \\
\text { vitamin C and } \\
\text { thiamine for the } \\
\text { treatment of severe } \\
\text { sepsis and septic shock }\end{array}$ & $\begin{array}{l}\text { Age, sex, diagnosis on } \\
\text { admission, comorbidities, need } \\
\text { for mechanical ventilation, use } \\
\text { of vasopressors, daily urine } \\
\text { output, fluid balance after } 24 \\
\text { and } 72 \text { hours, length of stay in } \\
\text { the ICU and laboratory values, } \\
\text { Immunocompromised patients } \\
\text { if they received cytotoxic } \\
\text { therapy or if diagnoses with } \\
\text { acquired immune deficiency } \\
\text { syndrome. Serum creatinine } \\
\text { levels, leukocyte counts (WB), } \\
\text { platelet count, total bilirubin, } \\
\text { PCT and lactate. Acute renal } \\
\text { injury (AKI), APACHE Il and } \\
\text { APACHE IV scores on admission, } \\
\text { including foreseen in-hospital } \\
\text { mortality in APACHE IV }\end{array}$ & Not reported & $\begin{array}{l}\text { Not } \\
\text { reported }\end{array}$ & PValue & $\begin{array}{l}\text { Logistic } \\
\text { regression }\end{array}$ & Survival \\
\hline 2017 & $\begin{array}{c}\text { Shou-Chun } \\
\text { Yu, }\end{array}$ & $\begin{array}{c}\text { World } \\
\text { Neurosurgery }\end{array}$ & Taiwan & Cohort & $\begin{array}{l}\text { One-year mortality } \\
\text { rate in patients with } \\
\text { spinal cord injury with } \\
\text { CKD and TRD and } \\
\text { comparison in patients } \\
\text { with spinal cord injury } \\
\text { without CKD }\end{array}$ & $\begin{array}{l}\text { Age, sex, comorbidities, length } \\
\text { of stay in the intensive care } \\
\text { unit and total length of stay }\end{array}$ & Stratification & $\begin{array}{c}\text { Not } \\
\text { reported }\end{array}$ & PValue & $\begin{array}{c}\text { Cox } \\
\text { regression }\end{array}$ & Mortality \\
\hline 218 & $\begin{array}{l}\text { Etienne } \\
\text { Gayat }\end{array}$ & $\begin{array}{l}\text { Intensive } \\
\text { Care Med }\end{array}$ & France & Cohort & $\begin{array}{l}\text { Association between } \\
\text { the use of ACEi and } \\
\text { ARA Il in patients with } \\
\text { acute renal failure in } \\
\text { the ICU with mortality } \\
\text { within } 1 \text { year }\end{array}$ & $\begin{array}{l}\text { Age, Charlson score, CKD, } \\
\text { diabetes mellitus, chronic heart } \\
\text { failure, ACEi/ARB adminis- } \\
\text { tration before ICU admission, } \\
\text { vasopressor administration } \\
\text { while in the ICU, RRT during ICU } \\
\text { stay, systolic blood pressure at } \\
\text { discharge from the ICU }\end{array}$ & $\begin{array}{l}\text { Coincidence } \\
\text { matching }\end{array}$ & $\begin{array}{l}\text { Nearest } \\
\text { neighbor }\end{array}$ & $\begin{array}{l}\text { Standardized } \\
\text { measurements }\end{array}$ & $\begin{array}{c}\text { Cox } \\
\text { regression }\end{array}$ & Mortality \\
\hline 2018 & Buyun Wu & $\begin{array}{l}\text { Scientific } \\
\text { Reports }\end{array}$ & China & Cohort & $\begin{array}{l}\text { Impact of low AKI } \\
\text { recognition (more than } \\
3 \text { days after onset) on } \\
\text { short-term prognosis }\end{array}$ & $\begin{array}{l}\text { Sex, age, setting in which AKI } \\
\text { occurred, eCFR on admission, } \\
\text { oliguria, history of malignant } \\
\text { neoplasm, APACHE II score, } \\
\text { SOFA score, risk factors for } \\
\text { AKI (hypovolemia, heart } \\
\text { failure, sepsis, surgery), AKI } \\
\text { stage, blood urea nitrogen and } \\
\text { whether RRT was used }\end{array}$ & $\begin{array}{c}\text { IPW } \\
\text { (weighting) y } \\
\text { Stratification }\end{array}$ & Caliper & $\begin{array}{l}\text { Standardized } \\
\text { measurements }\end{array}$ & $\begin{array}{l}\text { Logistic } \\
\text { regression }\end{array}$ & Mortality \\
\hline 2018 & $\begin{array}{l}\text { Shih-Ting } \\
\text { Huang_- } \\
\text { nuevo }\end{array}$ & CMA] & Taiwan & Cohort & $\begin{array}{l}\text { Renal outcomes in } \\
\text { patients with no pre- } \\
\text { existing renal disease } \\
\text { who were admitted due } \\
\text { to critical acute disease }\end{array}$ & $\begin{array}{l}\text { Age (5-year periods), sex } \\
\text { and index year with control } \\
\text { patients, comorbidities }\end{array}$ & $\begin{array}{l}\text { Coincidence } \\
\text { matching }\end{array}$ & $\begin{array}{c}\text { Not } \\
\text { reported }\end{array}$ & $\begin{array}{l}\text { Standardized } \\
\text { measurements }\end{array}$ & $\begin{array}{l}\text { Logistic } \\
\text { regression } \\
\text { and Cox } \\
\text { regression }\end{array}$ & $\begin{array}{l}\text { Mortality } \\
\text { and Renal } \\
\text { failure }\end{array}$ \\
\hline 2019 & $\begin{array}{l}\text { AMANDA } \\
\text { YWANG }\end{array}$ & Nephrology & Australia & Cohort & $\begin{array}{l}\text { HMG-CoA reductase } \\
\text { inhibitors (statins) and } \\
\text { acute renal injury }\end{array}$ & $\begin{array}{l}\text { Age, sex, sepsis, mechanical } \\
\text { ventilation and APACHE } \\
\text { III scores at the time of } \\
\text { randomization }\end{array}$ & $\begin{array}{l}\text { Coincidence } \\
\text { matching }\end{array}$ & $\begin{array}{c}\text { Not } \\
\text { reported }\end{array}$ & PValue & $\begin{array}{c}\text { Cox } \\
\text { regression }\end{array}$ & $\begin{array}{l}\text { Renal } \\
\text { failure }\end{array}$ \\
\hline 2019 & Ana p. A & ccmjournal & Brazil & Cohort & $\begin{array}{c}\text { Assessment of in- } \\
\text { hospital mortality and } \\
\text { mortality risk factors } \\
\text { in patients with cancer } \\
\text { discharged from the } \\
\text { ICU after the decision } \\
\text { to refuse vital support } \\
\text { therapies }\end{array}$ & $\begin{array}{l}\text { SAPS } 3 \text { and SOFA on admission } \\
\text { to the ICU, setting prior to } \\
\text { admission to the ICU, infection } \\
\text { on admission to de ICU, use } \\
\text { of non-invasive mechanical } \\
\text { ventilation, acute renal injury } \\
\text { and delirium during while in } \\
\text { the ICU }\end{array}$ & $\begin{array}{l}\text { Coincidence } \\
\text { matching }\end{array}$ & Caliper & PValue & $\begin{array}{l}\text { Logistic } \\
\text { regression }\end{array}$ & Mortality \\
\hline
\end{tabular}




\begin{tabular}{|c|c|c|c|c|c|c|c|c|c|c|c|}
\hline Year & Author & Journal & Country & $\begin{array}{l}\text { Study } \\
\text { type }\end{array}$ & Exposure & Variables & $\begin{array}{l}\text { Matching } \\
\text { algorithm }\end{array}$ & $\begin{array}{l}\text { Close- } \\
\text { ness }\end{array}$ & $\begin{array}{c}\text { Balance } \\
\text { assessment }\end{array}$ & $\begin{array}{l}\text { Analytical } \\
\text { method } \\
\text { used }\end{array}$ & Outcomes \\
\hline 2019 & $\begin{array}{l}\text { lan E. } \\
\text { McCoy, }\end{array}$ & $\begin{array}{c}\text { Crit Care } \\
\text { Expl }\end{array}$ & $\begin{array}{l}\text { United } \\
\text { States }\end{array}$ & Cohort & $\begin{array}{c}\text { Estimation of the } \\
\text { effects of diuretic use } \\
\text { in the first } 24 \text { hours in } \\
\text { the ICU }\end{array}$ & $\begin{array}{l}\text { Age, sex, race, comorbidities, } \\
\text { type of admission, ICU } \\
\text { type, serum creatinine on } \\
\text { admission, mechanical } \\
\text { ventilation and each of } \\
\text { the SOFA score items on } \\
\text { admission, out of six ICU items }\end{array}$ & $\begin{array}{l}\text { Coincidence } \\
\text { matching }\end{array}$ & $\begin{array}{l}\text { Creedy } \\
\text { mat- } \\
\text { ching }\end{array}$ & $\begin{array}{l}\text { Standardized } \\
\text { measurements }\end{array}$ & $\begin{array}{l}\text { Logistic } \\
\text { regression }\end{array}$ & $\begin{array}{l}\text { Renal } \\
\text { failure }\end{array}$ \\
\hline 2019 & $\begin{array}{l}\text { Muham- } \\
\text { mad } \\
\text { Zeeshan }\end{array}$ & $\begin{array}{l}\text { American } \\
\text { Association } \\
\text { for the } \\
\text { Surgery of } \\
\text { Trauma }\end{array}$ & $\begin{array}{l}\text { United } \\
\text { States }\end{array}$ & Cohort & $\begin{array}{l}\text { Four-factor } \\
\text { prothrombin complex } \\
\text { plus fresh frozen } \\
\text { plasma vs. fresh } \\
\text { frozen plasma alone in } \\
\text { patients with trauma- } \\
\text { related bleeding }\end{array}$ & $\begin{array}{l}\text { Age, sex, race, body mass } \\
\text { index, vital signs (systolic } \\
\text { blood pressure, heart rate, } \\
\text { Clasgow scale), time to } \\
\text { therapy initiation, injury } \\
\text { mechanisms, injury severity } \\
\text { score, abbreviated injury scale } \\
\text { (AIS), Head-AIS, chest-AIS, } \\
\text { abdominal-AIS, spine-AIS, } \\
\text { limb-AIS, comorbidities, use } \\
\text { of anti-platelet agents before } \\
\text { injury, and trauma center level }\end{array}$ & Stratification & $\begin{array}{l}\text { Nearest } \\
\text { neighbor }\end{array}$ & PValue & $\begin{array}{l}\text { Logistic } \\
\text { regression }\end{array}$ & $\begin{array}{l}\text { Mortality } \\
\text { and Renal } \\
\text { failure }\end{array}$ \\
\hline 2019 & $\begin{array}{l}\text { Philippe } \\
\text { Gaudard }\end{array}$ & $\begin{array}{c}\text { BMC } \\
\text { Infectious } \\
\text { Diseases }\end{array}$ & France & Cohort & $\begin{array}{l}\text { Acute renal injury } \\
\text { during treatment } \\
\text { with daptomycin vs. } \\
\text { vacomycin in critically } \\
\text { ill cardiovascular } \\
\text { patients }\end{array}$ & $\begin{array}{l}\text { Severity score such as } \\
\text { simplified acute physiology } \\
\text { (SAPS II) on admission to the } \\
\text { ICU and sequential organ } \\
\text { failure assessment (SOFA) } \\
\text { upon initiation of treatment, } \\
\text { history of chronic renal failure } \\
\text { (creatinine clearance under } 50 \\
\text { mL/min), creatinine and AKI } \\
\text { before initiation of treatment } \\
\text { (defined as baseline), } \\
\text { sepsis-related or heart- } \\
\text { failure related circulatory } \\
\text { shock (defined as systolic } \\
\text { blood pressure undere } 90 \\
\text { mmHHg and resistant to fluid } \\
\text { challenge, with evidence of } \\
\text { end-organ hypoperfusion such } \\
\text { as oliguria, altered mentation } \\
\text { or high plasma lactate level), } \\
\text { need for cardiopulmonary } \\
\text { bypass for surgery (within } 48 \\
\text { hof antibiotic initiation), use } \\
\text { of other nephrotoxic agents } \\
\text { (iodine contrast, aminoglycosides, } \\
\text { cyclosporin), bacteremia } \\
\text { documented by CPC }\end{array}$ & $\begin{array}{l}\text { Coincidence } \\
\text { matching }\end{array}$ & $\begin{array}{c}\text { Not } \\
\text { reported }\end{array}$ & PValue & $\begin{array}{l}\text { Logistic } \\
\text { regression }\end{array}$ & $\begin{array}{l}\text { Renal } \\
\text { failure }\end{array}$ \\
\hline 2019 & $\begin{array}{l}\text { Raphael } \\
\text { Donadio } \\
\text { Pitta }\end{array}$ & $\begin{array}{l}\text { European } \\
\text { Journal of } \\
\text { Clinical } \\
\text { Microbiology } \\
\text { \& Infectious } \\
\text { Diseases }\end{array}$ & Brazil & $\begin{array}{c}\text { Cross- } \\
\text { sectional }\end{array}$ & $\begin{array}{l}\text { Comparison of } \\
\text { the incidence of } \\
\text { AKI in critically ill } \\
\text { patients treated with } \\
\text { aminoglycosides or } \\
\text { meropenem in the } \\
\text { intensive care setting }\end{array}$ & $\begin{array}{c}\text { Age, sex and use of } \\
\text { vancomycin, polymyxin, } \\
\text { diuretic and amphotericin }\end{array}$ & $\begin{array}{l}\text { Coincidence } \\
\text { matching }\end{array}$ & $\begin{array}{l}\text { Nearest } \\
\text { neighbor } \\
\text { y Caliper }\end{array}$ & PValue & $\begin{array}{l}\text { Logistic } \\
\text { regression }\end{array}$ & $\begin{array}{l}\text { Renal } \\
\text { failure }\end{array}$ \\
\hline 2019 & $\begin{array}{l}\text { Sarah A. } \\
\text { Schubert }\end{array}$ & $\begin{array}{l}\text { The Journal } \\
\text { of Thoracic } \\
\text { and Car- } \\
\text { diovascular } \\
\text { Surgery }\end{array}$ & $\begin{array}{l}\text { United } \\
\text { States }\end{array}$ & Cohort & $\begin{array}{l}\text { Determine the } \\
\text { influence of } \\
\text { perioperative } \\
\text { administration } \\
\text { of betablockers } \\
\text { before aortic valve } \\
\text { replacement }\end{array}$ & $\begin{array}{l}\text { Rates of hypertension, } \\
\text { anemia, coronary artery } \\
\text { disease, preoperative atrial } \\
\text { fibrillation or heart failure, } \\
\text { among others }\end{array}$ & Stratification & $\begin{array}{c}\text { Greedy } \\
\text { matching }\end{array}$ & $\begin{array}{l}\text { Standardized } \\
\text { measurements }\end{array}$ & $\begin{array}{l}\text { Logistic } \\
\text { regression }\end{array}$ & Mortality \\
\hline
\end{tabular}




\begin{tabular}{|c|c|c|c|c|c|c|c|c|c|c|c|}
\hline Year & Author & Journal & Country & $\begin{array}{l}\text { Study } \\
\text { type }\end{array}$ & Exposure & Variables & $\begin{array}{l}\text { Matching } \\
\text { algorithm }\end{array}$ & Closeness & $\begin{array}{c}\text { Balance } \\
\text { assessment }\end{array}$ & $\begin{array}{l}\text { Analytical } \\
\text { method } \\
\text { used }\end{array}$ & Outcomes \\
\hline 2019 & $\begin{array}{l}\text { Wuhua } \\
\text { Jiang }\end{array}$ & $\begin{array}{l}\text { Braz ] } \\
\text { Cardiovasc } \\
\text { Surg }\end{array}$ & China & Cohort & $\begin{array}{l}\text { Discover potentially } \\
\text { modifiable } \\
\text { perioperative } \\
\text { predictors for renal } \\
\text { replacement therapy } \\
\text { (RRT) in patients with } \\
\text { cardiac surgery- } \\
\text { associated acute renal } \\
\text { injury }\end{array}$ & $\begin{array}{l}\text { Age, comorbidities, history } \\
\text { of contrast media exposure, } \\
\text { preoperative cardiac function } \\
\text { status (NYHA classification), } \\
\text { baseline eCFR (CKD-EPI), } \\
\text { creatinine levels surgery-related } \\
\text { factors (proceduresk urgency, } \\
\text { time on cardiopulmonary } \\
\text { bypass, red blood cell } \\
\text { transfusion) and operative } \\
\text { characteristics of central venous } \\
\text { pressure and red blood cell } \\
\text { transfusion. If }>1 \text { cardiac surgery } \\
\text { procedures were performed } \\
\text { during the same admission, } \\
\text { only the data for the first } \\
\text { surgery were considered }\end{array}$ & $\begin{array}{l}\text { Coincidence } \\
\text { matching }\end{array}$ & $\begin{array}{c}\text { Not } \\
\text { reported }\end{array}$ & PValue & $\begin{array}{l}\text { Logistic } \\
\text { regression }\end{array}$ & $\begin{array}{l}\text { Renal } \\
\text { failure }\end{array}$ \\
\hline 2019 & $\begin{array}{l}\text { Yanfei } \\
\text { Shen }\end{array}$ & $\begin{array}{c}\text { Critical Care } \\
\text { BMC }\end{array}$ & China & Cohort & $\begin{array}{l}\text { Relationship between } \\
\text { the use of loop diuretics } \\
\text { and in-hospital } \\
\text { mortality in critically } \\
\text { ill patients with } \\
\text { vasopressor support }\end{array}$ & $\begin{array}{l}\text { Age, weight, diabetes mellitus, } \\
\text { hypertension, heart disease, } \\
\text { AKI, SOFA score on admission } \\
\text { to the ICU, white count, fluid } \\
\text { volume intake and proportions } \\
\text { of various vasopressors }\end{array}$ & Stratification & $\begin{array}{l}\text { Nearest } \\
\text { neighbor } \\
\text { y Caliper }\end{array}$ & $\begin{array}{l}\text { Standardized } \\
\text { measurements }\end{array}$ & $\begin{array}{l}\text { Logistic } \\
\text { regression }\end{array}$ & $\begin{array}{c}\text { Mortality } \\
\text { and Renal } \\
\text { failure }\end{array}$ \\
\hline 2019 & $\begin{array}{l}\text { Yoshihisa } \\
\text { Miyamoto }\end{array}$ & $\begin{array}{l}\text { Intensive } \\
\text { Care Med }\end{array}$ & Japan & Cohort & $\begin{array}{l}\text { Examine the asso- } \\
\text { ciation between the } \\
\text { use of intravenous } \\
\text { contrast and no } \\
\text { recovery from } \\
\text { acute renal injury } \\
\text { requiring dialysis } \\
\text { (AKI-D) and hospital } \\
\text { in-hospital morta- } \\
\text { lity in patients with } \\
\text { sepsis }\end{array}$ & $\begin{array}{l}\text { Age, sex, } \mathrm{CCl} \text {, congestive heart } \\
\text { failure, diabetic nephropathy, } \\
\mathrm{CKD} \text {, consciousness level with } \\
\text { JCS, discharge year, source } \\
\text { of infection, emergency } \\
\text { surgery due to infectious } \\
\text { source, hispital volume and } \\
\text { treatments performed within } \\
\text { the next } 2 \text { days after discharge }\end{array}$ & $\begin{array}{l}\text { Coincidence } \\
\text { matching }\end{array}$ & $\begin{array}{l}\text { Nearest } \\
\text { neighbor }\end{array}$ & $\begin{array}{l}\text { Standardized } \\
\text { measurements } \\
\text { and Cstatistic }\end{array}$ & $\begin{array}{c}\text { Logistic } \\
\text { regression }\end{array}$ & $\begin{array}{l}\text { Mortality } \\
\text { and Renal } \\
\text { failure }\end{array}$ \\
\hline 2019 & $\begin{array}{l}\text { Yu Hsiang } \\
\text { Chou }\end{array}$ & $\begin{array}{l}\text { Journal of } \\
\text { Nephrology }\end{array}$ & Taiwan & Cohort & $\begin{array}{l}\text { Preoperative } \\
\text { continuation of renin- } \\
\text { angiotensin system } \\
\text { inhibitor and cardiac } \\
\text { surgery-associated } \\
\text { acute kidney injury }\end{array}$ & $\begin{array}{c}\text { Age, sex, CKD, DM, } \\
\text { decompensated heart failure, } \\
\text { coronary heart disease, occlusive } \\
\text { peripheral artery disease, } \\
\text { hypertension, hyperlipidemia, } \\
\text { chronic obstructive } \\
\text { pulmonary disease, cirrhosis, } \\
\text { hyperuricemia, metastatic } \\
\text { cancer, smoking, hemoglobin, } \\
\text { baseline creatinine, albumin, } \\
\text { urinary protein, surgery type, } \\
\text { antihypertensives and statins }\end{array}$ & $\begin{array}{l}\text { Coincidence } \\
\text { matching }\end{array}$ & Caliper & PValue & $\begin{array}{l}\text { Logistic } \\
\text { regression } \\
\text { and Cox } \\
\text { regression }\end{array}$ & $\begin{array}{l}\text { Renal } \\
\text { failure }\end{array}$ \\
\hline 2019 & Yuya Coto & $\begin{array}{l}\text { Coto et al. } \\
\text { Critical Care }\end{array}$ & Japan & Cohort & $\begin{array}{l}\text { Assess the effect of } \\
\text { contrast media on } \\
\text { renal function and } \\
\text { mortality in patients } \\
\text { with sepsis who } \\
\text { already had AKI }\end{array}$ & $\begin{array}{l}\text { Age, sex, infection site, history } \\
\text { of chronic kidney disease, } \\
\text { diabetes mellitus, septic } \\
\text { shock, immune compromise, } \\
\text { use of aminoglycosides or } \\
\text { vancomycin, laboratory } \\
\text { data (hemoglobin, Cr, total } \\
\text { bilirubin, platelets, lactate), } \\
\text { partial oxygen pressure/ } \\
\text { inspired oxygen fraction ratio, } \\
\text { and Clasgow coma scale on } \\
\text { admission to the ICU }\end{array}$ & $\begin{array}{l}\text { Coincidence } \\
\text { matching }\end{array}$ & $\begin{array}{c}\text { Not } \\
\text { reported }\end{array}$ & PValue & $\begin{array}{l}\text { Logistic } \\
\text { regression }\end{array}$ & $\begin{array}{c}\text { Mortality } \\
\text { and Renal } \\
\text { failure }\end{array}$ \\
\hline 2019 & Lisa-Mae & Chest & $\begin{array}{l}\text { United } \\
\text { States }\end{array}$ & Cohort & $\begin{array}{l}\text { Association between } \\
\text { contrast and acute } \\
\text { renal injury in critically } \\
\text { ill patients with } \\
\text { normal renal function }\end{array}$ & $\begin{array}{l}\text { Age, gender, comorbidities, } \\
\text { use of contrast, race, obesity, } \\
\text { primary diagnosis, APACHE }\end{array}$ & Stratification & $\begin{array}{l}\text { Nearest } \\
\text { neighbor } \\
\text { y Caliper }\end{array}$ & $\begin{array}{l}\text { Standardized } \\
\text { measurements }\end{array}$ & $\begin{array}{l}\text { Logistic } \\
\text { regression }\end{array}$ & $\begin{array}{l}\text { Renal } \\
\text { failure }\end{array}$ \\
\hline
\end{tabular}




\begin{tabular}{|c|c|c|c|c|c|c|c|c|c|c|c|}
\hline Year & Author & Journal & Country & $\begin{array}{l}\text { Study } \\
\text { type }\end{array}$ & Exposure & Variables & $\begin{array}{l}\text { Matching } \\
\text { algorithm }\end{array}$ & Closeness & $\begin{array}{c}\text { Balance } \\
\text { assessment }\end{array}$ & $\begin{array}{c}\text { Analytical } \\
\text { method } \\
\text { used }\end{array}$ & Outcomes \\
\hline 2020 & $\begin{array}{l}\text { Ala Abu- } \\
\text { dayyeh }\end{array}$ & $\begin{array}{c}\text { American } \\
\text { Journal of } \\
\text { Hospice }\end{array}$ & $\begin{array}{l}\text { United } \\
\text { States }\end{array}$ & Cohort & $\begin{array}{l}\text { Determine the impact } \\
\text { of dialysis on survival } \\
\text { of patients admitted } \\
\text { to the ICU with stage } \\
\text { IV cancer and renal } \\
\text { failure }\end{array}$ & $\begin{array}{l}\text { Age, sex, race/ethnicity and } \\
\text { vital status (alive vs. dead). } \\
\text { Clinical data included type } \\
\text { of malignant neoplasm, } \\
\text { peripheral vascular disease } \\
\text { and/or dementia diagnosis, } \\
\text { and consults for dialysis and } \\
\text { palliative care. Dementia, } \\
\text { peripheral vascular diseases } \\
\text { and reduced albumin, length } \\
\text { of stay in the ICU, SOFA score } \\
\text { and disposition. First albumin } \\
\text { level obtained in the first } 3 \\
\text { days in the ICU }\end{array}$ & $\begin{array}{l}\text { Coincidence } \\
\text { matching }\end{array}$ & $\begin{array}{l}\text { Nearest } \\
\text { neighbor }\end{array}$ & $\begin{array}{l}\text { Standardi- } \\
\text { zed measu- } \\
\text { rements }\end{array}$ & $\begin{array}{l}\text { Logistic } \\
\text { regression } \\
\text { and Cox } \\
\text { regression }\end{array}$ & $\begin{array}{l}\text { Renal } \\
\text { failure }\end{array}$ \\
\hline 2020 & $\begin{array}{l}\text { Cuang-ju } \\
\text { Zhao }\end{array}$ & $\begin{array}{l}\text { Zhao et al. } \\
\text { Critical Care } \\
\text { BMC }\end{array}$ & $\begin{array}{l}\text { United } \\
\text { States }\end{array}$ & Cohort & $\begin{array}{l}\text { Administración de } \\
\text { furosemida y los re- } \\
\text { sultados en pacientes } \\
\text { críticos con lesión } \\
\text { renal aguda. }\end{array}$ & $\begin{array}{l}\text { Edad, género, etnia, tipo de } \\
\text { admisión, comorbilidades, } \\
\text { puntuación simplificada de } \\
\text { fisiología aguda II (SAPSII), } \\
\text { puntuación de evaluación } \\
\text { de falla orgánica secuencial } \\
\text { (SOFA), presión arterial } \\
\text { media (MAP), nivel de } \\
\text { creatinina en suero, uso de } \\
\text { vasopresores e inotrópicos, } \\
\text { entrada diaria de líquidos, } \\
\text { fluido equilibrio, tipos de } \\
\text { líquidos, cirugía cardiaca, } \\
\text { TSR y ventilación mecánica. }\end{array}$ & $\begin{array}{l}\text { Coincidence } \\
\text { matching }\end{array}$ & $\begin{array}{l}\text { Nearest } \\
\text { neighbor } \\
\text { y Caliper }\end{array}$ & $\begin{array}{l}\text { Standardi- } \\
\text { zed measu- } \\
\text { rements }\end{array}$ & $\begin{array}{l}\text { Logistic } \\
\text { regression } \\
\text { and Cox } \\
\text { regression }\end{array}$ & $\begin{array}{l}\text { Renal } \\
\text { failure }\end{array}$ \\
\hline 2020 & $\begin{array}{c}\text { Custavo A. } \\
\text { Ospi- } \\
\text { na-Tascón }\end{array}$ & Critical care & $\begin{array}{c}\text { Colom- } \\
\text { bia }\end{array}$ & Cohort & $\begin{array}{l}\text { Effects of very } \\
\text { early initiation of } \\
\text { noradrenaline in } \\
\text { patients with septic } \\
\text { shock }\end{array}$ & $\begin{array}{l}\text { Age, APACHE II, comorbidities } \\
\text { and patient origin (emergency } \\
\text { room, general ward or } \\
\text { intensive care unit) were } \\
\text { documented. Heart rate and } \\
\text { blood pressure were also } \\
\text { documented and at 2, 4, } 6 \text {, } \\
8 \text { and } 24 \text { h after vasopressor } \\
\text { administration. Multiple } \\
\text { organ dysfunction was } \\
\text { assessed using the sequential } \\
\text { organ failure assessment score } \\
\text { (SOFA). Days off ventilation, } \\
\text { renal replacement therapy } \\
\text { requirement and days without } \\
\text { RRT were also calculated. } \\
\text { Finally, ICU and hospital } \\
\text { length of stay were recorded } \\
\text { together with ICU, in-hospital } \\
\text { and } 28 \text {-day mortality }\end{array}$ & $\begin{array}{l}\text { Coincidence } \\
\text { matching }\end{array}$ & $\begin{array}{l}\text { Nearest } \\
\text { neighbor }\end{array}$ & P Value & $\begin{array}{l}\text { Cox } \\
\text { regression }\end{array}$ & $\begin{array}{c}\text { Mortality } \\
\text { and Renal } \\
\text { failure }\end{array}$ \\
\hline
\end{tabular}

SOURCE. Authors. 
COMPLEMENTAR CONTENT 2. Evolution of publications using PS, adjusted for every 10000 publications.

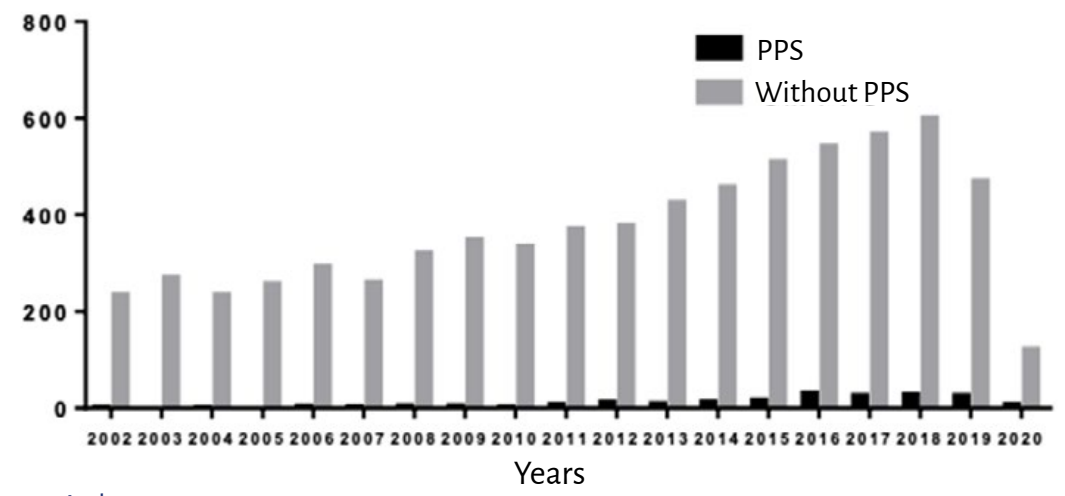

SOURCE. Authors.

COMPLEMENTAR CONTENT 3. Number of publications with propensity score by journal.

\begin{tabular}{|c|c|}
\hline Journal & $n(\%)$ \\
\hline Critical Care & 13(13.1) \\
\hline Critical Care Medicine & 11(11.1) \\
\hline Intensive Care Medicine & $7(7.1)$ \\
\hline Medicine (Baltimore) & $5(5.1)$ \\
\hline Plos One & $4(4.0)$ \\
\hline Clinical Journal of the American Society of Nephrology & $3(3.0)$ \\
\hline The Annals of Thoracic Surgery & $3(3.0)$ \\
\hline Journal of Cardiothoracic and Vascular Anesthesia & $3(3.0)$ \\
\hline Anesthesiology & $3(3.0)$ \\
\hline Journal of the American Society of Nephrology & $2(2.0)$ \\
\hline Medicina Intensiva & $2(2.0)$ \\
\hline $\begin{array}{l}\text { Scandinavian Journal of Trauma Resuscitation and Emergency } \\
\text { Medicine }\end{array}$ & $2(2.0)$ \\
\hline Nephrology & $2(2.0)$ \\
\hline Chest & $2(2.0)$ \\
\hline The American journal of medicine & $1(1.0)$ \\
\hline JAMA & $1(1.0)$ \\
\hline The International Journal of Artificial Organs & $1(1.0)$ \\
\hline JAAPA & $1(1.0)$ \\
\hline European Journal of Cardio-Thoracic Surgery & $1(1.0)$ \\
\hline European Journal of Vascular and Endovascular Surgery & $1(1.0)$ \\
\hline Acta Anaesthesiologica Scandinavica & $1(1.0)$ \\
\hline American Journal of Respiratory and Critical Care Medicine & $1(1.0)$ \\
\hline Antimicrobial Agents and Chemotherapy & $1(1.0)$ \\
\hline Cardiology & $1(1.0)$ \\
\hline Military Medicine & $1(1.0)$ \\
\hline Interactive Cardiovascular and Thoracic Surgery & $1(1.0)$ \\
\hline BMC Nephrology & $1(1.0)$ \\
\hline The Journal of Trauma and Acute Care Surgery & $1(1.0)$ \\
\hline Pharmacotherapy & $1(1.0)$ \\
\hline Annals of Intensive Care & $1(1.0)$ \\
\hline Liver Transplantation & $1(1.0)$ \\
\hline World Journal of Surgery & $1(1.0)$ \\
\hline Clinical Science Articles & $1(1.0)$ \\
\hline Journal of Anesthesia & $1(1.0)$ \\
\hline Clinical Therapeutics & $1(1.0)$ \\
\hline Journal of Intensive Care Medicine & $1(1.0)$ \\
\hline Nephron & $1(1.0)$ \\
\hline Neurosurgery & $1(1.0)$ \\
\hline World Neurosurgery & 1(1.0) \\
\hline Canadian Medical Association Journal & 1(1.0) \\
\hline critical care explorations & 1(1.0) \\
\hline American Association for the Surgery of Trauma & $1(1.0)$ \\
\hline BMC Infectious Diseases & 1(1.0) \\
\hline European Journal of Clinical Microbiology \& Infectious Diseases & 1(1.0) \\
\hline The Journal of Thoracic and Cardiovascular Surgery & 1(1.0) \\
\hline Brazilian Journal of Cardiovascular Surgery & 1(1.0) \\
\hline Journal of Nephrology & 1(1.0) \\
\hline American Journal of Hospice & 1(1.0) \\
\hline Scientific Reports & 1(1.0) \\
\hline Nephrology Dialysis Transplantation & $1(1.0)$ \\
\hline
\end{tabular}

SOURCE. Authors
COMPLEMENTAR CONTENT 4. Number of publications with propensity score by country.

\begin{tabular}{|c|c|}
\hline Country & $n(\%)$ \\
\hline United States & $35(35.3)$ \\
\hline Taiwán & $10(10.1)$ \\
\hline France & $9(9.1)$ \\
\hline Brasil & $7(7.1)$ \\
\hline Canada & $6(6.1)$ \\
\hline Korea & $6(6.1)$ \\
\hline Japan & $5(5.1)$ \\
\hline China & $5(5.1)$ \\
\hline Spain & $4(4.0)$ \\
\hline Finland & $3(3.0)$ \\
\hline Australia & $2(2.0)$ \\
\hline Germany & $2(2.0)$ \\
\hline Italy & $1(1.0)$ \\
\hline UK & $1(1.0)$ \\
\hline South korea & $1(1.0)$ \\
\hline Sweden & $1(1.0)$ \\
\hline Colombia & $1(1.0)$ \\
\hline
\end{tabular}

SOURCE. Authors.

Complementar content 6. Fórmule 1.

The difference in standardized measurements is defined as follows:

$$
d=\frac{100 x X_{\text {Tratados }}-\bar{X}_{\text {Control }}}{\frac{\sqrt{S_{\text {Tratados }}^{2}+S_{\text {Control }}^{2}}}{2}}
$$

Where $\dddot{X}_{\text {Tratados }}$ and $\dddot{X}_{\text {Control }}$. represents variable averages between treated and not treated, while $S_{\text {Tratados }}^{2}$ and $S_{\text {Control }}^{2}$ corresponds to standard deviations of the covariables between treated and not treated subjects.

SOURCE. Austin (6).
COMPLeMENTAR CONTENT 5. Exposures in critically ill patients with renal outcomes.

\begin{tabular}{|c|c|}
\hline Exposure & $n(\%)$ \\
\hline \multicolumn{2}{|l|}{ Intervención farmacológica } \\
\hline Antibiotic & $7(7.1)$ \\
\hline IV fluids & $6(6.1)$ \\
\hline Diuretics & $5(5.1)$ \\
\hline Statins & $3(3.0)$ \\
\hline Midazolam. propofol & $2(2.0)$ \\
\hline ACEi/ARAII & $2(2.0)$ \\
\hline Inotropes & $1(1.0)$ \\
\hline Inhaled nitric oxide & $1(1.0)$ \\
\hline Hydrocortisone. vitamin $\mathrm{C}$ and thiamine & $1(1.0)$ \\
\hline $\begin{array}{l}\text { Prothrombin + fresh frozen plasma vs. } \\
\text { fresh plasma }\end{array}$ & $1(1.0)$ \\
\hline Betablockers & $1(1.0)$ \\
\hline Diuretics + vasopressors & $1(1.0)$ \\
\hline Vasopressors & $1(1.0)$ \\
\hline Aspirin & $1(1.0)$ \\
\hline \multicolumn{2}{|l|}{ Risk factor } \\
\hline History of acute renal failure & $10(10.1)$ \\
\hline End-stage renal disease & $2(2.0)$ \\
\hline Factors affecting healing. angiosome & $1(1.0)$ \\
\hline Renal transplant & $1(1.0)$ \\
\hline Age under or over 80 years & $1(1.0)$ \\
\hline Diabetes mellitus & $1(1.0)$ \\
\hline Obstructive sleep apnea & $1(1.0)$ \\
\hline $\begin{array}{l}\text { Critical disease in patient with no past } \\
\text { history of acute renal injury }\end{array}$ & $1(1.0)$ \\
\hline Post-traumatic acute renal failure & 1(1.0) \\
\hline \multicolumn{2}{|l|}{ Dialysis therapy } \\
\hline Early/late & $5(5.1)$ \\
\hline Continuous/intermittent & $4(4.0)$ \\
\hline Renal replacement therapy & $4(4.0)$ \\
\hline Chronic dialysis & $1(1.0)$ \\
\hline Continuous veno-venous hemodiafiltration & $1(1.0)$ \\
\hline Bicarbonate in replacement solution & $1(1.0)$ \\
\hline \multicolumn{2}{|l|}{ Surgical and other invasive procedures } \\
\hline lodinated contrast medium & $5(5.1)$ \\
\hline $\begin{array}{l}\text { Coronary revascularization surgery } \\
\text { (bypass) }\end{array}$ & $4(4.0)$ \\
\hline $\begin{array}{l}\text { Invasive techniques in patients with } \\
\text { NSTEMI and renal dysfunction }\end{array}$ & $2(2.0)$ \\
\hline Immediate postoperative extubation & $1(1.0)$ \\
\hline Red blood cell transfusion & $1(1.0)$ \\
\hline $\begin{array}{l}\text { Radiofrequency ablation for atrial } \\
\text { fibrillation }\end{array}$ & $1(1.0)$ \\
\hline Pulmonary artery catheterization & $1(1.0)$ \\
\hline Intra-aortic balloon pump & $1(1.0)$ \\
\hline Radical cystectomy & $1(1.0)$ \\
\hline Liver transplant (ABO compatibility) & $1(1.0)$ \\
\hline $\begin{array}{l}\text { Transcatheter/surgical aortic valve } \\
\text { replacement }\end{array}$ & 1(1.0) \\
\hline Cardiopulmonary resuscitation & $1(1.0)$ \\
\hline \multicolumn{2}{|l|}{ Administrative processes and biomarkers } \\
\hline Postoperative hypoalbuminemia & $3(3.0)$ \\
\hline $\begin{array}{c}\text { Care by residents/medical assistance/ } \\
\text { trauma team }\end{array}$ & $2(2.0)$ \\
\hline Nephrology consult (early/late) & 1(1.0) \\
\hline Specialized equipment for RRT & $1(1.0)$ \\
\hline Volume of patients on dialysis in the ICU & $1(1.0)$ \\
\hline Paresis in ICU & $1(1.0)$ \\
\hline Refusal of vital support therapies in the ICU & $1(1.0)$ \\
\hline Creatinine measurement methods & 1(1.0) \\
\hline
\end{tabular}

SOURCE. Authors. 